University of Tennessee Health Science Center UTHSC Digital Commons

$12-2009$

\title{
Stepped Care for Smoking Cessation: A Cost-Effectiveness Analysis and Simulation of Future Outcomes
}

Brandi E. Franklin

University of Tennessee Health Science Center

Follow this and additional works at: https://dc.uthsc.edu/dissertations

Part of the Health and Medical Administration Commons

\section{Recommended Citation}

Franklin, Brandi E. , "Stepped Care for Smoking Cessation: A Cost-Effectiveness Analysis and Simulation of Future Outcomes" (2009). Theses and Dissertations (ETD). Paper 78. http://dx.doi.org/10.21007/ etd.cghs.2009.0097.

This Dissertation is brought to you for free and open access by the College of Graduate Health Sciences at UTHSC Digital Commons. It has been accepted for inclusion in Theses and Dissertations (ETD) by an authorized administrator of UTHSC Digital Commons. For more information, please contact jwelch30@uthsc.edu. 


\title{
Stepped Care for Smoking Cessation: A Cost-Effectiveness Analysis and Simulation of Future Outcomes
}

\begin{abstract}
It has been well established that smoking is the leading avoidable cause of premature morbidity and mortality in the United States and abroad. Smoking is attributable to over 400,000 annual deaths, and $\$ 193$ billion in healthcare costs and lost productivity. Despite the apparent dangers and tremendous costs of tobacco use and dependence, smokers find difficulty quitting. Recently, stepped care has been proposed as a viable intensive approach for achieving long-term cessation. This research sought to evaluate cost-effectiveness of stepped care in a diverse population of smokers and analyze future health outcomes of smoking cessation.

Cost-effectiveness analysis was conducted from an institutional perspective alongside an $\mathrm{NIH}$-funded multi-site study, "Long-term Smoking Cessation Using Prescription Step Care" (STEP), which compared stepped care to a repeat care intervention. The outcome of interest was incremental cost per quit achieved by stepped care. Secondly, long-term cost-effectiveness of successful smoking cessation was analyzed using a societal perspective. A microsimulation model was developed to predict changes in morbidity and mortality over the lifetime for four smoking-related diseases (ischemic heart disease, cerebrovascular disease, lung cancer, and emphysema) due to successful cessation. Here, the outcome of interest was incremental cost per quality-adjusted life year due to successful cessation. Lastly, sensitivity analyses were conducted to gauge robustness of estimates.
\end{abstract}

In the STEP study, costs for stepped versus repeat care were $\$ 875.09$ and $\$ 422.26$, respectively. Pointprevalence abstinence was validated among $20.5 \%$ (versus $22.5 \%$ ) of stepped care patients; continuous abstinence was achieved by $11.9 \%$ (versus $14.3 \%$ ) of stepped care patients. Stepped care was dominated by repeat care, being more costly but less effective. Stepped care produced a favorable incremental costeffectiveness ratio only among women achieving continuous abstinence in the Mayo sample. All other scenarios favored repeat care. When future outcomes of cessation were analyzed, average costs in original versus amended analyses were $\$ 49,025$ and $\$ 48,956$, respectively; QALYS gained were 8.62 and 8.6, for the aforementioned analyses. Successful cessation yielded incremental cost-effectiveness of $\$ 3,450$ per QALY. In sensitivity analysis, incremental cost-effectiveness varied from cost-saving to $\$ 13,700$ per QALY.

Stepped care was not cost-effective relative to repeat intervention. Quitting at the UTHSC site and among ethnic minorities was low, despite better rates of participation. Higher depression scores may have attributed to these results. Success of repeat care in STEP affirms findings of two recent studies. However, long-term cessation did prove highly cost-effective. Smoking cessation interventions continue to be extremely cost-effective and provide sizable returns on investment to employers and payers alike; enhanced coverage of smoking cessation treatments and programs will likely increase quit attempts and ultimately, cessation.

\section{Document Type}

Dissertation

Degree Name

Doctor of Philosophy (PhD)

Program

Health Science Administration 


\section{Research Advisor}

Robert C. Klesges, PhD.

\section{Keywords}

Cost-effectiveness analysis, Nicotine replacement therapy, Smoking cessation, Stepped care

\section{Subject Categories}

Health and Medical Administration | Medicine and Health Sciences 
STEPPED CARE FOR SMOKING CESSATION: A

COST-EFFECTIVENESS ANALYSIS AND SIMULATION OF FUTURE OUTCOMES

\author{
A Dissertation \\ Presented for \\ The Graduate Studies Council \\ The University of Tennessee \\ Health Science Center
}

\begin{abstract}
In Partial Fulfillment
Of the Requirements for the Degree

Doctor of Philosophy

From The University of Tennessee
\end{abstract}

By

Brandi E. Franklin

December 2009 
Copyright (C) 2009 by Brandi E. Franklin All rights reserved 


\section{DEDICATION}

This dissertation is dedicated to the memory of my grandmother, Ms. Fannie Everett, my grandfather, Mr. Sammy Johnson, and my uncle, Mr. Bob Johnson. In addition, I dedicate this work to my parents, David and Sammie Everett, my siblings, my husband, Rodney Franklin, and my extended families (Everett, Johnson, Franklin, and Morris). Their love, support, and guidance have helped to shape me into a person in whom I take much pride! 


\section{ACKNOWLEDGEMENTS}

First and foremost, I give honor to God for the blessings of life and its abundance. I thank Him for strength, patience, and perseverance to realize such a great accomplishment. I am grateful for my parents, David and Sammie Everett, who have instilled in me Godly principles for living and continue to encourage and support my many endeavors. I also acknowledge the love and support of my sisters, Sadatra Gaines and Bridget Everett, and my extended family members.

I thank my husband, Dr. Rodney Franklin, who brought me every flowchart he could find until I could develop my own! He endured many lengthy discussions of my dissertation, gripes about writing, revising, and formatting, and checked on me in wee hours of the morning to see if I was making progress.

Finally, I'd like to acknowledge my committee members: Drs. Hong, Hersch, Klesges, White-Means, and Wong. Your contributions to this dissertation were invaluable. Thank you for your diligence and patience throughout this process. I also acknowledge my classmates for their input and support during my mock defense. This research could not have been conducted without the gracious support of National Institutes of Health (NIH) supplement grant funding (3R01CA106667-06S1). Thank you for your belief in this research endeavor. 


\begin{abstract}
It has been well established that smoking is the leading avoidable cause of premature morbidity and mortality in the United States and abroad. Smoking is attributable to over 400,000 annual deaths, and \$193 billion in healthcare costs and lost productivity. Despite the apparent dangers and tremendous costs of tobacco use and dependence, smokers find difficulty quitting. Recently, stepped care has been proposed as a viable intensive approach for achieving long-term cessation. This research sought to evaluate cost-effectiveness of stepped care in a diverse population of smokers and analyze future health outcomes of smoking cessation.

Cost-effectiveness analysis was conducted from an institutional perspective alongside an NIH-funded multi-site study, "Long-term Smoking Cessation Using Prescription Step Care" (STEP), which compared stepped care to a repeat care intervention. The outcome of interest was incremental cost per quit achieved by stepped care. Secondly, long-term cost-effectiveness of successful smoking cessation was analyzed using a societal perspective. A microsimulation model was developed to predict changes in morbidity and mortality over the lifetime for four smoking-related diseases (ischemic heart disease, cerebrovascular disease, lung cancer, and emphysema) due to successful cessation. Here, the outcome of interest was incremental cost per qualityadjusted life year due to successful cessation. Lastly, sensitivity analyses were conducted to gauge robustness of estimates.

In the STEP study, costs for stepped versus repeat care were $\$ 875.09$ and $\$ 422.26$, respectively. Point-prevalence abstinence was validated among $20.5 \%$ (versus $22.5 \%$ ) of stepped care patients; continuous abstinence was achieved by $11.9 \%$ (versus $14.3 \%$ ) of stepped care patients. Stepped care was dominated by repeat care, being more costly but less effective. Stepped care produced a favorable incremental costeffectiveness ratio only among women achieving continuous abstinence in the Mayo sample. All other scenarios favored repeat care. When future outcomes of cessation were analyzed, average costs in original versus amended analyses were $\$ 49,025$ and $\$ 48,956$, respectively; QALYS gained were 8.62 and 8.6, for the aforementioned analyses. Successful cessation yielded incremental cost-effectiveness of $\$ 3,450$ per QALY. In sensitivity analysis, incremental cost-effectiveness varied from cost-saving to $\$ 13,700$ per QALY.
\end{abstract}

Stepped care was not cost-effective relative to repeat intervention. Quitting at the UTHSC site and among ethnic minorities was low, despite better rates of participation. Higher depression scores may have attributed to these results. Success of repeat care in STEP affirms findings of two recent studies. However, long-term cessation did prove highly cost-effective. Smoking cessation interventions continue to be extremely costeffective and provide sizable returns on investment to employers and payers alike; enhanced coverage of smoking cessation treatments and programs will likely increase quit attempts and ultimately, cessation. 


\section{TABLE OF CONTENTS}

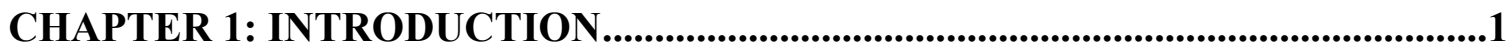

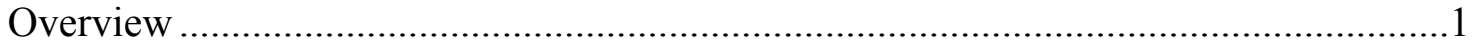

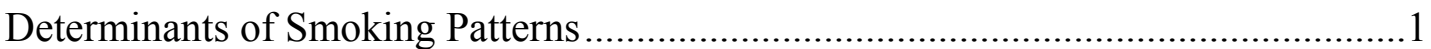

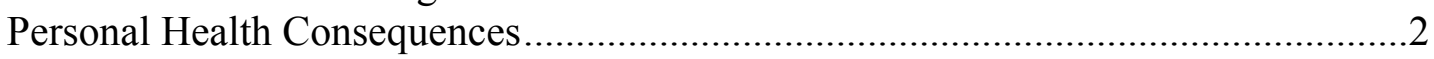

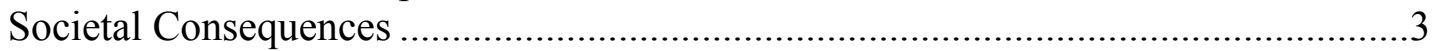

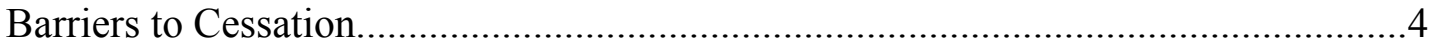

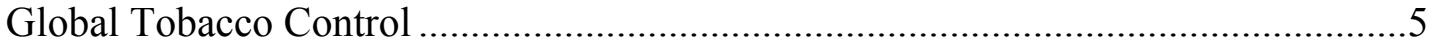

Stepped Care for Tobacco Cessation......................................................................10

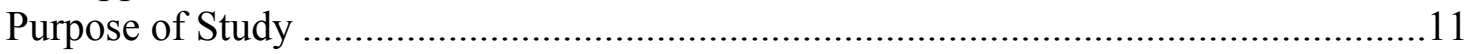

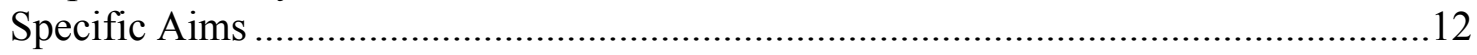

Evaluate Cost-Effectiveness of the STEP Study ………………..............................12

Use Study Outcomes to Simulate Future Health Consequences ..................................12

Compare Cost-Effectiveness Results to Previous Analyses.........................................12

Conceptual Framework of STEP Study ...............................................................13

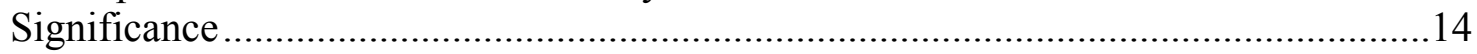

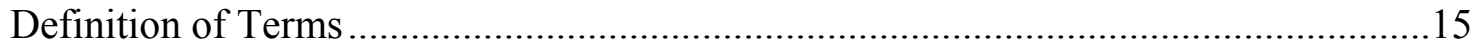

CHAPTER 2: LITERATURE REVIEW..................................................................18

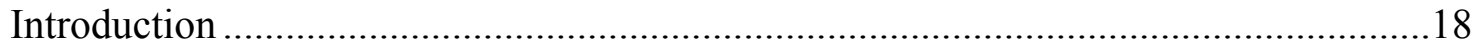

Overview of Smoking Cessation Studies .................................................................18

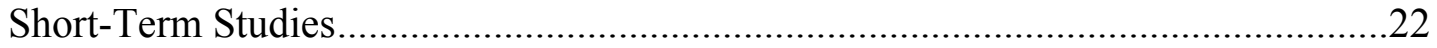

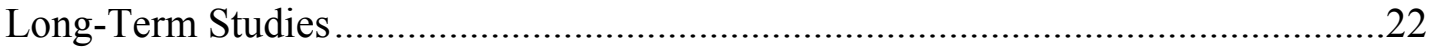

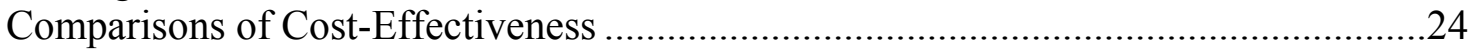

Recommendations for Conduct of Economic Evaluation .........................................27

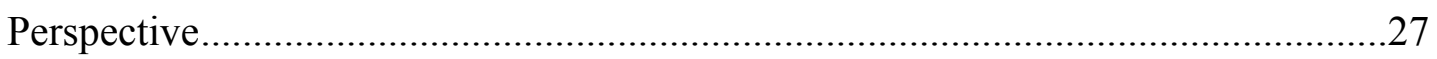

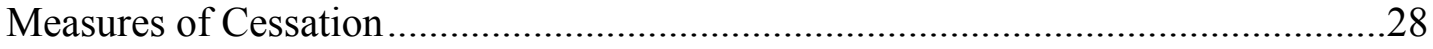

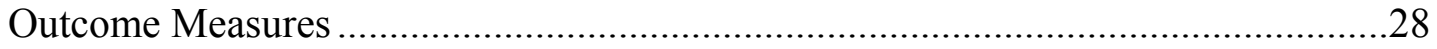

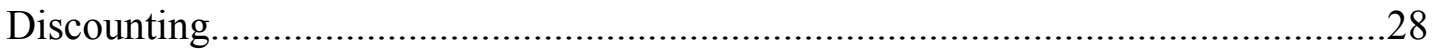

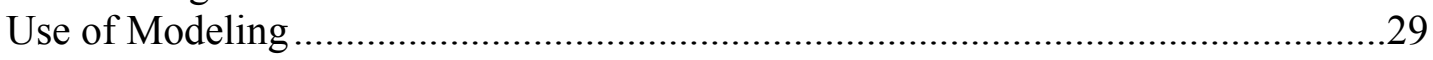

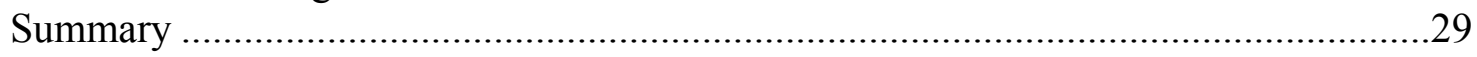

CHAPTER 3: METHODS ..............................................................................................31

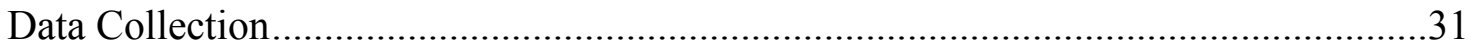

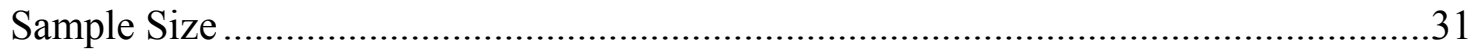

Conducting Cost-Effectiveness Analysis ..................................................................

Study Design .......................................................................................................

Calculation of Research Costs...............................................................................33

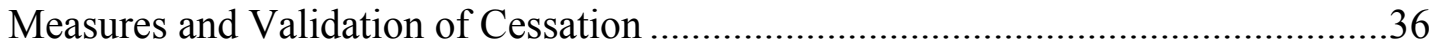

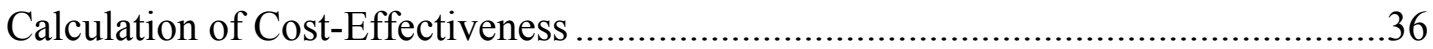

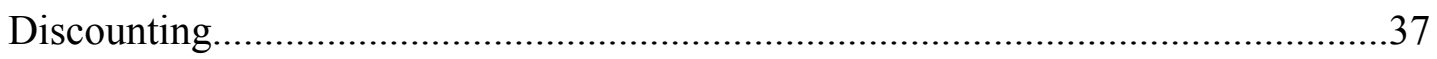

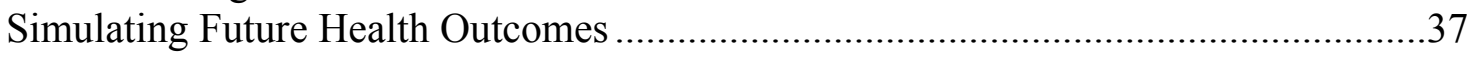

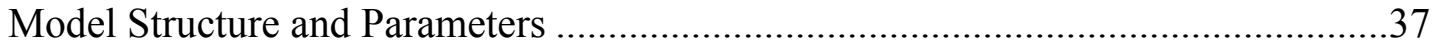

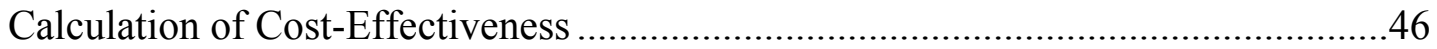

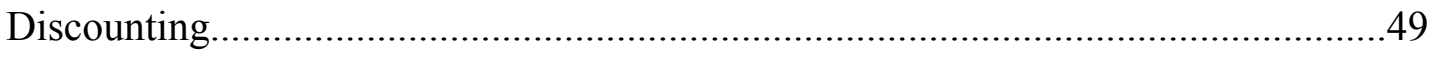




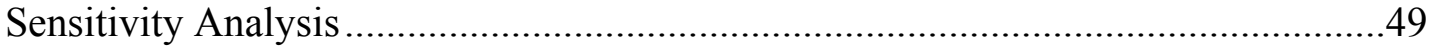

Comparing Results to Cost-Effectiveness Literature .............................................49

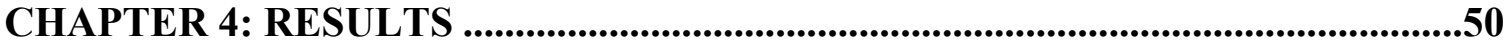

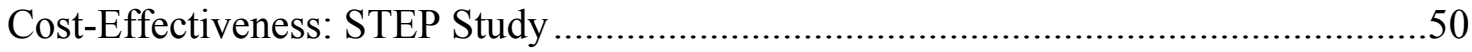

Simulating Future Outcomes of Smoking Cessation ...................................................56

Comparing STEP Cost-Effectiveness Analyses to the Literature ................................65

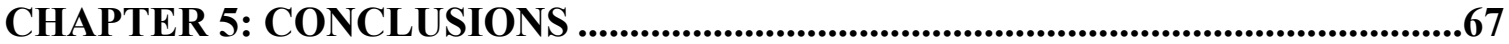

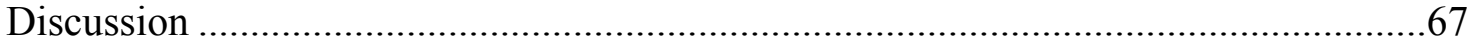

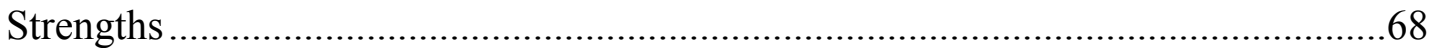

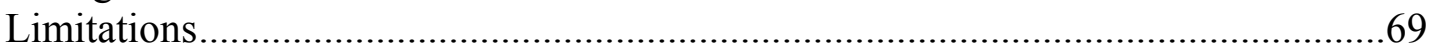

Promoting Smoking Cessation in Primary Care ................................................. 70

Economic Evaluation for Healthcare Financing................................................... 70

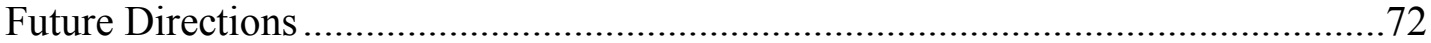

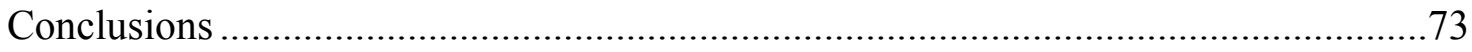

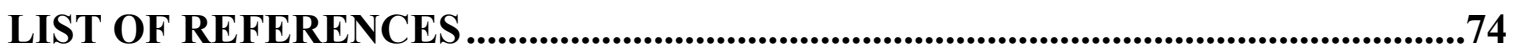

VITA 


\section{LIST OF TABLES}

Table 1-1. First-Line Pharmacotherapies for Smoking Cessation ............................... 7

Table 2-1. Study Characteristics: Cost-Effectiveness Analyses of Smoking Cessation Interventions ....

Table 2-2. League Table of International Cost-Effectiveness Analyses of Smoking

Cessation Interventions

Table 2-3. League Table of U.S. Cost-Effectiveness Analyses of Smoking Cessation Interventions

Table 3-1. Characteristics of Completers versus Remaining Participants.................. 32

Table 3-2. Cost Calculations for STEP CEA............................................................. 35

Table 3-3. Mortality Rates by Age, Race, and Gender.............................................. 41

Table 3-4. Incidence Rates for Smoking-Related Diseases ..................................... 44

Table 3-5. Annual Healthcare Costs and Utilities Estimates.................................... 47

Table 3-6. Changes in Costs and Utilities with Smoking/SR Disease ...................... 48

Table 4-1. Characteristics of STEP Study Sample .............................................. 51

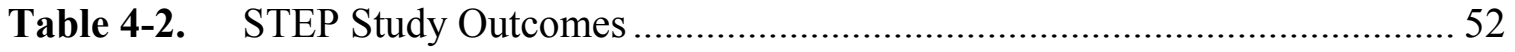

Table 4-3. Cost-Effectiveness Results, Overall and by Site ...................................... 53

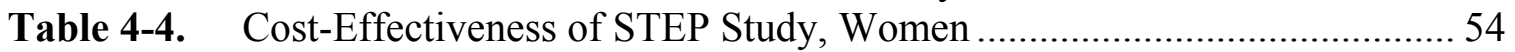

Table 4-5. Cost-Effectiveness of STEP Study, Men ............................................... 55

Table 4-6. Cost-Effectiveness of STEP Study, Non-Hispanic Whites ....................... 57

Table 4-7. Cost-Effectiveness of STEP Study, Ethnic Minorities.............................. 58

Table 4-8. Cost-Effectiveness of Future Outcomes Simulation, Summary

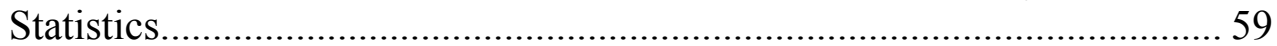

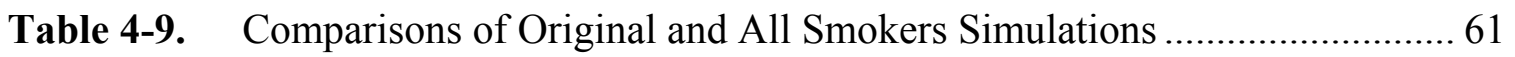

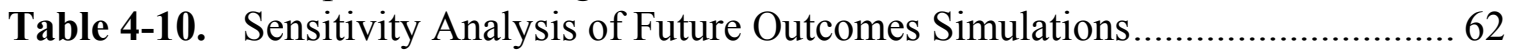

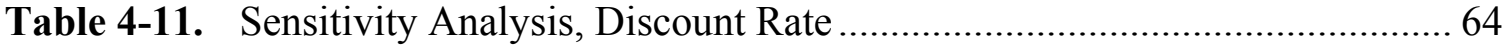

Table 4-12. Adjusted League Table, Cost-Effectiveness of Smoking Cessation Interventions. 


\section{LIST OF FIGURES}

Figure 1-1. Factors Influencing the Decision to Smoke ............................................ 2

Figure 1-2. Conceptual Framework of STEP Study ................................................ 13

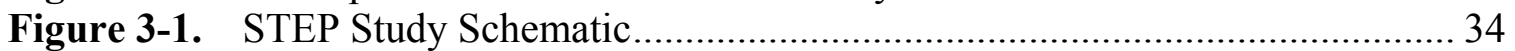

Figure 3-2. Change in Disease Pathway with Successful Cessation............................. 38

Figure 3-3. Long-Term Outcomes Simulation Model .......................................... 39

Figure 4-1. Distribution of Cost-Effectiveness Ratios........................................... 59 


\section{CHAPTER 1: INTRODUCTION}

\section{Overview}

Smoking remains the leading cause of premature death and disability in the United States. According to latest estimates, nearly one in five (19.8\%) Americans smokes. Smoking claims over 438,000 lives each year, and contributes $\$ 40$ billion in annual healthcare expenditures. ${ }^{1}$ Prevalence of smoking among adults stalled between 2004 and 2006, following a seven year decline; 2007 estimates indicate a significant decrease in prevalence compared to the previous period. Despite efforts to curtail adolescent initiation and current smoking, declines in smoking among youth between 1997 and 2003 have also stalled. In the United States, smoking prevalence is highest among youth and young adult groups, signaling cause for concern. Outside the United States, the toll of smoking on health is equally high. The World Health Organization (WHO) estimates that global tobacco use results in 5.4 million annual deaths - one every six seconds. Unless urgent action is taken, WHO expects that smoking will claim 1 billion lives by the end of the $21^{\text {st }}$ century. ${ }^{2}$

\section{Determinants of Smoking Patterns}

Most smokers initiate habits in adolescence or early adulthood. Several factors, both positive and negative, influence one's decision to smoke. Figure 1-1, taken from the 2000 Surgeon General's Report, outlines several factors (protobacco and antitobacco) which may promote or deter one's decision to initiate. ${ }^{3}$ For example, widespread social and community norms which support tobacco use, coupled with peer pressure, strategic marketing and placement of tobacco products in youth and community outlets, in the absence of antitobacco efforts, will negatively influence adolescents' perceptions about smoking. Such factors support increased exposure to tobacco, which can lead to uptake. Conversely, implementation of educational initiatives, creation of nonsmoking social norms, and restrictions on tobacco marketing and product availability can delay or deter adolescent initiation. Likewise, these factors influence decisions for continued smoking, quitting, and relapse.

Psychosocial factors strongly influence predisposition to smoking. A number of previous reports have revealed educational attainment as a strong sociodemographic predictor of smoking patterns. ${ }^{4-7}$ This correlation continues to be supported in recent literature, including new results from Meara and colleagues. ${ }^{8}$ Their analysis of changes in mortality and life expectancy from 1981-2000 concluded that education level is a mediator of life expectancy. Better educated individuals experienced a half-year increase from the 1980s to 1990s, and a 1.6 year increase from 1990-2000, while the less educated saw no changes during those periods. Moreover, the researchers found much of the mortality gap to be attributed to smoking related illnesses - namely lung cancer and chronic obstructive pulmonary disorder. Recent trends in quitting have paralleled those related to uptake and current smoking. Often, groups that exhibit the greatest likelihood of smoking behaviors are the least likely quitters. 


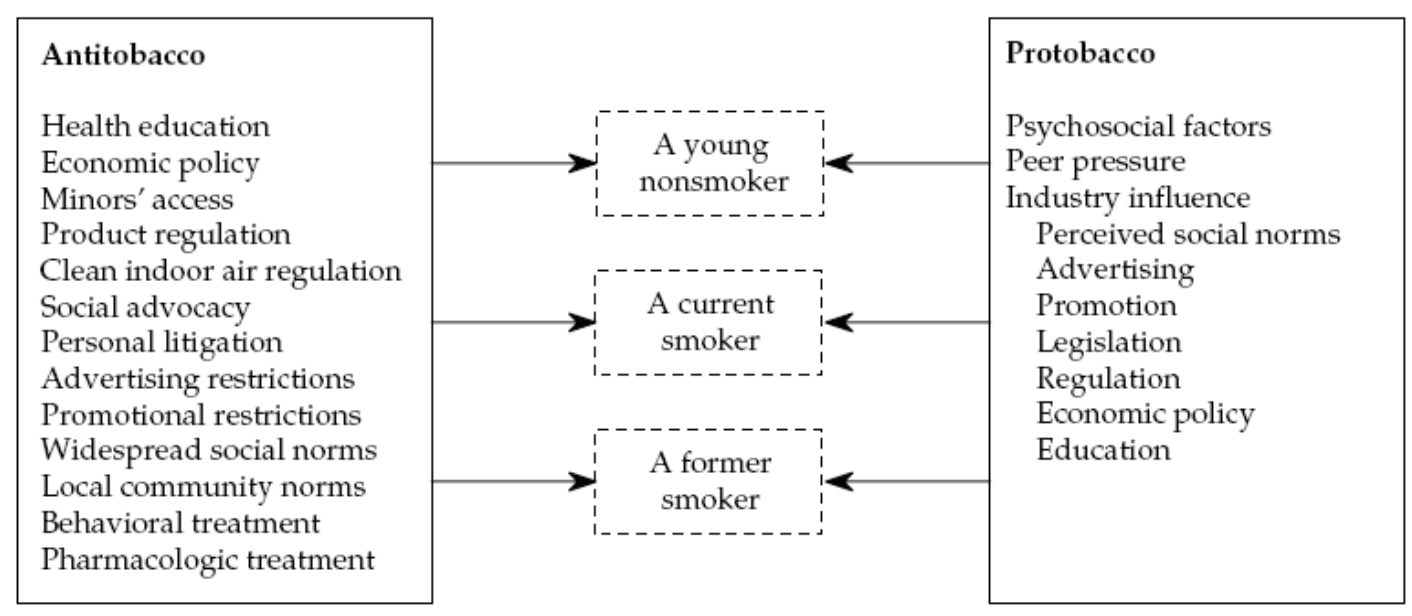

Figure 1-1. Factors Influencing the Decision to Smoke

Source: U.S. Department of Health and Human Services. Reducing tobacco use : a Report of the Surgeon General. Rockville, MD: U.S. Department of Health and Human Services, Public Health Service, Office of the Surgeon General; 2000: p.7. ${ }^{3}$

\section{Personal Health Consequences}

Smoking harms nearly every organ of the body, attributing to heart disease, stroke, certain cancers, pregnancy complications, and respiratory illnesses. Moreover, annual tobacco-related deaths surpass those caused by human immunodeficiency virus (HIV), illegal drug use, alcohol use, motor vehicle injuries, suicides, and murders combined. ${ }^{9}$ Unfortunately, smokers ignore the risks associated with tobacco use, as tobacco-related disease may not surface for decades. Recent estimates reveal that premature death due to smoking takes, on average, 12 years of life. ${ }^{10}$ The Centers for Disease Control and Prevention reports that smokers are 2 to 4 times more likely to develop coronary heart disease than nonsmokers; coronary heart disease is the leading cause of death in the United States. Smokers also double their risk for stroke and are 10 times more likely to develop peripheral vascular disease, due to impaired circulation. ${ }^{11}$ Nearly all lung cancer deaths are attributable to smoking; other tobacco-related cancers include the bladder, oral cavity, pharynx, larynx, esophagus, cervix, kidney, lung, pancreas, and stomach. AfricanAmerican men have the highest rates of cancer related to smoking. Negative reproductive outcomes, including infertility, stillbirth, low birth weight delivery, and sudden infant death syndrome (SIDS) are typically attributable to prenatal smoking. ${ }^{11}$ Lastly, smoking can lead to asthma diagnosis and exacerbations, upper and lower respiratory illnesses and infections, and in most cases, emphysema. ${ }^{11}$

Personal consequences of tobacco use, though delayed, are quite costly. In the last few decades, several estimates of personal costs of smoking have been published in the literature. One such study, conducted by Sloan et al., used available national data to estimate lifetime private and social costs attributable to smoking. ${ }^{12}$ They calculated a lifetime cost of $\$ 86,000$ for a 24 -year old woman; the cost increased to $\$ 183,000$ for a 
male the same age. If these costs were considered in cigarette pricing, the price per pack would be valued at $\$ 33$. This accounted for both the cost of the product and the costs of resultant ill health. Viscusi and Hersch, in 2007, estimated personal mortality costs to smokers to be much higher than previous estimates, $\$ 222 /$ pack for men and $\$ 94 /$ pack for women. ${ }^{13}$ The differences lie in valuation methods. Sloan and others presume that loss of life due to smoking occurs at the end of life; these life-years supposedly have identical values that are discounted to the present to represent mortality costs. Viscusi and Hersch maintain that the "present value of the mortality cost of smoking is the discounted value of the incremental probability of death at different ages for smokers relative to otherwise comparable nonsmokers."

\section{Societal Consequences}

Consequences of smoking extend beyond the individual; there is sufficient evidence to confirm that nonsmokers experience negative health effects from exposure to environmental tobacco smoke. ${ }^{2,14,15}$ Passive smoking occurs when exhaled or ambient smoke from a cigarette (or related product) is inhaled by others. The U.S. Centers for Disease Control and Prevention estimates that $60 \%$ of Americans show biological evidence of second-hand smoke exposure, and that second-hand smoke causes 35,000 deaths from coronary heart disease and 3,000 deaths from lung cancer among nonsmokers each year.

Children are typically most vulnerable to environmental tobacco smoke exposure. Etzel and others report that approximately $42 \%$ of children 2 months to 11 years of age live in a home with at least 1 smoker and an estimated 8.7 to 12.4 million US children younger than 5 years are exposed to cigarette smoke at home. ${ }^{16,17}$ These exposures place children at risk for asthma diagnosis and complications. Gilliland et al. and DiFranza et al. affirm the effects of prenatal and maternal smoke exposure on developmental lung defects, wheezing, and bronchial complications in children. ${ }^{18,19}$ Additional research affirms that prenatal smoke exposure (PSE) explains above asthma-related and other health outcomes. ${ }^{18,20-22}$

Adults exposed to environmental tobacco smoke face similar consequences. In their recent report, Frieden and Blakeman found environmental tobacco exposure to be associated with $25 \%$ higher risk for chronic respiratory disease, $40-60 \%$ higher risk for developing asthma, and $50-100 \%$ higher risk for acute respiratory illnesses among adults. ${ }^{23}$ These effects take a detrimental toll on the labor force. In the United States, the Environmental Protection Agency estimates that second-hand smoke accounts for nearly 3,000 annual lung cancer deaths among non-smokers in the country, though the methodology used to derive these estimates has been contested. ${ }^{24}$ Even abroad, the International Labor Organization estimates that at least 200,000 employees die annually due to exposure to smoke at work. In recent years, employers have responded by mandating smoke-free workplaces; these and other clean air acts should greatly reduce this number. ${ }^{25-28}$ 
Enstrom and Kabat have challenged these observations, purporting that health effects of secondhand smoke are exaggerated. ${ }^{29}$ In their 39 -year study of environmental tobacco smoke exposure and related mortality among nonsmoking Californians, they found no significant evidence of a causal relationship between smoke exposure and tobacco related mortality. The authors argue that most epidemiologic studies show positive, yet statistically insignificant associations between environmental smoke exposure and coronary heart disease and lung cancer. Meta-analyses yield significant summary statistics, only when these data are combined, which do not provide strong enough evidence to establish causality. These challenges have likely gone unnoticed by consumers, whose perceptions about risks of second-hand smoke are relatively strong. Dr. Rick Blizzard, a consultant for Gallup Healthcare, captured Americans' beliefs in a 2004 poll regarding perceived effects of second-hand smoke. ${ }^{30}$ Over half of all respondents (54\%) believed that second-hand smoke is "very harmful". Specifically, women, more than men, held this view (63\% and $44 \%$, respectively). Another $32 \%$ of participants believed that second-hand smoke is "somewhat harmful". Only $4 \%$ of all participants viewed second-hand smoke as not at all harmful. Younger respondents (under 50) were more likely to view second-hand smoke as harmful as compared to older respondents. These results may be due to enhanced efforts across the country to raise awareness about second-hand smoke and its consequences.

The costs of smoking to society continue to grow drastically as more smokers live with tobacco-related illnesses. These rising costs have fueled greater efforts across the United States to promote smoking cessation. Costs of smoking are borne by employers, managed care companies, spouses and families, as well as the larger community. Thus, costs such as medical care (beyond the individual's share), productivity, absenteeism, spousal and familial morbidity, mortality and disability, transportation, and caregiver time related to smoking must be considered. In 1998, Leonard Miller and his colleagues at University of California estimated a total annual cost of care for tobacco-related disease of $\$ 72.7$ billion, using healthcare expenditure data from $1993 .{ }^{31}$ According to their analysis, smoking accounted for nearly $12 \%$ of all healthcare expenditures. In addition, they predicted that the actual cost of medical care for smoking-related diseases would swell to $\$ 1.8$ trillion over the next 25 years. Current estimates are nearly $\$ 96$ billion for healthcare costs related to smoking. When productivity losses are included, that estimate doubles to approximately $\$ 193$ billion in annual tobacco-related losses. ${ }^{10}$

\section{Barriers to Cessation}

Nicotine addiction is pervasive among smokers and remains a key barrier to longterm smoking cessation..$^{32}$ As the psychoactive drug element of tobacco products, nicotine produces chemical dependence similar to that of heroin, cocaine, or alcohol. Nearly three in four smokers report a desire to quit, but only a portion of them make successful quit attempts. While onset of disease is a typical driver of cessation; data from the 2006 National Health Insurance Study reveals significant age-adjusted smoking prevalence among patients with any smoking-related chronic disease (36.9\%). One in five lung cancer patients and nearly half of those with emphysema in the sample were

current smokers. ${ }^{15}$ For these reasons, expert panel members of the Agency for Health 
Care Policy and Research (AHCPR) Clinical Practice Guidelines for Treating Tobacco Use and Dependence consider tobacco dependence a chronic disease requiring consistent, sustained intervention. ${ }^{33}$ Patients often require multiple attempts, as nicotine withdrawal symptoms can trigger relapse(s). Common withdrawal symptoms include nicotine craving, irritability, anxiety, difficulty concentrating, restlessness, and increased appetite. ${ }^{9}$ Weight gain relative to cessation is also a commonly cited concern among female smokers, especially those who are overweight or obese. ${ }^{34,35}$

\section{Global Tobacco Control}

Significant efforts to control tobacco use in the United States began around the 1960s, prompted by a landmark study of British doctors by Doll \& Hill. ${ }^{36}$ Their 1954 study definitively linked smoking and lung cancer; previous studies on tobacco's harmful effects had been largely ignored. Researchers in the United States began similar observations of smoking and its effects. In 1964, the first report of the Surgeon General on smoking was released, initiating a unified movement in the U.S. toward reducing tobacco use. Since then, various tobacco control strategies targeting current smokers have been developed to promote cessation, namely pharmacotherapy and behavioral counseling.

\section{Pharmacotherapy}

Pharmacological therapy was first introduced in 1985 and has been used extensively over the past few decades to treat tobacco dependence. Pharmacological agents for smoking cessation typically fall into two major categories: nicotine replacement therapy (NRT) products and non-nicotine medications. ${ }^{9}$ Currently, seven pharmacologic agents are approved in the United States as first-line for treating tobacco dependence (5 NRT products and 2 non-nicotine products); these agents are highlighted in the U.S. Guidelines for Treating Tobacco Use and Dependence: 2008 Update. ${ }^{33} \mathrm{~A}$ large body of evidence exists which confirms the effectiveness and cost-effectiveness of these agents, used alone or in combination, in achieving cessation.

Nicotine replacement therapies are designed to reduce withdrawal symptoms by substituting for some of the nicotine absorbed from tobacco. ${ }^{2}$ NRT products are available in various forms (patch, gum, inhaler, lozenge, nasal spray) and doses $(0.5 \mathrm{mg}-21 \mathrm{mg}$ depending on product type). Most are sold over-the-counter in local pharmacy, retail, and grocery outlets; inhalers and nasal sprays require a prescription. Nicotine gums, lozenges, and inhalers deliver nicotine orally, patches deliver nicotine through the skin, and sprays deliver nicotine through the nasal cavity. Provision of a variety of NRT therapies enhances smoking cessation efforts across a broad range of smokers. Preference studies of nicotine replacement therapies reveal differential ratings of likability, perceived safety, and ease of use. ${ }^{37}$ Patches rank high for convenience; they are adhered once daily and provide sustained release of nicotine into the bloodstream. In contrast, smokeless tobacco users may find nicotine gum more appealing; its administration is similar to chewing tobacco, which (once activated) is placed between gum and cheek. Nicotine inhalers look like plastic cigarettes; their administration mimics the hand-to-mouth movement of 
smoking. Nicotine nasal spray delivers nicotine to the bloodstream faster than any other form, making it a great choice for smokers who need immediate relief from cravings. Side effects of NRT are generally mild and well-tolerated; these vary by type. ${ }^{38}$ Most side effects associated with NRT are minimized when used appropriately.

Besides nicotine replacement therapies, two non-nicotine medications, bupropion and varenicline, can also be used first-line. Bupropion was approved in 1997 as a smoking cessation aid, marketed as Zyban. It is also sold as the antidepressant Wellbutrin in the United States. Bupropion is a relatively weak inhibitor of the neuronal uptake of norepinephrine, serotonin, and dopamine, and does not inhibit monoamine oxidase. The mechanism by which bupropion enhances the ability of patients to abstain from smoking is unknown. However, it is presumed that this action is mediated by noradrenergic and/or dopaminergic mechanisms. ${ }^{39}$ Varenicline, marketed as Chantix, is the first partial agonist of the $\alpha 4 \beta 2$ neuronal nicotinic acetylcholine receptor to be developed. ${ }^{38}$ The efficacy of varenicline in smoking cessation is believed to be the result of its activity at a sub-type of the nicotinic receptor where its binding produces agonist activity, while simultaneously preventing nicotine binding to $\alpha 4 \beta 2$ receptors. ${ }^{40}$ Both bupropion and varenicline are associated with side effects. Bupropion users commonly report dry mouth and insomnia; these are well tolerated and usually disappear after a few weeks. Hypertension has also been reported. Common side effects of varenicline include nausea, insomnia, and abnormal dreams. In addition, varenicline has become increasingly associated with neuropsychiatric symptoms including changes in behavior, agitation, depressed mood, suicidal ideation and suicidal behavior that may lead to discontinuation of therapy. ${ }^{41}$ These non-nicotine medications are available only by prescription.

Duration of pharmacotherapy ranges from a few weeks to six months and treatment courses vary by product. In the Guidelines for Treating Tobacco Use and Dependence, doses and recommendations for administration and duration are outlined for all pharmacotherapies. Details for first-line agents are listed in Table 1-1. Wide variations in duration and dosing indicate that treatment can be tailored to individual preferences, dependence levels, and cessation history to enhance effectiveness. Assuming daily cigarette consumption of one pack per day and treatment duration of six weeks using nicotine patches, the typical smoker would begin with a daily dose of $21 \mathrm{mg}$ for four weeks, followed by two weeks at the $14 \mathrm{mg}$ dose, and $7 \mathrm{mg}$ for the final two weeks. Most NRT treatment courses involve step-down dosing and depend on the cigarette consumption of the smoker; however, dosing increases over the treatment period for nonnicotine medications. Patients interested in using pharmacotherapy to aid cessation should consult their physician to determine which product(s) are most effective. In addition, patient preferences and prior experiences with pharmacotherapy should be considered when recommending a particular form for smoking cessation. Misuse of nicotine replacement therapy is commonly cited in the literature, likely due to improper administration, misconceptions of effectiveness, and safety concerns. Schneider and others encourage sampling of smoking cessation therapies as a method for improving treatment outcomes. ${ }^{37,42}$ When used appropriately, smokers can decrease their dependence on nicotine and quit smoking permanently. 
Table 1-1. First-Line Pharmacotherapies for Smoking Cessation

\begin{tabular}{|c|c|c|c|}
\hline Pharmacotherapy & $\begin{array}{c}\text { Treatment } \\
\text { length }\end{array}$ & Dosage & Cost \\
\hline Nicotine gum & 4-12 weeks & $\begin{array}{l}2 \mathrm{mg} \text { or } 4 \mathrm{mg} \text { dose; } 1 \text { piece/ } \\
1-2 \mathrm{~h} ; \text { NMT } 24 \text { pieces/day }\end{array}$ & $\begin{array}{l}\$ 48 / \mathrm{box} 2 \mathrm{mg}, \\
\$ 63 / \mathrm{box} 4 \mathrm{mg}\end{array}$ \\
\hline Nicotine patch & Varies $^{3}$ & $\begin{array}{l}\text { Various doses; } 21 \mathrm{mg} \\
\text { patch/day for } 4 \text { weeks, then } \\
14 \mathrm{mg} \text { patch/day for } 2 \\
\text { weeks, then } 7 \mathrm{mg} \text { patch/day } \\
\text { for } 2 \text { weeks }\end{array}$ & $\begin{array}{l}\$ 37 / \text { box } 7 \mathrm{mg}, \\
\$ 47 / \text { box } 14 \\
\mathrm{mg}, \$ 48 / \mathrm{box} \\
21 \mathrm{mg}\end{array}$ \\
\hline Nicotine inhaler & $\begin{array}{l}\text { Up to } 6 \\
\text { months }\end{array}$ & $\begin{array}{l}4 \mathrm{mg} ; 6-16 \text { cartridges/day, } \\
\text { then tapered dosing final 6- } \\
12 \text { weeks }^{4}\end{array}$ & $\begin{array}{l}\$ 197 / \text { box }(168 \\
10 \mathrm{mg} \\
\text { cartridges })\end{array}$ \\
\hline Nicotine nasal spray & 3-6 months & $\begin{array}{l}0.5 \mathrm{mg} / \mathrm{nostril} \text { (1-mg dose); } \\
1-2 \text { doses } / \mathrm{h} \text {; at least } 8 \\
\text { doses/day, NMT } 40 \\
\text { doses/day }\end{array}$ & $\begin{array}{l}\$ 49 / \text { bottle } \\
(\sim 100 \text { doses })\end{array}$ \\
\hline Nicotine lozenge & 6-12 weeks & $\begin{array}{l}2 \mathrm{mg} \text { or } 4 \mathrm{mg}^{5} ; 1 \text { lozenge/ } 1- \\
2 \mathrm{~h} \text { for } 6 \text { weeks, then } 1 \\
\text { lozenge } 2-4 \mathrm{~h} \text { for weeks } 7- \\
9, \text { then } 1 \text { lozenge/4- } 8 \mathrm{~h} \text { for } \\
\text { weeks } 10-12\end{array}$ & $\begin{array}{l}\text { \$34/box } 2 \mathrm{mg}, \\
\$ 38 / \text { box } 4 \mathrm{mg} \\
(72 \\
\text { lozenges/box) }\end{array}$ \\
\hline Bupropion & $\begin{array}{l}7-12 \text { weeks; } \\
\text { Up to } 6 \\
\text { months }\end{array}$ & $\begin{array}{l}150 \mathrm{mg} \text { daily for three days; } \\
\text { then } 150 \mathrm{mg} \text { twice daily }\end{array}$ & $\begin{array}{l}\$ 97 / \text { month }(60 \\
\text { tablets) }\end{array}$ \\
\hline Varenicline & 3-6 months & $\begin{array}{l}0.5 \mathrm{mg} / \text { day for } 3 \text { days, then } \\
0.5 \mathrm{mg} \text { twice daily for } 4 \\
\text { days, then } 1 \mathrm{mg} \text { twice daily }\end{array}$ & $\begin{array}{l}\$ 131 / \text { month } \\
\text { (56 tablets) }\end{array}$ \\
\hline
\end{tabular}

${ }^{1}$ Dose depends on cigarette consumption

${ }^{2} 2 \mathrm{mg}$ box (100-170 pieces); $4 \mathrm{mg}$ box (100-110 pieces)

${ }^{3}$ Treatment of 8 weeks or less as efficacious as longer periods

${ }^{4} \mathrm{~A} 10 \mathrm{mg}$ cartridge delivers a $4 \mathrm{mg}$ dose

${ }^{5}$ Dose depends on nicotine dependence

Abbreviations: h-hour, NMT- no more than

Source: Fiore MC, Jaén CR, Baker TB et al. Treating tobacco use and dependence: 2008 update. Clinical Practice Guideline ed. Rockville, MD: Department of Health and Human Services. Public Health Service; 2008. ${ }^{33}$ 
Effectiveness of nicotine replacement therapies has been widely established, with well over 3,000 studies published to date. In meta-analyses, NRT in all forms exhibited similar efficacy, doubling cessation rates when compared to no therapy. ${ }^{43-45}$ Results of meta-analyses of bupropion and varenicline confirm that these non-nicotine agents are more effective than NRT in producing abstinence. ${ }^{46-49}$ When NRT products are used in combination with other NRT agents or in combination with non-nicotine products, they produce even higher rates of cessation than any pharmacotherapy alone. Combination NRT and non-nicotine medication therapy is well tolerated. Pharmacotherapies for smoking cessation are highly cost-effective; this is well established in the literature. Incremental cost-effectiveness figures in smoking cessation typically fall well below established thresholds of \$20,000/life-year saved and \$50,000/QALY. ${ }^{50}$

When treatments with first-line therapies fail, two second-line non-nicotine agents, clonidine and nortriptyline, can be used to aid in smoking cessation. ${ }^{33}$ Clonidine is a hypertensive agent available as a tablet or transdermal patch for smoking cessation treatment. Dosing ranges from $0.10-0.75 \mathrm{mg} /$ daily (oral) or $0.10-0.20 \mathrm{mg} /$ daily (transdermal) for up to 12 weeks. Though well-tolerated, clonidine use is associated with dry mouth, drowsiness, dizziness, and sedation. Clonidine cannot be stopped abruptly; is must be tapered to avoid sharp increases in blood pressure and catecholamine levels. Nortriptyline is an older antidepressant that can be used second-line for smoking cessation. Its mechanism of action (in tobacco dependence) is largely unknown. Dosing begins at $25 \mathrm{mg}$ daily, and typically increases to $75 \mathrm{mg}$ or $100 \mathrm{mg}$ for up to 12 weeks. Common side effects include sedation, dry mouth, lightheadedness, and shaky hands. Abrupt discontinuation of nortriptyline can cause withdrawal; patients must be carefully monitored when using this agent for smoking cessation. Neither of these agents has been FDA-approved for smoking cessation; however, adequate evidence of efficacy and safety exists.

\section{Behavioral Counseling}

Behavioral counseling is a viable alternative or adjunct to pharmacotherapy for smoking cessation. Counseling is usually individually tailored, ranges from brief advice to intensive counseling, and is conducted through various media (i.e. in person, by telephone, via internet or printed materials). Group counseling methods also exist, but will not be discussed here. Counseling on smoking cessation is generally provided by primary care clinicians, but can be delivered by other health professionals (i.e. nurses, pharmacists, dentists, psychologists) across a variety of settings (i.e. hospitals, clinics, quitlines). The physician/patient encounter is an optimal opportunity to provide practical counseling (problem-solving). This type of behavioral counseling educates smokers on recognizing situations that trigger smoking/relapse, developing coping skills, and emphasizing the dangers of smoking and the benefits of quitting. Intra- and extratreatment social support counseling can also utilized. Here, practitioners provide additional support, encouraging patients to express their concerns about quitting and identifying external support systems to aid patients through the cessation process.

As an alternative to face-to-face counseling, telephone quitlines provide an

effective medium for targeting smokers to encourage cessation. Quitlines eliminate most 
barriers associated with face-to-face counseling, including transportation, patient/provider availability, and cost. ${ }^{51}$ Consequently, quitlines can reach more smokers, especially vulnerable groups for whom services are not offered. California initiated the first publicly funded telephone quitline in 1992 as part of its state tobacco control program. ${ }^{51,52}$ By 2004, 37 other states had established their own; all states now operate quitlines. In the last decade, quitline use increased substantially enough to be analyzed separately in the 2008 Guidelines. ${ }^{33}$

Like pharmacotherapy, behavioral counseling methods have proven effective across a variety of settings and smoking populations. Behavioral counseling is widely used for pregnant smokers, due to inadequate evidence to confirm the efficacy and safety of pharmacotherapy use. ${ }^{53}$ Meta-analyses show that brief counsel by a health professional provides some benefit, but increased intensity of counseling (increased number or length of sessions) is associated with more than a two-fold increase in cessation rates. ${ }^{33}$ Due to its established efficacy, the U.S. Public Health Service now recommends that health professionals screen all patients for smoking status and advise smokers on strategies for quitting. Counseling is appropriate for all smokers, though the strategy employed is determined by the patient's motivation to quit. At minimum, every smoker should be counseled on the five "A"s, as detailed by the Guidelines: ${ }^{.5}$

1. Ask all patients whether they smoke and if they are interested in quitting.

2. Advise patients about the health risks associated with tobacco use and the benefits of quitting.

3. Assess a patient's readiness to quit. For example, is the patient ready to quit in the 1-6 months?

4. Assist in the quit process by educating patients about strategies such as adding pharmacotherapy and making behavioral changes, which will improve their success.

5. Arrange for follow-up by phone or in person to improve the patient's likelihood for success.

For smokers motivated to quit, this initial session should yield a viable strategy for cessation. If a smoker is not yet motivated, clinicians should probe for potential barriers to cessation and continue emphasizing the 5 "A"s, risks associated with smoking, as well as benefits of cessation during subsequent visits.

Despite its effectiveness, use of behavioral counseling is challenged by several factors. Research indicates that disparities in the provision and utilization of counseling persist. Cokkinides et al. demonstrated in analyses of 2000 and 2005 National Health Interview Survey (NHIS) data that compared to whites, black and Hispanic smokers were significantly less likely to be screened for tobacco use, receive advice to quit, or use tobacco cessation treatment. ${ }^{54,55}$ Across the two survey periods, receipt of advice to quit among smokers surveyed increased only modestly (53\% to 61\%). Despite the increased reach of quitlines, they too are underutilized. In a qualitative review of surgical patients and providers, Warner et al. found that both groups had limited knowledge of quitlines. ${ }^{56}$ Providers indicated willingness to refer patients to quitlines, but reported time as a key barrier to receiving training in smoking cessation interventions. A report of quitline 
operations for 2004 revealed that most quitlines offered proactive versus reactive counseling (89.5\% versus $62.2 \%$ ), mainly through proactive referrals from physicians. ${ }^{51}$ While proactive telephone counseling is considered effective, little research has been conducted to establish the efficacy of smoker-initiated telephone counsel relative to other methods. ${ }^{57}$ In addition, Sood et al highlights that smokers may not be interested in intensive counseling methods, which among highly dependent smokers may be necessary for cessation. ${ }^{57}$

\section{Future Efforts}

Tobacco control efforts have contributed to the significant decline in smoking prevalence, now reduced by nearly half. The decline in tobacco use has produced a resultant decline in mortality, though life expectancy increases have yielded an increasing proportion of deaths caused by the chronic diseases associated with smoking - primarily cancer, cardiovascular disease, and emphysema. ${ }^{3}$ However, much work remains. Hughes purports that smokers able to quit have already done so, leaving older recalcitrant smokers likely exhibiting higher levels of nicotine dependence, depression, and comorbid substance abuse. ${ }^{58}$ A review of cessation interventions among these smokers indicate a lack of responsiveness to treatment. ${ }^{59}$ Newer cessation methods have been proposed to address this more difficult-to-treat smoking population.

\section{Stepped Care for Tobacco Cessation}

Stepped care has surfaced as an intensive approach that could possibly improve long-term cessation rates among smokers. Stepped care is defined as the practice of initiating treatment with low-intensity intervention, exposing treatment failures to more intense intervention at subsequent steps until the desired outcome is reached. Stepped care is not an intervention in itself. Rather, it is a way to sequence interventions so that the intensity, complexity, and costs of care are guided by each patient's observed outcome. ${ }^{60}$ Stepped care, as a treatment approach, has been employed extensively in the management of hypertension. Current and previous reports of the Joint National Committee on Prevention, Detection, Evaluation, and Treatment of Blood Pressure present a hypertension stepped care algorithm combining empirically validated treatment strategies in three areas: lifestyle modification, first-line pharmacologic agents, and second-line combination regimens. Treatment recommendations vary depending on risk, degree of blood pressure elevation, evidence of target organ damage, and presence of cardiovascular disease, medication side effects, and other risk factors. ${ }^{61}$ Stepped care is advocated in various guidelines for treatment of asthma, ${ }^{62}$ rheumatoid arthritis, ${ }^{63}$ diabetes, ${ }^{64}$ depression, ${ }^{65}$ and has been explored in treatment of various chronic disorders including back pain, ${ }^{60}$ migraine, ${ }^{66}$ obesity, ${ }^{67}$ eating disorders, ${ }^{68}$ multiple sclerosis, ${ }^{69}$ alcohol dependence, ${ }^{70-72}$ and heroin dependence. ${ }^{73}$

Evidence of the efficacy of stepped care in treating nicotine dependence has not been established; only a few published studies exist investigating this new approach. ${ }^{74,75}$ Reid and colleagues examined the viability of stepped care among 254 smokers hospitalized with coronary artery disease. ${ }^{74}$ Patients were randomized to receive either 
usual care, consisting of brief counsel, or intensive stepped care, which combined brief counsel and pharmacotherapy. After three months, short-term cessation rates favored stepped care, but this trend was not sustained at one year. The authors attributed the results to timing and content of the stepped care intervention. Specifically, initial treatment was limited by duration of inpatient stay, and patients were not followed up until four weeks post-discharge. This delay in assessing quit status made it difficult to prevent relapse in the interim. For relapsers, three counseling sessions and up to eight weeks of nicotine replacement therapy were offered, which showed benefit only at three months. Similarly, a study by Smith and colleagues failed to demonstrate that either of two stepped care treatments improved long-term cessation above brief intervention. ${ }^{75}$ They too attributed poor results to a one week delay in offering step up therapy, a period most critical to relapse. Thus, panel members contributing to the AHCPR guidelines have not made a formal recommendation for stepped care approaches to smoking cessation. ${ }^{33}$

\section{Purpose of Study}

Stepped care provides a framework for achieving professional support for chronic illness that is cost-effective and is based on patients' observed response to treatment. ${ }^{70} \mathrm{It}$ promotes efficient resource allocation, by exposing only treatment failures to more intensive therapy. ${ }^{76}$ A current research study, CA106667: "Long-term Smoking Cessation Using Prescription Step Care" (STEP), explores a novel, aggressive stepped care approach to increasing tobacco cessation relative to a repeat therapy approach. However, the stepped care approach in this study (relative to previous studies) more closely aligns with methods in hypertensive care, in which therapy (pharmacologic and behavioral) is intensified over a maximum of three steps to increase likelihood of cessation by study end. Investigators expect the study to yield more favorable results than seen previously because of its increased intensity and duration. Moreover, it is necessary to determine cost-effectiveness of stepped care in smoking cessation, as only one study to date has examined this. ${ }^{77}$ Thus, the purpose of this research is to use results from the aforementioned STEP study to ascertain if stepped care relative to repeat care is a costeffective method for achieving tobacco cessation.

STEP is a multi-site study comprised of participants in Memphis, Tennessee and Rochester, Minnesota. Participants are at least 18 years old and self-reported smokers of at least 10 cigarettes per day, who have consented to participate in the research study. This group serves as the cohort for the cost-effectiveness analysis. Though smokers across both sites are typically one-pack-a-day smokers and have similar levels of nicotine dependence, it is important to note the unique differences that exist among smokers across study sites. Smokers in Memphis fit the typical demographic profile - they are mainly low income and minority. The National Institutes of Health has deemed low income and minority smokers as special populations which require greater study, as these populations exhibit low rates of cessation, especially long-term. Minority race and low socioeconomic status are factors which primarily drive disparities in tobacco cessation. In addition, Memphis smokers in the sample have higher CES-D (Center for Epidemiologic Studies Depression Scale) scores compared to Rochester smokers (9.84 vs. 7.59); CES-D scores indicate severity of depressive symptoms. Smokers in Rochester, Minnesota are a 
strong contrast to those in Memphis; they are primarily Caucasian and have higher income levels. In fact, minorities only comprise about $9 \%$ of the Rochester sample, as compared to $50 \%$ in the Memphis sample. Recruitment through Mayo Clinic may influence these differences as the recruited sample mirrors the Rochester, Minnesota population. Baseline characteristics for the sample are detailed further in Chapter 3.

\section{Specific Aims}

\section{Evaluate Cost-Effectiveness of the STEP Study}

Data collected from the research study will be used to conduct a costeffectiveness analysis. The primary outcome of interest is incremental cost per quit for stepped care versus repeat care. Although the research study defines three cessation measures (point-prevalent, prolonged, and continuous) to be captured, point prevalent and continuous abstinence are most commonly cited in previous studies and will be used to calculate incremental cost per quit. Given the research setting, costs will reflect study rates.

\section{Use Study Outcomes to Simulate Future Health Consequences}

Simulation models are widely used in healthcare interventions to simulate future events. Results from the study can be used to predict changes in disease risk, incidence, and mortality resulting from cessation. Use of simulation models (microsimulation, discrete event simulation) in healthcare studies is gaining popularity. These methods transcend the constraints of Markov modeling in their ability to better predict individuals' movement through a disease or health process. Individual characteristics of study participants are used as model inputs to simulate impacts of long-term cessation (i.e. change in morbidity and mortality) in a diverse population and its resultant impact on societal costs. Results of the simulation are presented as incremental cost per qualityadjusted life year (QALY). Because health-related quality of life measures are not provided in the STEP study, synthetic estimates from the literature can be substituted. Short-term and long-term STEP outcomes can then be analyzed against previous studies.

\section{Compare Cost-Effectiveness Results to Previous Analyses}

Results of the cost-effectiveness analyses for STEP will be compared to other studies reviewed in the literature. By using multiple outcomes measures, study results can be compared to a broad range of literature. Most cost-effectiveness analyses of smoking cessation interventions use cost per quit as a primary measure. Cost per QALY is generally the standard measure used in cost-effectiveness analyses of other major lifesaving health interventions; it allows for easier comparison and comprehension and ultimately broadens the audience for whom cost-effectiveness research can benefit. 


\section{Conceptual Framework of STEP Study}

The conceptual framework which grounds the cost-effectiveness analysis is derived from the framework of the original intervention, described in Figure 1-2. The model is based on principles of social and operant learning and combines psychosocial, neuropharmacologic, and environmental determinants of tobacco use at several levels. At the top of the diagram, a variety of factors predispose individuals to smoking including social (culture, socioeconomic status, media/family/peer influences), psychological (comorbidity, personality, stress), and biological (genetics, nutrition) factors. These and other factors, such as nicotine dependence or past attempts to quit, will influence a smoker's motivation to make one or more attempts to quit. Cessation represents an opportunity for new learning (which opposes the previous learned behavior of smoking); this will no doubt effect both one's motivation to make a quit attempt and his/her self-efficacy (belief about the ability to quit) (box 3). A novel approach (box 2) to cessation can positively influence motivation to quit, outcomes expectancies, and smokers' belief in their ability to quit. It is expected that a novel approach will increase readiness to quit (box 4) and lead to a quit attempt (box 5).

After a quit, risk of relapse exists, especially as nicotine withdrawal symptoms surface. As seen in the diagram, predisposing factors (i.e. nicotine dependence) again will influence risk factors which often lead to relapse. Negative affect or weight gain may prompt smokers to resort to older learning, thus retuning to smoking. Therefore, reinforcement is provided (i.e. phone calls, mailings) to discourage relapse and encourage

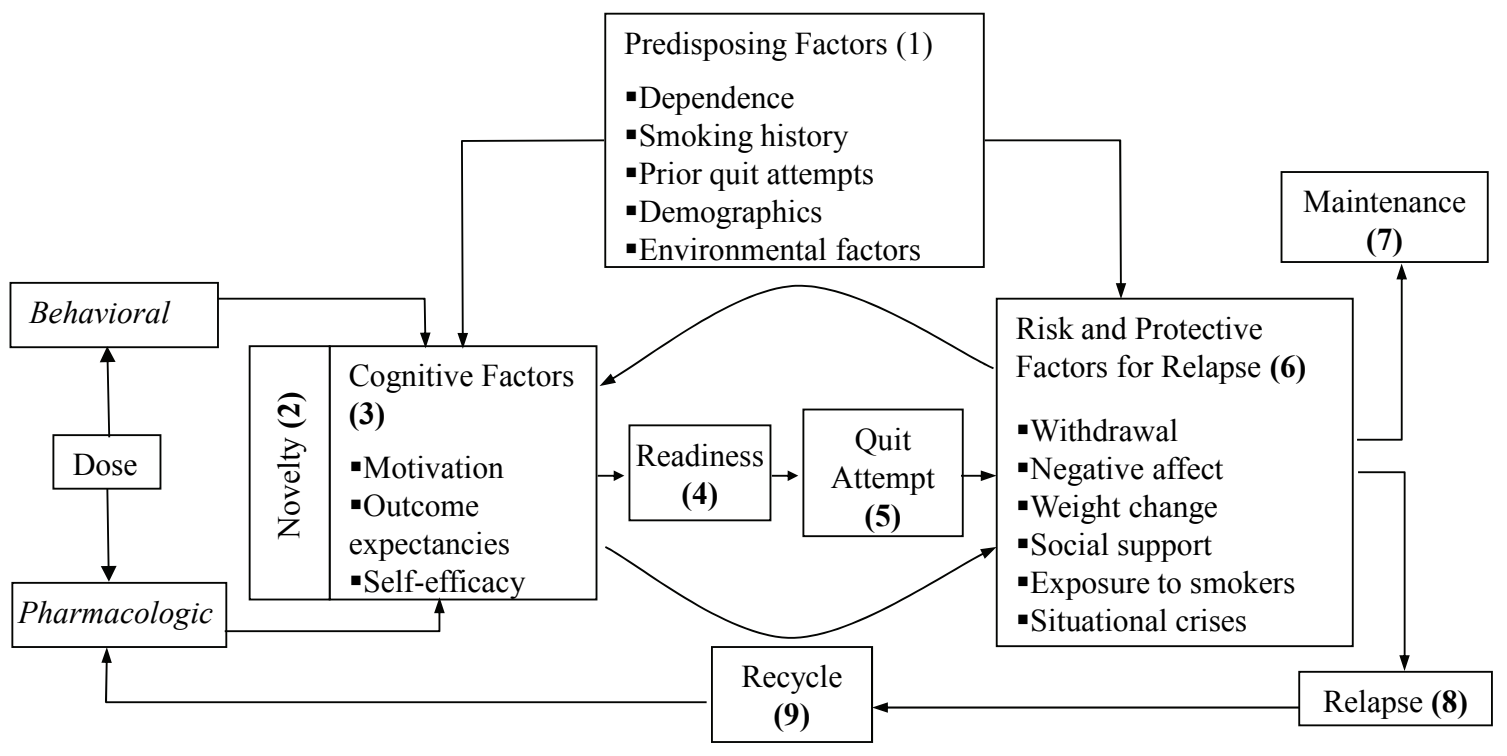

Figure 1-2. Conceptual Framework of STEP Study

Source: Klesges, RC. Step Care Manual of Procedures. 2006: p.11 (unpublished). ${ }^{78}$ 
maintenance of cessation (box 7). Smoking status is determined several weeks following treatment; in case an individual returns to smoking (box 8), a smoker is recycled quickly (box 9) into a renewed quit attempt. For stepped care patients who relapse, the dose of pharmacological and behavioral therapy is "stepped up"; this intensified intervention is presented as new novel approach to make another quit attempt. Stepped care offers a new opportunity for learning at each quit attempt; by presenting an alternative novel therapy, motivation, outcome expectancies, and self-efficacy remain positive instead of becoming negative. Smokers offered stepped care will be more likely to make additional quit attempts. Each new attempt increases one's likelihood of cessation through an increased number of trials. Over time, the probability of quitting is expected to increase with the number of quit attempts in a negatively accelerated pattern.

\section{Significance}

Several factors justify significance of this research. First, the underlying intervention evaluates a new method for smoking cessation. Given the current difficulties of achieving both short- and long-term cessation among smokers ready to quit, providing a new approach can boost cessation efforts across the United States and abroad. Moreover, this intervention features a significant portion of minority and low-income smokers; cessation has proven far more difficult to achieve in this population. These results will inform current research on establishing effective interventions to achieve cessation in key populations. In the most recent AHCPR guidelines, Fiore and colleagues highlight low-income individuals and racial/ethnic minorities as special populations for which more effective intervention is needed. ${ }^{33}$ In addition, they stated that stepped-care interventions in smoking cessation warranted further research, due to its paucity in current practice.

The economic evaluation connected to the intervention will contribute positively to a growing body of literature assessing cost-effectiveness of smoking cessation studies and programs. O'Sullivan, Gold, and others contend that conducting economic evaluation alongside studies is feasible and convenient. ${ }^{79,80}$ Growth in this area of the literature is critically necessary to inform policymakers of the value of smoking cessation to society. Currently, the lack of standards in the use of cost-effectiveness for funding smoking cessation has resulted in sub-optimal uptake in the coverage of such programs across health plans. Several studies have demonstrated both increased participation and improved outcomes in cessation health plan-sponsored programs that cover all or part of costs. These benefits are enhanced with coverage of related pharmacologic therapies to help more smokers kick their habits.

Additionally, the growing burden of U.S. healthcare costs on taxpayers, businesses, and government will build evidence to encourage the government to establish national standards for economic evaluation of new drug therapies and disease management programs, and set thresholds for justification of coverage. Many countries already mandate cost-effectiveness analysis as a requirement for approval and coverage of new drug therapies, and have realized significant cost savings. 


\section{Definition of Terms}

- Biochemical verification. The use of biological samples (expired air, blood, saliva, or urine) to measure tobacco-related compounds such as thiocyanate, cotinine, nicotine, and carboxyhemoglobin to verify users' reports of abstinence.

- Bupropion (bupropion). A non-nicotine aid for smoking cessation, originally developed and marketed as an antidepressant. It is chemically unrelated to tricyclics, tetracyclics, selective serotonin re-uptake inhibitors, or other known antidepressant medications. Its mechanism of action is presumed to be mediated through its capacity to block the reuptake of dopamine and norepinephrine centrally. Marketed as Zyban for smoking cessation.

- Cost-effectiveness. A ratio of costs incurred and averted by a particular treatment or service and the benefits achieved by treatment/service.

- Efficacy. The outcome achieved from a treatment provided under near-ideal circumstances of control (typically, in a research study). Efficacy studies involve recruitment of motivated participants, random assignment, intensive assessment, and methods designed to keep participants in treatment.

- Environmental tobacco smoke (ETS). Also known as "secondhand smoke" (SHS) or passive smoke. The smoke inhaled by an individual not actively engaged in smoking, but who is exposed to smoke from the lit end of a cigarette and the smoke exhaled by the smoker.

- Failure (treatment). Defined by self-reported relapse or abnormal biochemical measure (expired carbon monoxide or cotinine measure)

- Intensive interventions. Comprehensive treatments that may occur over multiple visits for long periods of time and may be provided by more than one clinician.

- Intervention. An action or program that aims to bring about identifiable outcomes. In tobacco dependence treatment, the intervention generally is clinical in nature and may consist of counseling and the use of medications. Also referred to as "treatment."

- Nicotine gum. Nicotine-containing gum, a smoking cessation aid, that delivers nicotine through the oral mucosa. It is available without a prescription.

- Nicotine patch. A nicotine-containing patch, a smoking cessation aid, that delivers nicotine through the skin; available with or without a prescription.

- Nicotine replacement therapy (NRT). Refers to medications containing nicotine that are intended to promote smoking cessation. There are five NRT delivery 
systems currently approved for use in the United States. These include nicotine gum, nicotine inhaler, nicotine lozenge, nicotine nasal spray, and nicotine patch.

- Point prevalence abstinence. A measure of tobacco abstinence based on smoking/tobacco use occurrence within a set period (usually 7 days), prior to a follow-up assessment.

- Prolonged abstinence. A measure of tobacco abstinence based on whether subjects are continuously abstinent from smoking/tobacco use from their quit day to a designated outcome point (e.g., end of treatment, 6 months after the quit day).

- Quality-adjusted life years (QALY). Measure of both the quality and the quantity of life lived. Used as a means of quantifying the benefits of a medical intervention.

- Quit. Successful cessation attempt, reported by self-reported or biochemically verified abstinence (where appropriate).

- Randomized controlled trial. A study in which subjects are assigned to conditions on the basis of chance, and where at least one of the conditions is a control or comparison condition.

- Relapse. Return to regular smoking by someone who has quit. A distinction is sometimes made between "relapse" and a "lapse" (or a "slip"), which is a return to reduced smoking or brief smoking after quitting that falls short of a return to regular smoking.

- Self-reported abstinence. Abstinence based on the patient's claim, which may or may not be verified clinically by biochemical confirmation.

- Serum nicotine. Level of nicotine in the blood. This often is used to assess a patient's tobacco/nicotine self-administration prior to quitting, and to confirm abstinence self-reports during follow-up. Nicotine commonly is measured in urine and saliva.

- Serum nicotine/cotinine levels. Level of nicotine/cotinine in the blood. Cotinine is nicotine's major metabolite, which has a significantly longer half-life than nicotine. This often is used to estimate a patient's tobacco/nicotine selfadministration prior to quitting, and to confirm abstinence self-reports during follow-up. Cotinine commonly is measured in urine and saliva.

- Smoker. A person that uses tobacco products in any form.

- Smokeless tobacco. Any form of unburned tobacco, including chewing tobacco, snus, and snuff. Smokeless tobacco can cause cancer of the gum, cheek, lip, mouth, tongue, throat, and pancreas. 
- Stepped care. The practice of initiating treatment with a low-intensity intervention and then exposing treatment failures to successively more intense interventions.

- Tobacco dependence. Dependence on any form of tobacco, including, but not exclusive to, cigarettes, pipes, cigars, and chewing tobacco.

- Varenicline. A non-nicotine aid for smoking cessation, and the first partial agonist of the $\alpha 4 \beta 2$ neuronal nicotinic acetylcholine receptor to be developed. It is presumed to work by preventing nicotine binding to $\alpha 4 \beta 2$ receptors. Varenicline is marketed in the United States as Chantix.

- Withdrawal symptoms. A variety of unpleasant symptoms (e.g., difficulty concentrating, irritability, anxiety, anger, depressed mood, sleep disturbance, and craving) that occur after use of an addictive drug is reduced or stopped. Withdrawal symptoms are thought to increase the risk for relapse. 


\section{CHAPTER 2: LITERATURE REVIEW}

\section{Introduction}

In WHO's 2008 report, six major policies are introduced that, when enacted together, will help prevent young people from initiating smoking, help current smokers quit, and protect nonsmokers from unnecessary secondhand exposure. ${ }^{2}$ Offering to help smokers quit is a key policy that encourages use of low-cost, effective interventions to increase cessation. Currently, such programs exist in nine countries, representing 5\% of the world's smoking population. Thus, information on cost-effectiveness of smoking cessation interventions is critical to justify funding of future studies and coverage of smoking cessation programs for smokers.

To this end, a review of literature of cost-effectiveness analyses in smoking cessation was conducted. The PubMed database was queried to identify full-text articles (including literature reviews and meta-analyses) that met these criteria: a) smoking cessation clinical trials/studies analyzing (or simulating) either a stepped care intervention or a moderate/intensive pharmacotherapy and counseling intervention, b) a cost-effectiveness component, c) face-to-face contact for interventions (versus telephone or mail contact only), and d) end-of-study follow-up of at least 12 months post initiation. These specific criteria were necessary for relevant comparison to the Step Care study. Articles had to clearly state a perspective (i.e. societal, third-party payer), cessation and outcomes measures, patient population, and duration of follow-up to be considered for review. Articles using return on investment or cost-benefit techniques or those analyzing cost-effectiveness of anti-smoking policies or taxes (instead of treatments or programs) were excluded. Analyses conducted in other countries were included as long as articles were printed in English and met all other criteria. Medical Subject Heading (MeSH) terms (costs and cost analysis, tobacco use cessation/economics) produced close to 100 full-text results; only nine met inclusion criteria. Following a brief overview, studies were analyzed in two areas: comparisons of cost-effectiveness and adherence to widely accepted recommendations for conduct of economic evaluations.

\section{Overview of Smoking Cessation Studies}

Nine studies utilizing intervention designs most comparable to the underlying study are reviewed to estimate an expected range of cost-effectiveness for the Step Care Study. Considering that these studies use shorter treatment periods, it is expected that they will provide a lower bound for expected cost-effectiveness of Step Care. The studies reviewed assess the impact of smoking cessation interventions across varied time horizons (18 months to lifetime); Table 2-1 outlines study characteristics. Only one study (Barnett) ${ }^{77}$ among those reviewed analyzed cost-effectiveness of a stepped care intervention (relative to brief intervention); all others compared brief interventions to other moderate or intensive interventions. Short-term studies analyzing intermediate outcomes (i.e. cost per quit) are reviewed separately from those analyzing long-term outcomes (i.e. cost per life-year saved, cost per QALY). 
Table 2-1. Study Characteristics: Cost-Effectiveness Analyses of Smoking Cessation Interventions

\begin{tabular}{|c|c|c|c|}
\hline \multirow[b]{2}{*}{ Characteristics } & \multicolumn{3}{|c|}{ Study, Year } \\
\hline & Barnett et al. (2008) & Bolin et al. (2006) & Cornuz et al. (2003) \\
\hline \multicolumn{4}{|l|}{ Methods } \\
\hline Analysis type & Prospective CEA & Prospective CEA & Prospective CEA \\
\hline Model type & decision tree & simulation model & Markov model \\
\hline \multicolumn{4}{|l|}{ Framing } \\
\hline Country & United States & Sweden & Switzerland \\
\hline Setting & $\begin{array}{l}322 \text { smokers in a } \\
\text { mental health } \\
\text { outpatient setting }\end{array}$ & $\begin{array}{l}\text { Model cohort of } \\
\text { male \& female } \\
\text { smokers, } \\
\text { proportionate to } \\
\text { Swedish population }\end{array}$ & $\begin{array}{l}\text { simulated twin } \\
\text { cohorts of one PAD } \\
\text { smokers }\end{array}$ \\
\hline \multirow[t]{5}{*}{ Intervention } & $\begin{array}{l}\text { 1. Brief counsel and } \\
\text { list of SC programs } \\
\text { (reference) }\end{array}$ & 1. Bupropion & $\begin{array}{l}\text { 1. Counseling only } \\
\text { from GP (reference) }\end{array}$ \\
\hline & 2. Stepped care* & 2. Nicotine gum & $\begin{array}{l}\text { 2. Counseling plus } \\
\text { gum }\end{array}$ \\
\hline & & 3. Nicotine patch & $\begin{array}{l}\text { 3. Counseling plus } \\
\text { patch }\end{array}$ \\
\hline & & & $\begin{array}{l}\text { 4. Counseling plus } \\
\text { spray }\end{array}$ \\
\hline & & & $\begin{array}{l}\text { 5. Counseling plus } \\
\text { inhaler } \\
6 \text {. Counseling plus } \\
\text { bupropion }\end{array}$ \\
\hline Perspective & Research & Societal & Third-party payer \\
\hline Time horizon & $\begin{array}{l}18 \text { month follow-up } \\
\text { following treatment }\end{array}$ & 20-year follow-up & $\begin{array}{l}12 \text { month follow-up } \\
\text { following treatment }\end{array}$ \\
\hline \multicolumn{4}{|l|}{ Effects } \\
\hline Cessation & Point-prevalence & Continuous & Point-prevalence \\
\hline Main effects & 1. $\mathrm{C} / \mathrm{Q}$ & 1. C/QALY & 1. C/LYS \\
\hline Discount rate & N/A & $3 \%$ & $3 \%$ \\
\hline Base year (costs) & 2003 & 2001 & 2001 \\
\hline
\end{tabular}


Table 2-1. (continued)

\begin{tabular}{|c|c|c|c|}
\hline \multirow[b]{2}{*}{ Characteristics } & \multicolumn{3}{|c|}{ Study, Year } \\
\hline & Cornuz et al. (2006) & $\begin{array}{c}\text { Feenstra et al. } \\
(2005)\end{array}$ & Gilbert et al. (2004) \\
\hline \multicolumn{4}{|l|}{ Methods } \\
\hline Analysis type & Prospective CEA & $\begin{array}{l}\text { CEA of cessation } \\
\text { programs }\end{array}$ & Prospective CEA \\
\hline Model type & Markov model & simulation model & Markov model \\
\hline \multicolumn{4}{|l|}{ Framing } \\
\hline Country & Multiple countries & The Netherlands & Seychelles \\
\hline Setting & $\begin{array}{l}\text { simulated twin } \\
\text { cohorts of one PAD } \\
\text { smokers }\end{array}$ & $\begin{array}{l}\text { simulated cohort of } \\
\text { Netherlands } \\
\text { population }\end{array}$ & $\begin{array}{l}\text { simulated twin } \\
\text { cohorts of one PAD } \\
\text { smokers }\end{array}$ \\
\hline \multirow[t]{6}{*}{ Intervention } & $\begin{array}{l}\text { 1. Counseling only } \\
\text { from GP (reference) }\end{array}$ & $\begin{array}{l}\text { 1. Minimal } \\
\text { counseling (MC) }\end{array}$ & $\begin{array}{l}\text { 1. Counseling only } \\
\text { from GP (reference) }\end{array}$ \\
\hline & $\begin{array}{l}\text { 2. Counseling plus } \\
\text { gum }\end{array}$ & 2. $\mathrm{MC}+\mathrm{NRT}$ & $\begin{array}{l}\text { 2. Counseling plus } \\
\text { gum }\end{array}$ \\
\hline & $\begin{array}{l}\text { 3. Counseling plus } \\
\text { patch }\end{array}$ & $\begin{array}{l}\text { 3. Intensive } \\
\text { counseling (IC) + } \\
\text { NRT }\end{array}$ & $\begin{array}{l}\text { 3. Counseling plus } \\
\text { patch }\end{array}$ \\
\hline & $\begin{array}{l}\text { 4. Counseling plus } \\
\text { spray }\end{array}$ & 4. IC + Bupropion & $\begin{array}{l}\text { 4. Counseling plus } \\
\text { spray }\end{array}$ \\
\hline & $\begin{array}{l}\text { 5. Counseling plus } \\
\text { inhaler }\end{array}$ & $\begin{array}{l}\text { 5. Telephone } \\
\text { counseling (TC) }\end{array}$ & $\begin{array}{l}\text { 5. Counseling plus } \\
\text { inhaler }\end{array}$ \\
\hline & $\begin{array}{l}\text { 6. Counseling plus } \\
\text { bupropion }\end{array}$ & $\begin{array}{l}\text { 6. Current practice } \\
\text { (reference) }\end{array}$ & $\begin{array}{l}\text { 6. Counseling plus } \\
\text { bupropion }\end{array}$ \\
\hline Perspective & Third-party payer & Societal & Third-party payer \\
\hline Time horizon & $\begin{array}{l}12 \text { month follow-up } \\
\text { following treatment }\end{array}$ & 75 years & $\begin{array}{l}12 \text { month follow-up } \\
\text { post treatment }\end{array}$ \\
\hline \multicolumn{4}{|l|}{ Effects } \\
\hline Cessation & Point-prevalence & $\begin{array}{l}\text { Prolonged } \\
\text { abstinence }\end{array}$ & Point-prevalence \\
\hline Main effects & 1. C/LYS & $\begin{array}{l}\text { 1. } \mathrm{C} / \mathrm{Q} \\
\text { 2. C/LYS } \\
\text { 3. C/QALY }\end{array}$ & 1. C/LYS \\
\hline Discount rate & $3 \%$ & $4 \%$ & $3 \%$ \\
\hline Base year (costs) & 2001 & 2000 (euros) & 2003 \\
\hline
\end{tabular}


Table 2-1. (continued)

\begin{tabular}{|c|c|c|c|}
\hline \multirow[b]{2}{*}{ Characteristics } & \multicolumn{3}{|c|}{ Study, Year } \\
\hline & Hall et al. (2005) & Wasley et al. (1997) & Woolacott (2002) \\
\hline \multicolumn{4}{|l|}{ Methods } \\
\hline Analysis type & Retrospective CEA & Prospective CEA & Prospective CEA \\
\hline Model type & decision tree & decision model & decision model \\
\hline \multicolumn{4}{|l|}{ Framing } \\
\hline Country & United States & United States & United Kingdom \\
\hline Setting & $\begin{array}{l}220 \text { cigarette } \\
\text { smokers }\end{array}$ & $\begin{array}{l}\text { Hypothesized } \\
\text { sample of } \\
\text { established PAD } \\
\text { smokers }\end{array}$ & $\begin{array}{l}\text { Hypothesized } \\
\text { sample of } \\
\text { established United } \\
\text { Kingdom smokers }\end{array}$ \\
\hline \multirow[t]{4}{*}{ Intervention } & $\begin{array}{l}\text { 1. Medical } \\
\text { management (MM) } \\
\text { (reference) }\end{array}$ & $\begin{array}{l}\text { 1. Counsel } \\
\text { (reference) }\end{array}$ & $\begin{array}{l}\text { 1. Counsel only } \\
\text { (reference) }\end{array}$ \\
\hline & 2. $\mathrm{MM}+\mathrm{PI}$ & 2. Counsel + patch & 2. NRT + counsel \\
\hline & 3. $\mathrm{MM}+$ Nortrip & & 3. Bupr + counsel \\
\hline & 4. $\mathrm{MM}+\mathrm{Bupr}$ & & $\begin{array}{l}\text { 4. NRT + Bupr + } \\
\text { counsel }\end{array}$ \\
\hline Perspective & Third-party payer & Patient & $\begin{array}{l}\text { Third-party payer } \\
\text { (NHS) }\end{array}$ \\
\hline Time horizon & $\begin{array}{l}52 \text { weeks following } \\
\text { initiation }\end{array}$ & $\begin{array}{l}12 \text { months following } \\
\text { treatment }\end{array}$ & Lifetime \\
\hline \multicolumn{4}{|l|}{ Effects } \\
\hline Cessation & Point-prevalence & Point-prevalence & Point-prevalence \\
\hline \multirow[t]{3}{*}{ Main effects } & 1. $\mathrm{C} / \mathrm{Q}$ & 1. $\mathrm{C} / \mathrm{Q}$ & 1. $\mathrm{C} / \mathrm{Q}$ \\
\hline & & 2. C/LYS & 2. $\mathrm{C} / \mathrm{LYS}$ \\
\hline & & & 3. C/QALY \\
\hline Discount rate & $\mathrm{N} / \mathrm{A}$ & $5 \%$ & $1.5 \%$ (effects only) \\
\hline Base year (costs) & 2000 & 1995 & 1998 \\
\hline
\end{tabular}

Note: *Stepped care involves: 1) up to 3 assessments of Readiness to Quit, 2) NRT and 6 counsel sessions, and 3) Bupropion and 2 additional counsel sessions.

Abbreviations: CEA: cost-effectiveness analysis; C/LYS: cost per life-year saved; C/Q: cost per quit; C/QALY: cost per quality adjusted life-year; G: gum; GP: general practitioner; I: inhaler; IC: intensive counseling; MC: minimal counseling; MI: motivational interviewing; MM: medical management; N/A: not applicable; NHS: National Health Service (United Kingdom); NRT: nicotine replacement therapy; P: patch; PAD: pack-a-day (20+ cigarettes); PI: psychological intervention; RCT: randomized controlled trial; SC: smoking cessation; TC: telephone counseling. 


\section{Short-Term Studies}

Barnett et al. randomized 322 smokers in a mental health outpatient setting to a brief contact intervention (comprising one counseling session and a list of available smoking cessation programs) or a stepped care intervention. ${ }^{77}$ Stepped care participants were offered up to three assessments of readiness to quit; contemplators or requestors of therapy were then offered six counseling sessions and 10 weeks of nicotine replacement therapy. Two additional counseling sessions and bupropion pharmacotherapy were offered as a third step, upon relapse. Point-prevalence abstinence (7-day) was verified at $3,6,12$, and 18 months. At study end, $24.6 \%$ of stepped care participants versus $19.1 \%$ of brief contact were abstinent, at an incremental cost of $\$ 6,204$ per additional quit.

Hall et al. examined incremental cost-effectiveness of bupropion, nortriptyline, and psychological intervention when added to medical management among San Francisco area volunteers participating in a clinical trial. ${ }^{81}$ Here, medical management comprised four brief counseling sessions in which physicians gave advice to quit, medication education and monitoring, and other materials, while psychological intervention involved five group sessions, providing more in-depth counsel and support. Nortriptyline and bupropion were pharmacotherapy options; all interventions were conducted over 12 weeks. Seven-day point prevalence abstinence was verified at end of treatments and at weeks 24,36 , and 52. Incremental cost-effectiveness estimates for psychological intervention, nortriptyline, and bupropion were $\$ 440, \$ 741$, and $\$ 1,509$ per quit, respectively. Hypothesis testing revealed that differences in cost-effectiveness of therapies were not significant.

\section{Long-Term Studies}

Bolin et al. evaluated the cost-effectiveness of bupropion and motivational support relative to NRT (patch and gum) and motivational support for a cohort of smokers simulating the Swedish population. ${ }^{82}$ A model was constructed to analyze treatment costs incurred, healthcare costs averted (due to decreased risk of disease), and productivity gains realized due to smoking cessation over a 20 -year horizon. A variety of external data sources were used for estimating quit, relapse, disease incidence, and mortality rates and treatment costs that were entered into the model. Bupropion was dominant to both nicotine gum and nicotine patch therapies for men and women in the simulation when direct and indirect costs of smoking cessation were considered; bupropion was less costly and more effective, producing net cost savings. However, when only direct costs were considered, bupropion remained dominant only when compared to nicotine gum therapy. Bupropion was cost-effective (more costly but more effective) relative to nicotine patch therapy, with incremental cost-effectiveness expressed in Swedish currency (6,600 SEK/QALY [men], 4,900 SEK/QALY [women]).

Cornuz et al. used Markov modeling to simulate twin cohorts of one pack-a-day smokers in Switzerland to analyze cost-effectiveness of adding first-line smoking cessation therapies to counseling alone. ${ }^{83}$ The reference cohort was offered routine counseling at office visits; the other cohort received, in addition to initial counseling, an 
offer for pharmacotherapy (gum, patch, spray, inhaler, bupropion). Smokers accepting pharmacotherapy received 5 additional follow-up consultations throughout treatment. The models used reference studies reporting point-prevalence abstinence at 12 months. A model was run for each of the five pharmacotherapies. Adding bupropion to counseling was most cost-effective, ranging from $€ 1,768$ to $€ 3,646$ (currency in euros), followed by the patch (€3,113 to $€ 6,423)$, spray (€3,669 to $€ 7,570)$, inhaler ( $€ 3,700$ to $€ 7,634)$, and then $\operatorname{gum}(€ 4,266$ to $€ 8,799)$.

Cornuz published a follow-up study in 2006, updating estimates from Switzerland and adding data from Canada, France, Spain, United States, and United Kingdom. ${ }^{84}$ Twin cohorts were simulated for each country to assess the adjunct of first-line pharmacotherapies to counseling alone. Again, adding bupropion was most cost-effective for men and women, followed by patch, spray, gum, and inhaler. Incremental costs per life-year saved for men ranged from $\$ 792$ in Canada to \$1,934 in the U.S., \$1,758 in Spain to \$3,396 in United Kingdom, \$1,935 in Spain to \$5,275 in the U.S., \$2,230 in Spain to $\$ 5,509$ in the U.S., and \$3,480 in Switzerland to \$5,759 in France for bupropion, patch, spray, gum, and inhaler therapies, respectively. Incremental costs per life-year saved for women ranged from \$1,196 in Canada to \$2,922 in the U.S., \$2,657 in Spain to $\$ 5,131$ in United Kingdom, $\$ 2,923$ in Spain to $\$ 7,969$ in the U.S., \$3,370 in Spain to $\$ 7,643$ in the U.S., and $\$ 5,257$ in Switzerland to $\$ 8,700$ in France for bupropion, patch, spray, gum, and inhaler therapies, respectively.

Feenstra et al. analyzed cost-effectiveness of increased implementation of five face-to-face interventions (minimal counseling with and without NRT, intensive counseling with NRT or with bupropion, and telephone counseling) over current practice in the Netherlands. ${ }^{85}$ Using modeling techniques, the number of additional quitters and subsequent life-years and quality-adjusted life-years gained were estimated assuming increased implementation of interventions over 1, 10, and 75 years for each intervention. Researchers used available country data to estimate cessation, natural quit, and relapse rates as well as intervention costs. Minimal counseling as a strategy dominated current practice, as it was less costly and more effective (yielding 45 additional quits for $\$ 680$ less per 1000 smokers). Permanent increased implementation (75 years) yielded the most favorable results, with incremental costs of $€ 1,400, € 1,800, € 4,300$, and $€ 6,200$ per lifeyear gained for telephone counseling, minimal counseling and NRT, intensive counseling and bupropion, and intensive counseling with NRT, respectively. Incremental costs per QALY were more attractive at $€ 1,100, € 1,400, € 3,400$, and $€ 4,900$ for the aforementioned therapies.

Gilbert et al. estimated incremental cost-effectiveness of first-line pharmacotherapies over physician counseling alone in Seychelles to justify the provision of pharmacotherapies in developing countries. ${ }^{86}$ The authors used a model validated by Cornuz, simulating identical smoker cohorts that receive either physician counseling or a combination of counseling and pharmacotherapy. The model was run for each of five first-line pharmacotherapies. Adding bupropion was most cost-effective, followed by patch, gum, inhaler, and spray. This order differed from Cornuz's findings mainly because of variations in drug prices across countries. 
Wasley et al. explored cost-effectiveness of providing nicotine patch therapy as an adjunct to brief counseling. ${ }^{87}$ Using data from meta-analysis and other literature, incremental cost per life-year saved was calculated for identical cohorts of 400 U.S. pack-a-day smokers. Nicotine patch therapy was relatively cost-effective, ranging from $\$ 1,796$ to $\$ 4,391$ per life-year saved depending upon gender and age.

Woolacott et al. used data from previous meta-analyses and cost-effectiveness analyses to assess incremental cost-effectiveness of adjunct smoking cessation strategies (nicotine replacement therapy, bupropion, and combination therapy) versus counseling only for the United Kingdom population. ${ }^{88}$ A decision model was developed to estimate costs and effects of the various strategies by cost per quit, cost per life-year saved, and cost per QALY. As seen with other studies, bupropion and counseling was the most costeffectiveness strategy, with ICERs of $£ 1,278$ per quit, $£ 639$ per life-year saved, and $£ 473$ per QALY (currency in pounds). Nicotine replacement therapy and bupropion and counseling produced ICERs of $£ 1,781$ per quit, $£ 890$ per life-year saved, and $£ 660$ per QALY. Nicotine replacement therapy and counseling produced ICERs of $£ 2,001$ per quit, $£ 1,000$ per life-year saved, and $£ 741$ per QALY.

\section{Comparisons of Cost-Effectiveness}

Cost-effectiveness analyses of life-saving interventions are often displayed in league tables, which allow study results to be compared. Due to differences in perspective, setting (country), and cost-effectiveness outcomes, results of studies must first be equalized to allow for comparison. In order to achieve equivalence across studies, incremental cost-effectiveness estimates required conversion to current year dollars, using a historical exchange rate database for exchanging foreign currencies to the U.S. dollar and the consumer price index (CPI) to update estimates to the year 2009. The studies were separated by geography (U.S. versus international) and effect (cost per quit, life-year saved, QALY) to evaluate the ranges of incremental cost-effectiveness across studies. Tables 2-2 and 2-3 summarize cost-effectiveness of international and U.S. studies, respectively.

Among international studies, smoking cessation interventions were extremely cost-effective, ranging from \$768-\$5,067/quit, \$954-\$11,601/LYS, and \$1,008$\$ 8,872$ QQALY. U.S.-based interventions were equally cost-effective, ranging from $\$ 545$ $\$ 7,189 /$ quit and $\$ 2,513-\$ 6,019 / \mathrm{LYS}$. These figures are small in comparison to the costs of other healthcare interventions; mammography screening or treatment for high cholesterol are \$50,000 and \$100,000/LYS, respectively. ${ }^{33}$ In 1995, Tengs and colleagues reviewed 500 life-saving interventions; overall, the median medical intervention cost $\$ 19,000$ per life-year saved (or $\$ 27,228$ in 2009 dollars). ${ }^{50}$ The cost-effectiveness of smoking cessation treatments is more evident when comparing incremental cost/QALY. Incremental costs for smoking cessation interventions are at most a tenth of the accepted threshold of \$50,000/QALY. 
Table 2-2. League Table of International Cost-Effectiveness Analyses of Smoking Cessation Interventions

\begin{tabular}{|c|c|c|}
\hline Author & Intervention & Cost $(\$, 2009)$ \\
\hline \multicolumn{3}{|c|}{ Cost/Quit } \\
\hline Feenstra et al. & MC vs. Current Practice & $\$ 768$ \\
\hline Woolacott et al. & Counsel + Bupr vs. Counsel & $\$ 2,723$ \\
\hline Feenstra et al. & TC vs. Current Practice & $\$ 2,798$ \\
\hline Feenstra et al. & MC + NRT vs. Current Practice & $\$ 2,986$ \\
\hline Woolacott et al. & Counsel + NRT + Bupr vs. Counsel & $\$ 3,795$ \\
\hline Feenstra et al. & IC + Bupr vs. Current Practice & $\$ 4,112$ \\
\hline Woolacott et al. & Counsel + NRT vs. Counsel & $\$ 4,264$ \\
\hline Feenstra et al. & IC + NRT vs. Current Practice & $\$ 5,067$ \\
\hline \multicolumn{3}{|c|}{ Cost/Life-Year Saved } \\
\hline Feenstra et al. & MC vs. Current Practice & cost-saving \\
\hline Cornuz et al. (2006) & Counsel + Bupr vs. CO (Males) & $\$ 954-\$ 2,330$ \\
\hline Woolacott et al. & Counsel + Bupr vs. Counsel & $\$ 1,362$ \\
\hline Cornuz et al. (2006) & Counsel + Bupr vs. CO (Females) & $\$ 1,441-\$ 3,520$ \\
\hline Gilbert et al. & Counsel + Bupr vs. CO (Males) & $\$ 1,519-\$ 2,014$ \\
\hline Woolacott et al. & Counsel + NRT + Bupr vs. Counsel & $\$ 1,896$ \\
\hline Cornuz et al. (2006) & Counsel + Patch vs. CO (Males) & $\$ 2,118-\$ 4,091$ \\
\hline Woolacott et al. & Counsel + NRT vs. Counsel & $\$ 2,131$ \\
\hline Gilbert et al. & Counsel + Patch vs. CO (Males) & $\$ 2,273-\$ 3,013$ \\
\hline Cornuz et al. (2006) & Counsel + Spray vs. CO (Males) & $\$ 2,331-\$ 6,354$ \\
\hline Gilbert et al. & Counsel + Bupr vs. CO (Females) & $\$ 2,378-\$ 3,264$ \\
\hline Feenstra et al. & TC vs. Current Practice & $\$ 2,389-\$ 2,316$ \\
\hline Cornuz et al. (2006) & Counsel + Gum vs. CO (Males) & $\$ 2,686-\$ 6,094$ \\
\hline Cornuz et al. (2003) & Counsel + Bupr vs. CO (Males) & $\$ 2,935-\$ 4,732$ \\
\hline Feenstra et al. & MC + NRT vs. Current Practice & $\$ 3,071-\$ 2,664$ \\
\hline Cornuz et al. (2006) & Counsel + Patch vs. CO (Females) & $\$ 3,200-\$ 6,180$ \\
\hline Cornuz et al. (2006) & Counsel + Spray vs. CO (Females) & $\$ 3,521-\$ 9,559$ \\
\hline Gilbert et al. & Counsel + Patch vs. CO (Females) & $\$ 3,558-\$ 4,883$ \\
\hline Cornuz et al. (2003) & Counsel + Bupr vs. CO (Females) & $\$ 3,562-\$ 6,052$ \\
\hline Cornuz et al. (2006) & Counsel + Gum vs. CO (Females) & $\$ 4,059-\$ 9,206$ \\
\hline Cornuz et al. (2006) & Counsel + Inhaler vs. CO (Males) & $\$ 4,192-\$ 6,937$ \\
\hline Gilbert et al. & Counsel + Gum vs. CO (Males) & $\$ 4,258-\$ 5,643$ \\
\hline Gilbert et al. & Counsel + Inhaler vs. CO (Males) & $\$ 4,922-\$ 6,523$ \\
\hline Cornuz et al. (2003) & Counsel + Patch vs. CO (Males) & $\$ 5,167-\$ 8,334$ \\
\hline Gilbert et al. & Counsel + Spray vs. CO (Males) & $\$ 5,273-\$ 6,989$ \\
\hline Cornuz et al. (2003) & Counsel + Spray vs. CO (Males) & $\$ 6,090-\$ 9,823$ \\
\hline
\end{tabular}


Table 2-2. (continued)

\begin{tabular}{|c|c|c|}
\hline Author & Intervention & Cost $(\$, 2009)$ \\
\hline \multicolumn{3}{|c|}{ Cost/Life-Year Saved } \\
\hline Cornuz et al. (2003) & Counsel + Inhaler vs. CO (Males) & $\$ 6,141-\$ 9,906$ \\
\hline Cornuz et al. (2003) & Counsel + Patch vs. CO (Females) & $\$ 6,272-\$ 10,661$ \\
\hline Cornuz et al. (2006) & Counsel + Inhaler vs. CO (Females) & $\$ 6,332-\$ 10,479$ \\
\hline Gilbert et al. & Counsel + Gum vs. CO (Females) & $\$ 6,666-\$ 9,147$ \\
\hline Cornuz et al. (2003) & Counsel + Gum vs. CO (Males) & $\$ 7,081-\$ 11,418$ \\
\hline Feenstra et al. & IC + Bupr vs. Current Practice & $\$ 7,336-\$ 8,019$ \\
\hline Cornuz et al. (2003) & Counsel + Spray vs. CO (Females) & $\$ 7,393-\$ 12,565$ \\
\hline Cornuz et & Counsel + Inhaler & $\$ 7,4$ \\
\hline Gilbert e & Counsel + Inhaler & \\
\hline Gilbert et al. & Counsel + Spray & 329 \\
\hline Cornuz et al. (2003) & Counsel + Gum vs. CO (Females & $5-\$ 14,605$ \\
\hline Feenstra et al. & IC + NRT vs. Current Practice & $\$ 10,578-\$ 11,601$ \\
\hline \multicolumn{3}{|c|}{ Cost/Quality-Adjusted Life-Year } \\
\hline Bolin et al. & Bupr vs. Patch (Males) & cost-saving \\
\hline Bolin et al. & Bupr vs. Gum (Males) & cost-saving \\
\hline Feenstra et al. & MC vs. Current Practice & cost-saving \\
\hline Woolacott et al. & Counsel + Bupr vs. Counsel & $\$ 1,008$ \\
\hline Woolacott et al. & Counsel + NRT + Bupr vs. Counsel & $\$ 1,406$ \\
\hline Woolacott et al. & Counsel + NRT vs. Counsel & $\$ 1,579$ \\
\hline Feenstra et al. & TC vs. Current Practice & $\$ 1,877-\$ 2,559$ \\
\hline Feenstra et al. & MC + NRT vs. Current Practice & $\$ 2,389-\$ 2,900$ \\
\hline Bolin et al. & Bupr vs. Patch (Females) & $\$ 2,539$ \\
\hline Bolin et al. & Bupr vs. Gum (Females) & $\$ 4,054$ \\
\hline Feenstra et al. & IC + Bupr vs. Current Practice & $\$ 5,801-\$ 6,142$ \\
\hline Feenstra et al. & IC + NRT vs. Current Practice & $\$ 8,360-\$ 8,872$ \\
\hline
\end{tabular}

Abbreviations: Bupr: bupropion; CO: counsel only; IC: intensive counseling; MC: minimal counseling; NRT: nicotine replacement therapy; PI: psychological intervention; TC: telephone counseling. 
Table 2-3. League Table of U.S. Cost-Effectiveness Analyses of Smoking Cessation Interventions

\begin{tabular}{llr}
\hline Author & \multicolumn{1}{c}{ Intervention } & Cost $(\$, 2009)$ \\
\hline & \multicolumn{1}{c}{ Cost/Quit } \\
Hall et al. & MM + PI vs. MM & $\$ 545$ \\
Hall et al. & MM + Nortrip vs. MM & $\$ 917$ \\
Hall et al. & MM + Bupr vs. MM & $\$ 1,868$ \\
Barnett et al. & Stepped Care vs. Brief Intervention & $\$ 7,189$ \\
& & \\
& $\quad$ Cost $/$ Life Year Saved & \\
Wasley et al. & Counsel + Patch vs. Counsel (Males) & $\$ 2,513-\$ 4,126$ \\
Wasley et al. & Counsel + Patch vs. Counsel (Females) & $\$ 4,253-\$ 6,143$ \\
Barnett et al. & Stepped Care vs. Brief Intervention & $\$ 6,019$ \\
\hline
\end{tabular}

Abbreviations: Bupr: bupropion; IC: intensive counseling; MM: medical management; Nortrip: nortriptyline; NRT: nicotine replacement therapy; PI: psychological intervention

\section{Recommendations for Conduct of Economic Evaluation}

While comparison of cost-effectiveness of smoking cessation programs, treatments, and services is highlighted in this review, the underlying methodology is of greater importance. Appropriate conduct of cost-effectiveness analysis in smoking cessation is necessary for achieving greater comparability across studies and is critical to designing the current analysis. Despite the existence of various guidelines addressing the design of economic evaluations, the recommendations from the U.S. Panel on CostEffectiveness in Health and Medicine (The Panel) are widely cited and accepted as a specific rubric for designing and conducting cost-effectiveness analyses. ${ }^{80}$ The Panel outlines key elements for the appropriate conduct of economic evaluation.

\section{Perspective}

Perspective considers the point of view from which the study is designed. To frame the research question(s) from a particular perspective will determine which costs and consequences should be included. Costs and consequences will differ among patients, third-party payers, employers, or society, thus yielding varied estimates of costeffectiveness. The Panel recommends framing cost-effectiveness analyses from a societal perspective, to account for all costs and effects attributable to treatment, regardless of who experiences them. Among reviewed studies, those which utilized a third-party payer or governmental perspective represented health plans or countries with single-payer healthcare systems. A broader search of the literature produced only four studies published after the release of Panel guidelines framed from the societal perspective. A few articles provide cost-effectiveness results from multiple perspectives-this is a common and widely accepted approach, as it enhances homogeneity across studies. 


\section{Measures of Cessation}

Point prevalence abstinence was used as the measure of cessation in all studies reviewed. This reflects its wide acceptance as a cessation measure. Many articles specified 7-day point prevalence as the measure; in several studies, abstinence was verified biochemically. Biochemical verification is commonly conducted at follow-up to encourage valid self-report of abstinence, as various methods can detect nicotine exposure up to three days prior to follow-up. Velicer and colleagues contend that verification, though encouraged, is not necessary due to the rare nature of report falsification. ${ }^{89}$ Though the specifics of cessation measures fall outside of Panel recommendations, they are used to validate a quit, which is a common outcome measure used in cost-effectiveness studies of smoking cessation.

\section{Outcome Measures}

Outcome measures provide the basis for calculating cost-effectiveness ratios. These ratios are used to explain a program's cost relative to achieving an effect. Outcome measures can be disease-specific or generic. In the smoking cessation literature, number of quits and life-years saved are more commonly used effects. These measures are preferred because they are easy to comprehend among healthcare decision makers. Among studies employing a societal perspective, cost per QALY is a standard, although cost per quit and cost per life-year saved are often reported as well. Panel recommendations encourage the use of a cost per QALY ratio, because it reflects the value to achieve both longer and more productive life. In addition, cost-effectiveness results should be reported as an incremental cost-effectiveness ratio, or the difference in costs for an intervention versus its comparator divided by the difference in their effects. None of the U.S. studies considered cost per QALY; only Barnett and Wasley's studies extended their analyses to consider cost per life-year saved. ${ }^{77,87}$

\section{Discounting}

The Panel, in their recommendations, strongly supports the use of discounting. It is necessary because costs and benefits in a study are not typically incurred within the same year. In many cases, both costs and benefits can occur over two different time horizons, thus necessitating discounting of costs and benefits. In a few cases, costs are incurred in one year, while only benefits occur across several years; here, only benefits should be discounted. A 3\% discount rate should be applied to costs and effects as appropriate, as well as an alternative 5\% rate. The suggested rate reflects current estimates of real economic growth, while the alternative rate accommodates comparison across older studies, which often used $5 \%$ as a discounting standard. Justifications for discounting were found in many studies; one such discussion is highlighted in the study by Feenstra and colleagues. ${ }^{85}$ In their simulation, discounting accounts for delayed accrual of health effects relative to the immediate accrual of intervention costs. Most studies cited a discount rate of 3\%, ${ }^{82-84,86}$ another used 5\%. ${ }^{87}$ Abroad, countries have adopted alternate standards; the Dutch standard of $4 \%$ was noted in Feenstra's study. ${ }^{85}$ In 
the United Kingdom, a rate $3.5 \%$ is recommended, ${ }^{90}$ although Woolacott's study used health effects discounted by $1.5 \%{ }^{88}$

\section{Use of Modeling}

Several studies utilize Markov modeling techniques to estimate, prospectively, cost-effectiveness of proposed programs. ${ }^{82-86}$ Prospective cost-effectiveness analysis with models can assist healthcare financing bodies in deciding whether it is beneficial or not to offer and even to cover certain smoking cessation products, services, or programs. Data extracted from clinical trials or other sources are used to estimate treatment course and duration, probabilities of success, and resulting risks and costs of adverse events (associated with treatment). Other literature sources are used to estimate physician time and costs for intervention, administrative costs of intervention, patient's costs for transportation and lost work-time, and other appropriate costs (depending on the perspective used). Examples of costing techniques are detailed in Cornuz's and Gilbert's studies. ${ }^{83,86}$

Markov modeling and related techniques are beneficial for simulating future outcomes, which extend beyond the time horizon of the study or trial. These models typically use long-term cost-effectiveness measures, such as life-years saved or QALYs, to estimate long-term impacts of smoking cessation on morbidity and/or mortality. This technique can be used prospectively to provide justification for long-term investments in interventions to achieve greater cessation. While this may not be of great importance to health plans, which typically focus on short-term outcomes, it provides great value to healthcare systems that finance the healthcare of a population over the lifetime.

\section{Summary}

Studies evaluating cost-effectiveness of moderate to intense smoking cessation interventions may be underrepresented in this review. This is due in part to selection criteria used. Requirement of pharmacotherapy and counseling caused several studies involving pregnant smokers to be excluded. In addition, newer studies in smoking cessation are analyzing alternative intervention contact methods (via computer, mail, or telephone counseling/quit lines), which were not included. A significant number of costeffectiveness analyses conducted abroad were also excluded because they were published in foreign languages. A broader body of literature in economic evaluation of smoking cessation exists; many of these studies address alternative strategies: reimbursement of smoking cessation treatments, tobacco taxation and anti-smoking policies and campaigns. Still, this review provides a strong base for which STEP results can be compared.

Among the studies reviewed here, only three were conducted in the United States and none of them comply with current recommendations outlined by the Panel. Given the expanded use of economic evaluations in healthcare to inform financing and clinical guidelines, studies must prove methodologically sound, clinically oriented, and policy relevant. The recent growth of cost-effectiveness literature in smoking cessation indicates wider acceptance of economic evaluation in the field. Conversely, as the characteristics 
of the smoking population changes (more established, recalcitrant smokers), researchers will need to place increased emphasis on conducting and evaluating more moderate to intense interventions. ${ }^{91}$ Smokers today are more likely to be low-income, educated at a high school level or less, and minority. Without focused intervention in these vulnerable populations, where a paucity of research already exists, disparities will continue to persist.

Conducting an economic evaluation for STEP is necessary for several reasons. First, it will build on literature evaluating cost-effectiveness of newer smoking cessation interventions. Fiore and colleagues have proposed further study of stepped care in smoking cessation; as yet, no formal recommendation for this or other tailored approaches has been made. ${ }^{33}$ In addition, conducting cost-effectiveness alongside a stepped care study is feasible and generally encouraged. ${ }^{79}$ Second, this study will adhere to standards recommended by the Panel. Economic evaluations conducted in the United States have consistently lacked a methodological standard, while the United Kingdom and other countries adhere to and enforce use of a single standard of conduct. Lastly, this evaluation is needed to justify future funding of tobacco control efforts, which must focus on the smoking population which remains. The underlying study is comprised of lowincome, minority smokers for which more research is needed to establish effectiveness and cost-effectiveness. 


\section{CHAPTER 3: METHODS}

\section{Data Collection}

Data for the study was collected as part of the original research intervention, STEP. Data was collected at each visit from research participants via questionnaires and patient chart records. The data captured smoking status, nicotine dependency, and other statistics relevant to the study. Data from forms and charts were checked for completeness and accuracy before being entered into the system. Validation checks were run periodically to identify data errors. More specific details regarding data collection and management are described elsewhere. Data collected through June 2009 were cleaned and converted into a de-identified dataset for use in the cost-effectiveness analysis. Although requirements for human subjects training have been satisfied, the original dataset with patient identifiers was not accessed to avoid unwarranted identification of participants. Appropriate security measures were taken to ensure that data and related components were not breached.

\section{Sample Size}

A total of 406 participants from University of Tennessee Health Science Center (Memphis, Tennessee) and Mayo Clinic (Rochester, Minnesota) were enrolled in the smoking cessation study. As of June 2009, data for 319 completers were available for analysis; this included the full sample from Mayo Clinic $(\mathrm{n}=136)$ and a significant portion from UTHSC (183 of 270). Descriptive analyses were conducted to test the statistical equivalence of completers and the remaining UTHSC sample. The results of this analysis, shown in Table 3-1, reveal no differences in most factors. Estimates for both cost-effectiveness analysis and simulation of future events were based on completers at June 2009.

\section{Conducting Cost-Effectiveness Analysis}

As mentioned earlier, methodological standards for conducting cost-effectiveness analyses in medicine and health were released in 1996 by the U.S. Public Health Service's Panel on Cost-Effectiveness in Health and Medicine. ${ }^{80}$ These standards have grounded the methodology of this analysis, using a reference case method. The Panel requires that cost-effectiveness analyses be conducted from the societal perspective, including all costs associated with disease and treatment as well as future costs averted by intervention. Additionally, the standards require use of cost-utility analysis (a specific subtype of cost-effectiveness analysis), where health-related quality of life measures are incorporating into cost-effectiveness ratios to produce a dollar cost per quality-adjusted life year (QALY) gained. In STEP, no measures are collected to evaluate health-related quality of life; further, the time horizon of the study (two years) is not adequate enough to assess long-term impacts of cessation on costs and quantity/quality of life. For purposes of this study, two analyses were conducted. First, the cost-effectiveness analysis of the 
Table 3-1. Characteristics of Completers versus Remaining Participants

\begin{tabular}{|c|c|c|c|c|c|c|}
\hline \multirow[b]{2}{*}{ Variable } & \multicolumn{4}{|c|}{ UTHSC } & \multicolumn{2}{|c|}{ Mayo Clinic } \\
\hline & $\begin{array}{l}\text { Stepped } \\
\text { care } \\
\text { sample } \\
(n=85)\end{array}$ & $\begin{array}{l}\text { Stepped } \\
\text { care } \\
\text { others } \\
(n=43)\end{array}$ & $\begin{array}{l}\text { Repeat } \\
\text { sample } \\
(n=98)\end{array}$ & $\begin{array}{l}\text { Repeat } \\
\text { others } \\
(n=44)\end{array}$ & $\begin{array}{l}\text { Repeat } \\
(\mathrm{n}=70)\end{array}$ & $\begin{array}{c}\text { Stepped } \\
\text { care } \\
(n=66)\end{array}$ \\
\hline Age, mean (SD) & $\begin{array}{r}44.1 \\
(9.7)\end{array}$ & $\begin{array}{r}44.7 \\
(11.1)\end{array}$ & $\begin{array}{r}45.1 \\
(11.4)\end{array}$ & $\begin{array}{r}46.4 \\
(9.7)\end{array}$ & $\begin{array}{r}40.8 \\
(10.7)\end{array}$ & $\begin{array}{r}40.4 \\
(12.6)\end{array}$ \\
\hline \multicolumn{7}{|l|}{ Gender, n (\%) } \\
\hline Male & $39(46)$ & $16(37)$ & $43(44)$ & $39(46)$ & $32(46)$ & $37(56)$ \\
\hline $\begin{array}{l}\quad \text { Female } \\
\text { Race/ethnicity, } \\
\text { n (\%) }\end{array}$ & $46(54)$ & $27(63)$ & $55(56)$ & $46(54)$ & $38(54)$ & $29(44)$ \\
\hline NHW & $40(47)$ & $18(42)$ & $54(55)$ & $40(47)$ & $65(93)$ & $59(89)$ \\
\hline NHB & $45(53)$ & $25(58)$ & $43(44)$ & $45(53)$ & $4(6)$ & $1(2)$ \\
\hline $\mathrm{OTH}$ & $0(0)$ & $0(0)$ & $1(1)$ & $0(0)$ & $1(1)$ & $5(9)$ \\
\hline Fagerstrom & 5.91 & 5.11 & 5.57 & 5.68 & 5.44 & 5.39 \\
\hline $\begin{array}{l}\text { score, mean } \\
\text { (SD) }\end{array}$ & $(2.2)$ & $(2.2)$ & $(2.3)$ & $(2.3)$ & $(1.7)$ & $(2.2)$ \\
\hline $\begin{array}{l}\text { CES-D score, } \\
\text { mean (SD) }\end{array}$ & $\begin{array}{r}10.07 \\
(6.9)\end{array}$ & $\begin{array}{r}6.84 \\
(6.6)^{\mathrm{a}}\end{array}$ & $\begin{array}{l}9.88 \\
(7.3)\end{array}$ & $\begin{array}{r}8.09 \\
(6.1)\end{array}$ & $\begin{array}{r}8.70 \\
(6.1)\end{array}$ & $\begin{array}{r}6.35 \\
(5.8)^{b}\end{array}$ \\
\hline CPD, mean & 23.0 & 20.7 & 23.7 & 23.5 & 21.3 & 20.5 \\
\hline$(\mathrm{SD})$ & $(11.6)$ & $(8.8)$ & $(11.2)$ & $(9.5)$ & $(8.4)$ & $(7.3)$ \\
\hline & 23.51 & 19.36 & 23.36 & 18.74 & 22.70 & 22.22 \\
\hline $\mathrm{CO}$, mean $(\mathrm{SD})$ & $(11.6)$ & $(8.4)^{\mathrm{c}}$ & $(12.2)$ & $(9.9)^{\mathrm{d}}$ & $(9.8)$ & $(10.9)$ \\
\hline
\end{tabular}

Note: Differences across UTHSC groups are noted by superscript letters.

${ }^{\text {a }}$ Significant at $\mathrm{p}=0.01$

${ }^{\mathrm{b}}$ Significant at $\mathrm{p}=0.02$

${ }^{c}$ Significant at $\mathrm{p}=0.01$

d Significant at $\mathrm{p}=0.03$

Abbreviations: CES-D: Center for Epidemiologic Studies Depression Scale; CO: carbon monoxide, CPD: cigarettes per day, NHB: non-Hispanic black, NHW: non-Hispanic white, OTH: other race, SD: standard deviation. 
STEP study was conducted from an institutional perspective. Next, the simulation of future outcomes, which extends cost-effectiveness to the lifetime, encompassed a societal perspective. This exception is accepted by Gold; evaluation of cost-effectiveness from multiple perspectives is permitted, as long as one (the reference case analysis) is societal. ${ }^{80}$

\section{Study Design}

A schematic of the STEP study is illustrated in Figure 3-1. As mentioned previously, patients received up to three opportunities to receive combined pharmacological and behavioral treatment. As baseline, eligible patients were randomized to stepped care or repeat care arms. They then received initial treatment (nicotine patch and one counseling session). Patients returned at six months, quit status was assessed, and appropriate treatment assigned. For example, a stepped care patient who relapsed at the six-month visit was stepped up to bupropion and four counseling sessions; a repeat care patient who relapsed at six months received nicotine patch therapy and one counseling session again. Patients who quit successfully did not receive intervention. A similar strategy was used for patients returning at twelve months. Patients could not receive treatment beyond the twelve month visit; quit status was assessed at 18 months and at final follow-up (24 months).

\section{Calculation of Research Costs}

Since analysis took place alongside a research study, only direct medical and treatment costs borne by the research study were considered. Costs included were for pharmacotherapy, treatment and follow-up visits, counseling sessions, telephone followup, and participant time lost in treatment. Any outside costs borne by patients to achieve and/or maintain cessation were not included. Indirect administrative costs were also excluded, as these data were not made available. Costs for pharmacotherapy reflect lowest retail costs; these were adjusted as necessary to reflect base year pricing. Treatment and follow-up visit costs were calculated using average visit time multiplied by the hourly wage(s) of the research personnel involved. Supplies used during the treatment visit were not considered (i.e. urinalysis and cotinine validation), as they were minimal and unlikely to differ between study arms. Costs of counseling were calculated by multiplying the research nurse's hourly wage by the amount of time spent counseling. Telephone follow-up costs were calculated using time spent making telephone follow-up calls multiplied by the hourly wage of research personnel. Participants received reimbursement at each treatment and follow-up visit; these costs were summed to represent time lost in treatment. A separate cost for missed visits was assigned. Labor costs were sourced from the Bureau of Labor Statistics, using 2006 median estimates for registered nurse and medical assistant titles. ${ }^{92}$ Details of the cost calculations are outlined in Table 3-2. 


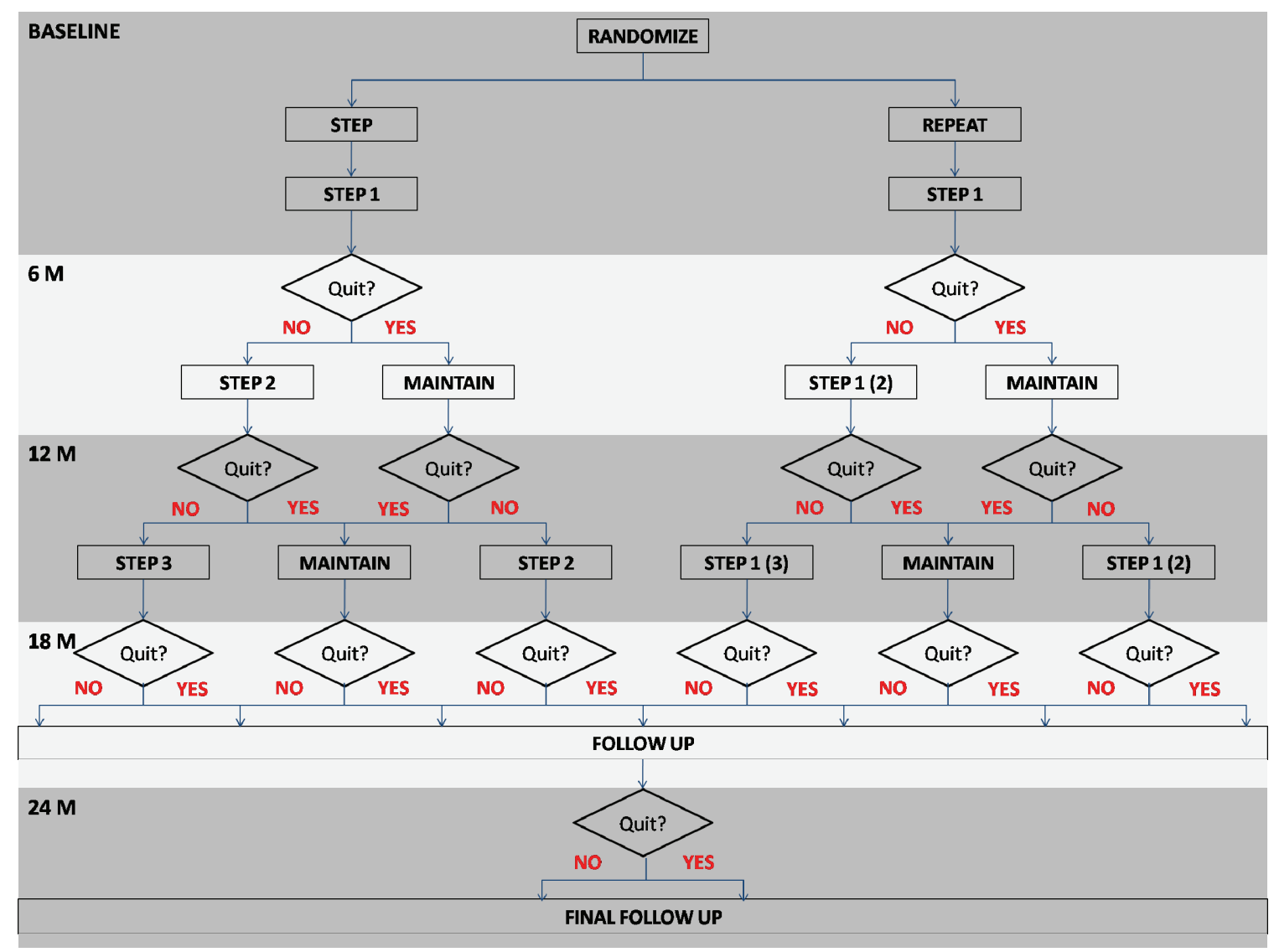

Figure 3-1. STEP Study Schematic

Note: Shaded areas denote study periods (i.e. baseline, 6-month visit, etc.).

Abbreviations: M: months; Maintain: maintenance phase; Step 1: nicotine patch plus 1 counseling session; Step 2: bupropion plus 4 counseling sessions; Step 3: nicotine patch and gum plus 6 counseling sessions. 
Table 3-2. Cost Calculations for STEP CEA

\begin{tabular}{|c|c|c|c|c|}
\hline Resource & Units & $\begin{array}{l}\text { Unit } \\
\text { cost }\end{array}$ & Total & Notes/Source \\
\hline \multicolumn{5}{|l|}{ Pharmacotherapy } \\
\hline Patch (Steps 1-3) & 1 & $\$ 85.97$ & $\$ 85.97$ & $\begin{array}{l}6 \text { weeks Habitrol (2 weeks @ } \\
21,14,7 \mathrm{mg} \text { ) }\end{array}$ \\
\hline Gum (pieces) & 1680 & $\$ 0.25$ & $\$ 424.84$ & $\begin{array}{l}\text { Nicorette gum (12 ppd, } 4 \\
\text { weeks; } 24 \text { ppd, } 8 \text { weeks) }\end{array}$ \\
\hline Patch + gum & & & $\$ 510.81$ & \\
\hline Bupropion (150 mg) & 123 & $\$ 1.17$ & $\$ 143.47$ & AWP, 2006 RedBook \\
\hline \multicolumn{5}{|l|}{ Clinic visit } \\
\hline Technician time (hrs) & 0.417 & $\$ 12.64$ & $\$ 5.27$ & $\begin{array}{l}\text { Technician costs to take labs, } \\
\text { verify CO levels, height/weight } \\
\text { ( } 25 \text { minutes) }\end{array}$ \\
\hline Nurse time (hrs) & 0.333 & $\$ 27.54$ & $\$ 9.18$ & $\begin{array}{l}\text { Nurse time for patient } \\
\text { assessment ( } 20 \text { minutes })\end{array}$ \\
\hline Counselor time (hrs) & 1 & $\$ 27.54$ & $\$ 27.54$ & $\begin{array}{l}\text { Counsel cost/session } \\
\text { (Counselor: Research nurse) }\end{array}$ \\
\hline $\begin{array}{l}\text { Patient time lost in } \\
\text { treatment }\end{array}$ & 1 & $\$ 25.00$ & $\$ 25.00$ & $\begin{array}{l}\text { Patient incentive for } \\
\text { participation }\end{array}$ \\
\hline $\begin{array}{l}\text { Telephone follow-up } \\
\text { (@7wk) }\end{array}$ & 0.25 & $\$ 12.64$ & $\$ 3.16$ & $\begin{array}{l}\text { Staff time spent to assess quit } \\
\text { status, provide support (15 } \\
\text { minutes) }\end{array}$ \\
\hline Total visit & & & $\$ 70.15$ & Total visit cost: Items 2a-2d \\
\hline \multicolumn{5}{|l|}{ Step cost } \\
\hline Patch & & & $\$ 156.12$ & Patch + Clinic visit \\
\hline Bupropion & & & $\$ 334.16$ & $\begin{array}{l}\text { Bupropion + Clinic visit }+3 \\
\text { additional counsel }+12 \text { phone } \\
\text { calls }\end{array}$ \\
\hline Patch + gum & & & $\$ 728.14$ & $\begin{array}{l}\text { Patch }+ \text { gum }+ \text { Clinic visit }+5 \\
\text { additional counsel }+3 \text { phone } \\
\text { calls }\end{array}$ \\
\hline Recycle cost (Patch) & & & $\$ 156.12$ & Patch + Clinic visit \\
\hline Missed visit & & & $\$ 9.48$ & Follow-up phone calls \\
\hline Maintain & & & $\$ 45.77$ & $\begin{array}{l}\text { Clinic visit + summary of } \\
\text { progress ( } 15 \text { minute assessment) }\end{array}$ \\
\hline Follow-up & & & $\$ 42.61$ & $\begin{array}{l}\text { Clinic visit }+ \text { summary of } \\
\text { progress ( } 15 \text { minute assessment) }\end{array}$ \\
\hline
\end{tabular}

Note: Costs not available for 2006 were adjusted accordingly, using the Consumer Price Index. 


\section{Measures and Validation of Cessation}

The underlying intervention relied on self-report of abstinence, with expired carbon monoxide readings as an auxiliary mechanism for validating point-prevalent cessation. Expired carbon monoxide measurements are captured by a small machine connected to a small disposable tube in which a participant exhales. This was performed at baseline and at each follow-up. If a participant reported abstinence but yielded an expired carbon monoxide reading beyond 10 parts-per-million (ppm), salivary cotinine measures were collected. Cotinine is a specific major metabolite of nicotine that can be detected in body fluids for 48 to 72 hours. It is considered the best biomarker for validating cessation. A self-reported abstainer with an unsatisfactory expired carbon monoxide reading ( $>10 \mathrm{ppm}$ ) and salivary cotinine level of $15 \mathrm{ng} / \mathrm{mL}$ or above was considered a continued smoker. This scenario is generally uncommon, as self-reports tend to be accurate with low false-negative rates. ${ }^{89}$

Point-prevalent abstinence was used throughout the study to determine treatment paths. As mentioned above, point-prevalent abstinence was biochemically validated. Unacceptable carbon monoxide and salivary cotinine measures, despite self-report of abstinence, were considered treatment failure at each follow-up. Otherwise, failure was defined as smoking seven consecutive days or at least once a week on two consecutive weeks after the quit date, in accordance with recommendations. ${ }^{93}$ Continuous abstinence was used as the primary measure for end-of study-cessation; because it accounted for lapses, it could not be biochemically verified and was obtained via self-report. Pointprevalence abstinence was used as a secondary end-of-study measure, as it was captured at each follow-up and used as a determinant of treatment. These measures were used in cost-effectiveness analysis to determine number of quitters in each treatment arm.

Patients with complete observations were allocated costs on the basis of quit status at each visit, as it determined the treatment received. Patients missing data an an treatment or follow-up visit were assigned a cost equivalent to three follow-up calls. This cost represented time spent following up with patients who had missed a visit to encourage continued participation in the trial. End of study abstinence was determined by smoking status at the final follow-up visit. Patients missing data for this visit were assumed to be smoking at study end.

\section{Calculation of Cost-Effectiveness}

Considering the setting of the research study, the outcome of interest is a ratio of incremental cost per additional cessation achieved by stepped care relative to repeat care. The numerator of this ratio is the difference in costs in the stepped care arm relative to the repeat care arm, whereas the denominator captures the difference in the number of quitters. The ratio of cost differences to effect differences yields incremental costeffectiveness, or the cost to achieve one additional unit of effect. Whether the study is considered 'cost-effective' depends on both the ICER and a predetermined threshold. In the United States, no standard threshold for cost-effectiveness exists. For the purposes of this research, a threshold was set at $\$ 10,000$ /quit, to account for differences in treatment 
time between short-term studies reviewed and STEP. Short-term studies were at most $\$ 5,067$ per quit; a threshold of twice this amount was considered reasonable for establishing cost-effectiveness of STEP. A separate cost-effectiveness calculation as made for each type of quit (point-prevalence, continuous), as explained previously. All figures were adjusted to 2009 U.S. dollars.

\section{Discounting}

Time gaps between costs of intervention and realization of benefits exists when valuating cost-effectiveness of smoking cessation interventions. Typically the time horizon of the trial is too short to realize long-term outcomes of treatment. Discounting becomes necessary to calculate the present value of costs incurred and benefits achieved beyond the base year. As mentioned previously, Gold and colleagues recommend a 3\% discount rate be applied to balance these differences in time. ${ }^{80}$ For this portion of the economic evaluation, discounting was applied only to costs incurred during year two of the study. Effects (number of quits) were not discounted.

\section{Simulating Future Health Outcomes}

The simulation model being used in the long-term analysis of smoking cessation considered lifetime effects of cessation on smoking-related morbidity and mortality and was adapted from Hoogenveen and Hurley. ${ }^{94,} 95$ Figure 3-2 depicts changes in the disease pathway that occurs as a result of cessation. In general, continued smoking leads to increased risk of morbidity and mortality resulting from smoking-related illnesses. For the purposes of this analysis, ischemic heart disease (including heart attack), cerebrovascular disease (including stroke), emphysema, lung cancer are modeled. Once tobacco-related disease is present, patients suffer decreased quality of life, increased healthcare expenditures and mortality risk. With timely intervention, a portion of current smokers will quit permanently. As a result, smoking-related disease can be averted, thus minimizing loss of quality of life, excess expenditures due to disease, and premature death.

\section{Model Structure and Parameters}

In order to model changes in smoking-related morbidity and mortality due to successful smoking cessation, a microsimulation model was constructed using TreeAge Pro Suite 2009 (TreeAge Software Inc., Williamstown, MA). Using TreeAge, simple or complex disease or decision processes can be modeled. A simulation model was chosen over a traditional Markov type to account for patient-level characteristics (i.e. gender, race, age, and smoking status) that would impact transitions through the model.

Figure 3-3 illustrates the simulation model used for long-term cost-effectiveness analysis. The model includes five health states; state numbers indicate progression of disease while state letters denote smoking status. Patients enter the model in state 1A or 1B, based on end-of-study smoking status. (The model assumes that, at entry, no one has 


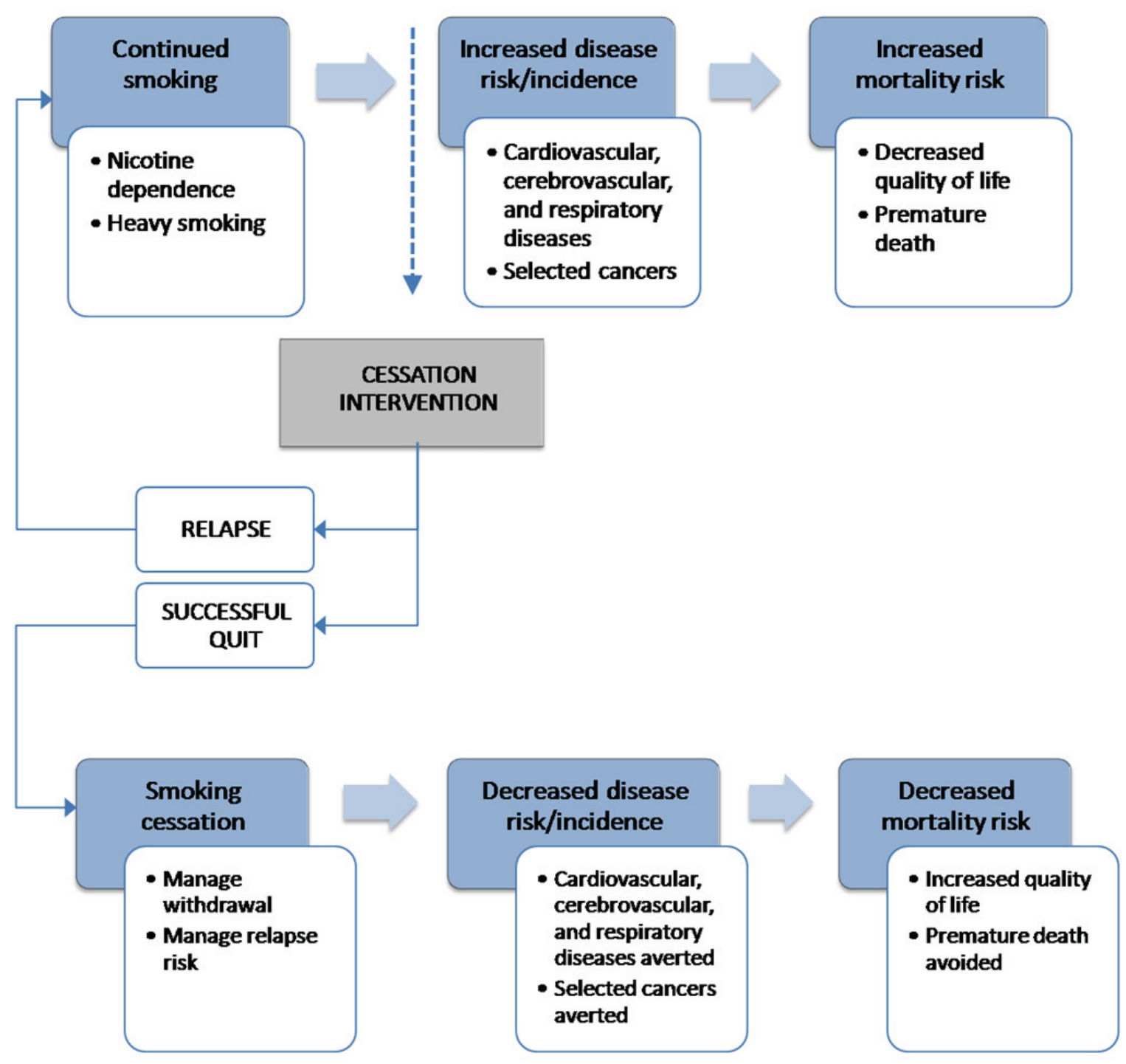

Figure 3-2. Change in Disease Pathway with Successful Cessation

Sources: Hoogenveen RT, van Baal PH, Boshuizen HC, Feenstra TL. Dynamic effects of smoking cessation on disease incidence, mortality and quality of life: The role of time since cessation. Cost Eff Resour Alloc. 2008 January 11; 6:1. ${ }^{94}$

Hurley SF, Matthews JP. The Quit Benefits Model: a Markov model for assessing the health benefits and health care cost savings of quitting smoking. Cost Eff Resour Alloc. 2007 January $23 ; 5: 2 .{ }^{95}$ 


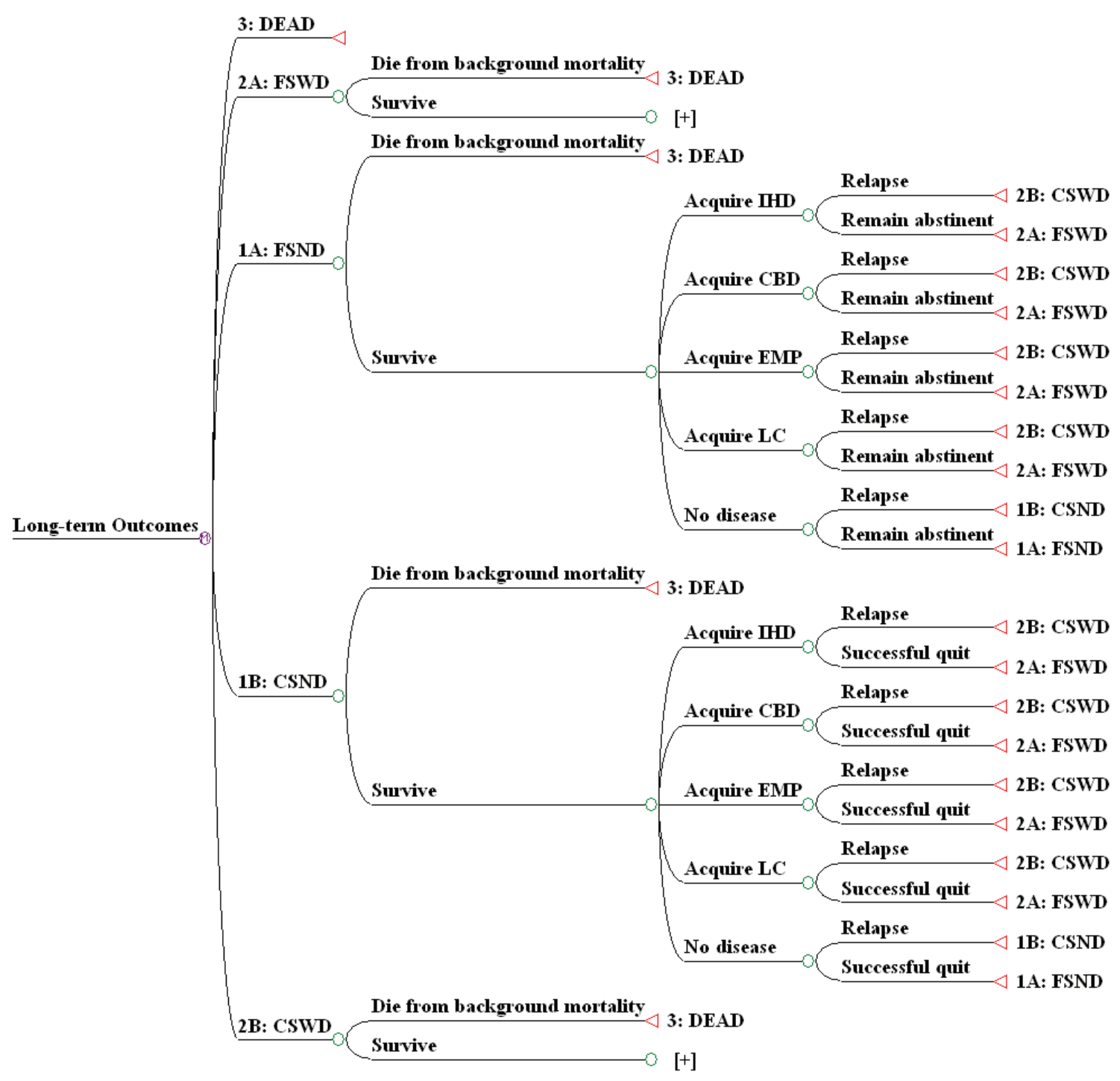

Figure 3-3. Long-Term Outcomes Simulation Model

Note: Stages 2A and 2B were partially collapsed to allow text to be readable at $100 \%$. Stages $1 \mathrm{~A}$ and $2 \mathrm{~A}$ are identical in structure, as are stages $1 \mathrm{~B}$ and $2 \mathrm{~B}$.

Abbreviations: CBD: cerebrovascular disease, CSND: current smoker no disease, CSWD: current smoker with disease, EMP: emphysema, FSND: former smoker no disease, FSWD: former smoker with disease, IHD: ischemic heart disease, LC: lung cancer.

Source: TreeAge Pro Suite 2009 (TreeAge Software Inc., Williamstown, MA). 
heart disease, COPD, or lung cancer.) These states are somewhat parallel, because until disease is acquired, smoking status will influence movement across them. However, patients in state 1B (current smoker, no disease) are more likely than those in 1A to either acquire disease or die, progressing to the next appropriate state (current smoker with disease or death). Only forward movement is allowed in the model; once a patient has disease, he cannot move backward to a non-diseased state. Likewise, once a patient moves to state 3 (death), they remain in that state until the model terminates. During each cycle, changes in smoking status, morbidity and mortality risks, annual treatment costs, and rewards (life-years or QALYs) are calculated. At the end of each cycle, survival, smoking and disease statuses determined state transitions.

\section{Smoking-Related Mortality}

At the beginning of each cycle, mortality risk was assessed. During the first cycle, mortality risk was conditional on race-, gender-, and age-specific risk of death from other causes (not including death from smoking-related diseases being modeled). In subsequent cycles, mortality risk was contingent upon race, age, gender, risk of background death, and presence of smoking-related diseases. Because death can occur at any time during a cycle (year), it was expected that patients dying during a cycle would incur some healthcare costs. As a result, the model assesses one-half of the expenditures that would have been incurred without changes in disease or smoking status. So, if a patient entered the cycle as a former smoker with no disease, one-half the annual expenditures for a former smoker of his current age without disease would be assessed at death. Mortality rates were sourced from the 2006 Compressed Mortality File using CDC WONDER, an interactive database tool that houses public-use data on mortality, cancer incidence, HIV and AIDS, etc. ${ }^{96}$ The system was queried first for deaths from all causes, and separately for any deaths with cerebrovascular disease, ischemic heart disease, lung cancer, or emphysema as an underlying cause. Here, underlying cause identifies the disease or injury which initiated the train of events leading directly to death and would not include deaths due to injury among persons with the above-listed disease. Multiple-decrement life tables were created for each race-gender group, rendering age-specific probabilities of mortality from background causes and presence of smoking-related diseases, shown in Table 3-3. Life tables methods were sourced from Anderson. ${ }^{97}$ A patient's risk of death was expressed as a summed probability of mortality (MR) conditional on race, age, gender (RAG) and presence of smoking-related diseases ( $1=$ present, $0=$ absent), as shown in Equation 3-1:

$$
\begin{aligned}
& \mathrm{MR}_{(\text {Background causes })}=\mathrm{MR}_{(\text {All causes|RAG) }}-\mathrm{MR}_{(\text {Lung cancer|RAG) }}-\mathrm{MR}_{(\text {Emphysema|RAG })}- \\
& \mathrm{MR}\left(\text { Cerebrovascular|RAG) }-\mathrm{MR}_{(\text {Ischemic|RAG) }}\right. \\
& \mathrm{MR}_{(\text {Patient })}=\mathrm{MR}_{(\text {Background causes } \mid \mathrm{RAG})}+\mathrm{MR}_{(\text {Lung cancer|RAG) }} *(1 / 0)+\mathrm{MR}_{(\text {Emphysema|RAG })} *(1 / 0)+ \\
& \mathrm{MR}_{(\text {Cerebrovascular|RAG) }} *(1 / 0)+\mathrm{MR}_{(\text {Ischemic|RAG })} *(1 / 0)
\end{aligned}
$$


Table 3-3. Mortality Rates by Age, Race, and Gender

\begin{tabular}{|c|c|c|c|c|c|c|c|}
\hline \multirow[b]{2}{*}{ Cause } & \multirow[b]{2}{*}{ Age group } & \multicolumn{2}{|c|}{ NHW } & \multicolumn{2}{|c|}{ NHB } & \multicolumn{2}{|c|}{ OTH } \\
\hline & & $\mathrm{M}$ & $\mathrm{F}$ & $\mathrm{M}$ & $\mathrm{F}$ & $\mathrm{M}$ & $\mathrm{F}$ \\
\hline \multirow[t]{8}{*}{$\mathrm{BC}$} & $15-24$ years & 0.0183 & 0.0064 & 0.0377 & 0.0123 & 0.0343 & 0.0164 \\
\hline & $25-34$ years & 0.0202 & 0.0080 & 0.0478 & 0.0226 & 0.0389 & 0.0232 \\
\hline & $35-44$ years & 0.0367 & 0.0195 & 0.0725 & 0.0513 & 0.0587 & 0.0419 \\
\hline & $45-54$ years & 0.0688 & 0.0391 & 0.1378 & 0.0942 & 0.0961 & 0.0772 \\
\hline & 55-64 years & 0.0978 & 0.0635 & 0.1729 & 0.1184 & 0.1320 & 0.1077 \\
\hline & $65-74$ years & 0.1644 & 0.1135 & 0.2457 & 0.1774 & 0.1913 & 0.1737 \\
\hline & $75-84$ years & 0.3677 & 0.2858 & 0.4208 & 0.3304 & 0.3641 & 0.3286 \\
\hline & $85+$ years & 0.3074 & 0.2516 & 0.3229 & 0.2539 & 0.3048 & 0.2406 \\
\hline \multirow[t]{8}{*}{ IHD } & $15-24$ years & 0.0001 & 0.0000 & 0.0003 & 0.0001 & 0.0001 & 0.0002 \\
\hline & 25-34 years & 0.0006 & 0.0002 & 0.0013 & 0.0006 & 0.0017 & 0.0002 \\
\hline & $35-44$ years & 0.0046 & 0.0012 & 0.0067 & 0.0036 & 0.0063 & 0.0013 \\
\hline & $45-54$ years & 0.0168 & 0.0042 & 0.0270 & 0.0127 & 0.0208 & 0.0061 \\
\hline & 55-64 years & 0.0332 & 0.0106 & 0.0492 & 0.0249 & 0.0383 & 0.0145 \\
\hline & $65-74$ years & 0.0570 & 0.0252 & 0.0787 & 0.0481 & 0.0642 & 0.0399 \\
\hline & $75-84$ years & 0.1314 & 0.0801 & 0.1306 & 0.1030 & 0.1250 & 0.0979 \\
\hline & $85+$ years & 0.1183 & 0.0910 & 0.1027 & 0.0897 & 0.1140 & 0.0941 \\
\hline \multirow[t]{8}{*}{ CBD } & $15-24$ years & 0.0001 & 0.0001 & 0.0002 & 0.0001 & 0.0001 & 0.0003 \\
\hline & $25-34$ years & 0.0002 & 0.0002 & 0.0006 & 0.0007 & 0.0003 & 0.0005 \\
\hline & $35-44$ years & 0.0009 & 0.0007 & 0.0027 & 0.0027 & 0.0021 & 0.0020 \\
\hline & $45-54$ years & 0.0025 & 0.0018 & 0.0089 & 0.0073 & 0.0082 & 0.0056 \\
\hline & $55-64$ years & 0.0050 & 0.0035 & 0.0152 & 0.0099 & 0.0113 & 0.0100 \\
\hline & $65-74$ years & 0.0124 & 0.0092 & 0.0256 & 0.0192 & 0.0229 & 0.0211 \\
\hline & $75-84$ years & 0.0375 & 0.0358 & 0.0482 & 0.0473 & 0.0536 & 0.0591 \\
\hline & $85+$ years & 0.0358 & 0.0382 & 0.0354 & 0.0385 & 0.0449 & 0.0459 \\
\hline \multirow[t]{8}{*}{ EMP } & $15-24$ years & 0.0000 & 0.0000 & 0.0000 & 0.0000 & 0.0000 & 0.0000 \\
\hline & 25-34 years & 0.0000 & 0.0000 & 0.0000 & 0.0000 & 0.0000 & 0.0000 \\
\hline & $35-44$ years & 0.0000 & 0.0000 & 0.0001 & 0.0000 & 0.0002 & 0.0000 \\
\hline & $45-54$ years & 0.0002 & 0.0002 & 0.0005 & 0.0002 & 0.0001 & 0.0002 \\
\hline & $55-64$ years & 0.0011 & 0.0008 & 0.0011 & 0.0005 & 0.0007 & 0.0005 \\
\hline & $65-74$ years & 0.0032 & 0.0022 & 0.0023 & 0.0009 & 0.0023 & 0.0011 \\
\hline & $75-84$ years & 0.0057 & 0.0039 & 0.0038 & 0.0016 & 0.0041 & 0.0014 \\
\hline & $85+$ years & 0.0026 & 0.0013 & 0.0021 & 0.0005 & 0.0018 & 0.0007 \\
\hline \multirow[t]{5}{*}{$\mathrm{LC}$} & $15-24$ years & 0.0000 & 0.0000 & 0.0000 & 0.0000 & 0.0000 & 0.0000 \\
\hline & $25-34$ years & 0.0001 & 0.0000 & 0.0001 & 0.0001 & 0.0003 & 0.0001 \\
\hline & $35-44$ years & 0.0010 & 0.0009 & 0.0018 & 0.0015 & 0.0022 & 0.0011 \\
\hline & $45-54$ years & 0.0062 & 0.0042 & 0.0120 & 0.0065 & 0.0080 & 0.0060 \\
\hline & $55-64$ years & 0.0187 & 0.0116 & 0.0281 & 0.0132 & 0.0182 & 0.0122 \\
\hline
\end{tabular}


Table 3-3. (continued)

\begin{tabular}{llcccccccc}
\hline & & \multicolumn{2}{c}{ NHW } & & \multicolumn{2}{c}{ NHB } & & \multicolumn{2}{c}{ OTH } \\
\cline { 3 - 4 } \cline { 8 - 9 } Cause & Age group & $\mathrm{M}$ & $\mathrm{F}$ & & $\mathrm{M}$ & $\mathrm{F}$ & & $\mathrm{M}$ & $\mathrm{F}$ \\
\hline LC & 65-74 years & 0.0359 & 0.0212 & & 0.0425 & 0.0209 & & 0.0380 & 0.0250 \\
& 75-84 years & 0.0482 & 0.0274 & & 0.0522 & 0.0247 & & 0.0483 & 0.0263 \\
& 85+ years & 0.0150 & 0.0066 & & 0.0160 & 0.0059 & & 0.0136 & 0.0072 \\
\hline
\end{tabular}

Notes: Estimates were truncated to the fourth decimal place to fit the page.

Deaths from diseases were identified by ICD-10 codes or groups: Ischemic heart disease (ICD-10: I20-I25), Cerebrovascular disease (ICD-10: GR113-070), Emphysema (ICD10: GR113-084), Lung cancer (ICD-10: GR113-027).

Abbreviations: $\mathrm{BC}$ : background causes, $\mathrm{CBD}$ : cerebrovascular disease, EMP: emphysema, F: female, IHD: ischemic heart disease, LC: lung cancer, M: male, NHB: non-Hispanic black, NHW: non-Hispanic white, OTH: other race.

Source: Centers for Disease Control and Prevention, National Center for Health Statistics. Compressed Mortality File 1999-2006. CDC WONDER Online Database, compiled from Compressed Mortality File 1999-2006 Series 20 No. 2L, 2009. Accessed at http://wonder.cdc.gov/cmf-icd10.html on August 19, 2009. ${ }^{99}$ 


\section{Smoking-Related Disease}

For patients surviving in a cycle, risk of acquiring smoking-related disease was assessed. As mentioned previously, patients' risk of developing lung cancer, emphysema, cerebrovascular disease, and ischemic heart disease was modeled. Data from the National Health and Nutrition Examination Survey (NHANES) for years 2001-2006 were pooled to estimate incidence of the above-mentioned smoking-related diseases. ${ }^{98}$ Data from the smoking, demographic, and medical conditions modules for the 2001-02, 2003-04, and 2005-06 NHANES cycles were merged by cycle, then resorted by SDMVSTRA and SDMVPSU variables and combined into a single dataset. The dataset was queried to identify incident cases of the four smoking-related diseases among never, former, current smokers by race, gender, and age (18-34 years, 35-64 years, and 65 years and above).

Prevalent cases of ischemic heart disease were identified by a positive response to one of two questions (positive diagnosis of coronary heart disease or previous heart attack). Prevalent cases of stroke, emphysema, and lung cancer were identified similarly, denoted by positive response to questions regarding physician diagnosis of disease. Time since diagnosis for smoking-related diseases was calculated by subtracting the survey respondent's age at diagnosis from age when interviewed. Prevalent cases with a time to diagnosis of 0 and half of cases with a time to diagnosis of 1 were identified as incident cases in the absence of specific dates of birth, diagnosis, and interview. Incidence estimates were calculated using larger age group intervals than before to generate more reliable estimates across race and smoking status. Several studies indicate that risk of cardiovascular disease among former smokers and never smokers is equal after about 10 years, while rates of emphysema and lung cancer remain elevated among former smokers. Since data were not robust enough to evaluate this trend, the appropriate incidence probabilities for never smokers were re- assigned to former smokers achieving abstinence beyond 10 years. In certain cases, incident cases were too low to provided estimates for specified cage groups and were combined to provide a single estimate for incidence risk. Table 3-4 summarizes the incidence probabilities generated for analysis.

\section{Cessation and Relapse}

Risk of relapse remains for quitters, although this probability decreases as a function of time spent abstinent. The longer a quitter remains a former smoker, the less likely they are to relapse in the future. To account for time since cessation, a tracker variable was created in TreeAge to count the number of continuous cycles spent in as a former smoker. The number of continuous cycles coincided with number of years of abstinence. The model assigned a probability of relapse, using published relapse rates for two to four years post cessation, ${ }^{100,101}$ and interpolated rates for years 5 and beyond. Current smokers who made a successful quit attempt during a cycle transitioned to a former smoker, while those who were unsuccessful remained as current smokers. Likewise, a former smoker that relapsed during a cycle would become a current smoker in the next, while those who remained abstinent would continue the next cycle as a former smoker. Here, the model assumed that any future quit attempts would be unaided, since results from a recent NHIS survey suggested that most smokers quit in this fashion. So, the model assigned a quit probability equivalent to 12 month abstinence for an unaided quit attempt. ${ }^{102}$ 
Table 3-4. Incidence Rates for Smoking-Related Diseases

\begin{tabular}{|c|c|c|c|c|c|c|c|c|}
\hline \multirow[b]{2}{*}{ Disease } & \multirow[b]{2}{*}{ Status } & \multirow[b]{2}{*}{ Age group } & \multicolumn{2}{|c|}{ NHW } & \multicolumn{2}{|c|}{ NHB } & \multicolumn{2}{|c|}{$\mathrm{OTH}$} \\
\hline & & & $\mathrm{E}$ & $\mathrm{SE}$ & $\mathrm{E}$ & $\mathrm{SE}$ & $\mathrm{E}$ & $\mathrm{SE}$ \\
\hline \multirow[t]{9}{*}{ IHD } & Current & $18-34$ years & 0.000 & 0.000 & 0.000 & 0.000 & 0.003 & 0.003 \\
\hline & & $35-64$ years & 0.010 & 0.004 & 0.010 & 0.005 & 0.007 & 0.005 \\
\hline & & $65+$ years & 0.005 & 0.004 & 0.010 & 0.005 & 0.005 & 0.004 \\
\hline & Former & $18-34$ years & 0.000 & 0.000 & 0.000 & 0.000 & 0.000 & 0.000 \\
\hline & & $35-64$ years & 0.011 & 0.004 & 0.015 & 0.008 & 0.010 & 0.005 \\
\hline & & $65+$ years & 0.029 & 0.004 & 0.022 & 0.007 & 0.018 & 0.014 \\
\hline & Never & $18-34$ years & 0.000 & 0.000 & 0.002 & 0.002 & 0.000 & 0.000 \\
\hline & & $35-64$ years & 0.008 & 0.002 & 0.003 & 0.002 & 0.002 & 0.001 \\
\hline & & $65+$ years & 0.026 & 0.005 & 0.029 & 0.011 & 0.026 & 0.017 \\
\hline \multirow[t]{9}{*}{ CBD } & Current & $18-34$ years & 0.000 & 0.000 & 0.000 & 0.000 & 0.009 & 0.007 \\
\hline & & $35-64$ years & 0.005 & 0.002 & 0.002 & 0.002 & 0.010 & 0.007 \\
\hline & & $65+$ years & 0.006 & 0.005 & 0.009 & 0.010 & 0.008 & 0.003 \\
\hline & Former & $18-34$ years & 0.000 & 0.000 & 0.000 & 0.000 & 0.000 & 0.000 \\
\hline & & $35-64$ years & 0.003 & 0.000 & 0.006 & 0.004 & 0.003 & 0.002 \\
\hline & & $65+$ years & 0.018 & 0.004 & 0.035 & 0.017 & 0.016 & 0.007 \\
\hline & Never & $18-34$ years & 0.000 & 0.000 & 0.000 & 0.000 & 0.000 & 0.000 \\
\hline & & $35-64$ years & 0.002 & 0.001 & 0.008 & 0.003 & 0.006 & 0.003 \\
\hline & & $65+$ years & 0.019 & 0.004 & 0.040 & 0.013 & 0.012 & 0.007 \\
\hline \multirow[t]{9}{*}{ EMP } & Current & $18-34$ years & 0.004 & 0.003 & 0.000 & 0.000 & 0.005 & 0.005 \\
\hline & & $35-64$ years & 0.008 & 0.002 & 0.001 & 0.001 & 0.015 & 0.010 \\
\hline & & $65+$ years & 0.030 & 0.014 & 0.001 & 0.001 & 0.003 & 0.003 \\
\hline & Former & $18-34$ years & 0.000 & 0.000 & 0.000 & 0.000 & 0.000 & 0.000 \\
\hline & & $35-64$ years & 0.002 & 0.001 & 0.003 & 0.003 & 0.000 & 0.000 \\
\hline & & $65+$ years & 0.011 & 0.004 & 0.006 & 0.006 & 0.003 & 0.004 \\
\hline & Never & $18-34$ years & 0.000 & 0.000 & 0.000 & 0.000 & 0.000 & 0.000 \\
\hline & & $35-64$ years & 0.001 & 0.001 & 0.000 & 0.000 & 0.001 & 0.001 \\
\hline & & $65+$ years & 0.002 & 0.001 & 0.000 & 0.000 & 0.002 & 0.002 \\
\hline \multirow[t]{9}{*}{$\mathrm{LC}$} & Current & $18-34$ years & 0.000 & 0.000 & 0.000 & 0.000 & 0.000 & 0.000 \\
\hline & & $35-64$ years & 0.000 & 0.000 & 0.000 & 0.000 & 0.000 & 0.000 \\
\hline & & $65+$ years & 0.000 & 0.000 & 0.000 & 0.000 & 0.000 & 0.000 \\
\hline & Former & $18-34$ years & 0.000 & 0.000 & 0.049 & 0.034 & 0.000 & 0.000 \\
\hline & & $35-64$ years & 0.002 & 0.001 & 0.005 & 0.002 & 0.000 & 0.000 \\
\hline & & $65+$ years & 0.008 & 0.003 & 0.005 & 0.002 & 0.000 & 0.000 \\
\hline & Never & $18-34$ years & 0.000 & 0.000 & 0.000 & 0.000 & 0.000 & 0.000 \\
\hline & & $35-64$ years & 0.000 & 0.000 & 0.000 & 0.000 & 0.000 & 0.000 \\
\hline & & $65+$ years & 0.000 & 0.000 & 0.000 & 0.000 & 0.000 & 0.000 \\
\hline
\end{tabular}




\section{Table 3-4. (continued)}

Note: Estimates were truncated to the third decimal place to fit on the page. In certain cases, no incidences of smoking-related diseases were reported; so rates were set to zero.

Abbreviations: CBD: cerebrovascular disease, EMP: emphysema, E: estimate, IHD: ischemic heart disease, LC: lung cancer, M: male, NHB: non-Hispanic black, NHW: nonHispanic white, OTH: other race, SE: standard error.

Source: Centers for Disease Control and Prevention (CDC). National Center for Health Statistics (NCHS). National Health and Nutrition Examination Survey Data. Hyattsville, MD: U.S. Department of Health and Human Services, Centers for Disease Control and Prevention, 2000-2006. Accessed online at: http://www.cdc.gov/nchs/nhanes.htm on August 19, 2009..$^{98}$ 


\section{Healthcare Costs}

Data from the 2006 Medical Expenditure Panel Survey (MEPS) were used to calculate relevant annual healthcare expenditures for patients dependent on age and presence of smoking-related diseases. ${ }^{103}$ Household component and medical conditions files were sorted by an identifier variable, DUPERSID, and merged to provide data on health expenditures resulting from smoking-related diseases. Medical conditions were identified by three-digit ICD-9 diagnosis codes and broader Clinical Classifications System (CCS) categories, which combine ICD-9 codes into more clinically relevant classes for easier analysis. CCS codes were used to denote observations recording expenditures due to lung cancer (CCS: 19), emphysema (CCS: 127), ischemic heart (CCS: 100,101) and cerebrovascular diseases (CCS: 109-113). The total expenditure variable, TOTEXP06, was fit to a regression equation, adjusting for age, gender, smoking status, and presence of the four smoking-related diseases. From the regression equation, gender- and age group-specific total expenditure and excess cost estimates for each disease were calculated.

\section{Quality-Adjusted Life Years (QALYs)}

Health-related quality of life (HRQL) scores were also estimated from the MEPS dataset used to calculate annual healthcare costs. ${ }^{103}$ In MEPS, several measures of health status are collected annually, including the Short Form-12 (SF-12) health survey. Despite its wide acceptance and application in health state evaluation, the SF-12 is limited in its ability to provide only HRQL measures. It cannot rate patient preferences for specific health states. Gold and colleagues recommend use of multi-attribute health status classification systems (MAHSCS), which use time trade-off or standard gamble techniques to elicit valuations of HRQL and preferences for other health states. ${ }^{79}$ These preferences are converted into utility scores that can be used in cost-effectiveness analysis. In the absence of these measures, mapping methods have been utilized to approximate MAHSCS scores from other health status surveys. Sullivan and Ghushchyan developed and validated a mapping algorithm to estimate EQ-5D scores from SF-12 measures using scores collected previously in MEPS. ${ }^{104}$ This algorithm was applied to approximate EQ-5D scores from the SF-12 measures. In addition, these values were modeled in ordinary least squares (OLS) regression, controlling for CCS codes, demographic variables (age, gender), smoking status, and survey weights to generate coefficients representing decrement(s) in utility resulting from smoking and smokingrelated disease(s). Table 3-5 illustrates age-specific annual healthcare costs and utility weights used in analysis. Table 3-6 displays regression coefficients used to estimate changes in annual costs and utilities due to smoking and smoking-related diseases.

\section{Calculation of Cost-Effectiveness}

Considering a societal perspective, the simulation model produced long-term costeffectiveness of STEP or the ratio of lifetime costs and effects among patients after intervention in the study. TreeAge models were rerun assuming that all participants were smokers to determine changes in lifetime healthcare costs, cases of smoking-related 
Table 3-5. Annual Healthcare Costs and Utilities Estimates

\begin{tabular}{lllllll}
\hline & & \multicolumn{2}{c}{ Costs } & & \multicolumn{2}{c}{ Utilities $^{\mathrm{a}}$} \\
\cline { 3 - 4 } \cline { 6 - 7 } Gender & Age group & \multicolumn{1}{c}{$\mathrm{AAC}^{\mathrm{b}}$} & $\mathrm{SE}$ & & AAU $^{\mathrm{c}}$ & $\mathrm{SE}$ \\
\hline Female & 18-24 years & $\$ 1,383.27$ & 361.95 & & 0.9755 & 0.004 \\
& 25-34 years & $\$ 2,694.59$ & 412.36 & & 0.9531 & 0.005 \\
& 35-44 years & $\$ 4,005.91$ & 462.77 & & 0.9307 & 0.006 \\
& 45-54 years & $\$ 5,317.23$ & 513.19 & & 0.9084 & 0.006 \\
& 55-64 years & $\$ 6,628.54$ & 563.60 & & 0.8860 & 0.007 \\
& 65-74 years & $\$ 7,939.86$ & 614.01 & & 0.8637 & 0.007 \\
& 75-84 years & $\$ 9,251.18$ & 664.42 & & 0.8413 & 0.008 \\
& 85+ years & $\$ 10,562.49$ & 714.83 & & 0.8189 & 0.008 \\
Male & & & & & & \\
& 18-24 years & $\$ 589.12$ & 544.36 & & 0.9912 & 0.006 \\
& 25-34 years & $\$ 1,900.44$ & 594.77 & & 0.9688 & 0.007 \\
& 35-44 years & $\$ 3,211.75$ & 645.18 & & 0.9465 & 0.007 \\
& 45-54 years & $\$ 4,523.07$ & 695.59 & & 0.9241 & 0.008 \\
& 55-64 years & $\$ 5,834.39$ & 746.00 & & 0.9017 & 0.008 \\
& 65-74 years & $\$ 7,145.70$ & 796.41 & & 0.8794 & 0.009 \\
& $75-84$ years & $\$ 8,457.02$ & 846.82 & & 0.8570 & 0.009 \\
& 85+ years & $\$ 9,768.34$ & 897.23 & & 0.8346 & 0.010 \\
\hline
\end{tabular}

Note: Estimates listed approximate annual costs and HRQL utilities for former smokers without disease.

${ }^{a}$ A mapping algorithm used to approximate EQ-5D scores from SF-12: EQ-5D= $0.057867+0.010367 *$ PCS42 + 0.00822*MCS42 - 0.000034*PCS42*MCS42 - 0.01067

b,c Total healthcare costs and EQ-5D scores were adjusted for age, gender, smoking status, and presence of smoking-related diseases

Abbreviations: AAC: adjusted average cost, AAU: adjusted average utility, SE: standard error

Sources: Center for Financing, Access, and Cost Trends, Agency for Healthcare Research and Quality. Medical Expenditure Panel Survey, 2006 ${ }^{103}$

Sullivan PW, Ghushchyan V. Mapping the EQ-5D index from the SF-12: US general population preferences in a nationally representative sample. Med Decis Making 2006 July-August; 26(4):401-9. ${ }^{104}$ 
Table 3-6. Changes in Costs and Utilities with Smoking/SR Disease

\begin{tabular}{lcrlrr}
\hline & \multicolumn{2}{c}{ Costs } & & \multicolumn{2}{c}{ Utilities } \\
\cline { 2 - 3 } \cline { 5 - 6 } Smoking/SR disease & $\Delta(\mathrm{AAC})^{\mathrm{a}}$ & \multicolumn{1}{c}{$\mathrm{SE}$} & & $\Delta(\mathrm{AAU})^{\mathrm{b}}$ & \multicolumn{1}{c}{$\mathrm{SE}$} \\
\hline Current smoker & $-\$ 284.66$ & 191.84 & & -0.03468 & 0.002794 \\
Ischemic heart disease & $\$ 4,533.64$ & 1016.23 & & -0.04821 & 0.01296 \\
Cerebrovascular disease & $\$ 5,133.11$ & 1192.85 & & -0.06138 & 0.016126 \\
Emphysema & $-\$ 595.31$ & 268.29 & & -0.00671 & 0.004633 \\
Lung cancer & $\$ 6,171.13$ & 3197.38 & & -0.12297 & 0.029451 \\
\hline
\end{tabular}

Note: Estimates listed represent increments/decrements to costs and utilities when smoking and/or smoking-related disease is present.

${ }^{\mathrm{a}, \mathrm{b}}$ Changes in costs, utilities expressed in natural units (dollars, QALYs).

Abbreviations: $\Delta(\mathrm{AAC})$ : change in adjusted average cost, $\Delta(\mathrm{AAU})$ : change in adjusted average utility, SE: standard error, SR: smoking-related.

Source: Center for Financing, Access, and Cost Trends, Agency for Healthcare Research and Quality. Medical Expenditure Panel Survey, 2006 $6^{103}$ 
disease, QALYs and survival due to successful cessation. The costs and effects yielded were subtracted from costs and effects in the initial model to calculate a ratio of incremental costs per quality-adjusted life-year (QALY) gained by successful cessation relative to unsuccessful cessation. The method of cessation (via stepped care or repeat care) is no longer of immediate importance; that successful cessation occurred is more relevant for examining future outcomes. The numerator of this ratio is the difference in future costs incurred by successful quitters relative to unsuccessful quitters, whereas the denominator captures the difference in the number of QALYs gained. The ratio of cost differences to effect differences yields incremental cost-effectiveness, or the cost to achieve one additional unit of effect. All figures were expressed in year 2009 U.S. dollars.

\section{Discounting}

As aforementioned, Gold and colleagues recommend a 3\% discount rate to balance time gaps between costs of intervention and realization of benefits. ${ }^{80}$ For the extended economic evaluation, discounting was applied to costs incurred and QALYs gained beyond the base year (2009).

\section{Sensitivity Analysis}

Certain model parameters were assigned lower and upper values to account for uncertainty around the model estimates; these values were used in sensitivity analysis. Parameters were set for unaided cessation, disease incidence, and mortality rates as well as annual healthcare costs and utilities, using calculated $95 \%$ confidence interval values or published ranges from the literature (unaided cessation). One-way and probabilistic sensitivity analyses (PSA) were conducted to evaluate impact of changes in disease incidence, mortality, unaided cessation, costs, and utilities on outcomes. A uniform distribution was applied to parameter values to equally select a range between lower and upper limit values. PSA generated average, minimum, maximum, and standard deviation values for costs and effects for treatment and comparator groups. The results of the original simulation were stored and re-run substituting discount rates of $0 \%$ and $5 \%$.

\section{Comparing Results to Cost-Effectiveness Literature}

Results of short-term and long-term analyses were compared to studies reviewed in Chapter 2 to determine where STEP analyses fall in terms of cost-effectiveness. Costeffectiveness of the STEP study was compared to other short-term studies using cost per quit as a measure. Results of the future outcomes simulation were compared to long-term studies, both U.S. and international, that measured cost per QALY. 


\section{CHAPTER 4: RESULTS}

\section{Cost-Effectiveness: STEP Study}

Characteristics of the STEP study sample are outlined in Table 4-1. Overall and by site, study arms were statistically equivalent. One exception was in the Mayo sample; a statistically significant difference in CES-D scores was observed. UTHSC participants were older and more racially diverse; in addition, they had higher depression scale and nicotine dependence scores, carbon monoxide readings, and smoked more cigarettes than Mayo Clinic counterparts. Only age and race differences were statistically significant. Study participation rates were relatively average; these details are noted in Table 4-2. Nearly $65 \%$ of study participants attended all treatment and follow-up visits; another 9\% attended all but one visit. The majority of patients attending all sessions were from UTHSC, with $87 \%$ of participants remaining active (versus 34\% of Mayo patients) throughout the study. Among Mayo patients, those randomized to stepped care attended more sessions than patients assigned to repeat intervention. This trend was similar in the UTHSC sample. Most STEP participants were available for final follow-up $(n=229)$; the remainder were assumed to be smoking. Point-prevalence abstinence was confirmed in 67 participants; 41 of these patients also reported continuous abstinence at end of study follow-up. Among those quitting, all but five reported to each treatment and follow-up visit.

Table 4-3 reports costs, effects, and cost-effectiveness estimates for the entire sample and by site. Stepped intervention was more costly than repeat care in every scenario. Mean costs (per patient) were \$875.09, \$617.09, and \$1,075.40 for overall, Mayo Clinic, and University of Tennessee Health Science Center (UTHSC) samples, respectively. All figures are expressed in 2009 U.S. dollars. Repeat costs were \$422.26, $\$ 332.55$, and $\$ 486.34$ for the respective samples. Point-prevalence abstinence was reported and validated among $20.5 \%$ (versus $22.6 \%$ ) of stepped care patients overall; among Mayo and UTHSC samples, $22.7 \%$ (versus 22.9\%) and 18.8\% (versus $22.5 \%$ ) reported quitting. Continuous abstinence was reported among $11.9 \%$ (versus $14.3 \%$ ), $16.7 \%$ (versus $15.7 \%$ ) and $8.2 \%$ (versus $13.3 \%$ ) of stepped care patients overall, at Mayo, and at UTHSC, respectively. Because effectiveness results favored repeated intervention rather than stepped care, an ICER could not be calculated for the overall sample. Stepped care was dominated by repeat care; it was more costly and less effective. Among Mayo participants, stepped care was more costly and more effective, producing and incremental cost effectiveness estimate of $\$ 29,640$ (continuous) per quit. This trend was opposite among patients at UTHSC, where repeat care was dominant.

Differences in effectiveness by gender are reported in Tables 4-4 and 4-5.

Overall, higher rates of point-prevalence and continuous abstinence were reported among men. Nearly $27 \%$ of men in the repeat intervention achieved point-prevalence abstinence at study end compared to only $19 \%$ of women. Quit rates among men and women in stepped care were similar, at $20 \%$ and $21 \%$, respectively. Continuous abstinence was reported in $13 \%$ and $11 \%$ of men and women in the stepped care arm and in $19 \%$ and $11 \%$ of men and women in the repeat intervention. Stepped care costs for women (versus 
Table 4-1. Characteristics of STEP Study Sample

\begin{tabular}{|c|c|c|c|c|c|c|}
\hline \multirow[b]{2}{*}{ Variables } & \multicolumn{2}{|c|}{ Overall } & \multicolumn{2}{|c|}{ UTHSC (sample) } & \multicolumn{2}{|c|}{ Mayo } \\
\hline & $\begin{array}{l}\text { Repeat } \\
(n=167)\end{array}$ & $\begin{array}{c}\text { Stepped } \\
\text { care } \\
(n=151)\end{array}$ & $\begin{array}{l}\text { Repeat } \\
(n=98)\end{array}$ & $\begin{array}{c}\text { Stepped } \\
\text { care } \\
(\mathrm{n}=85)\end{array}$ & $\begin{array}{l}\text { Repeat } \\
(n=70)\end{array}$ & $\begin{array}{c}\text { Stepped } \\
\text { care } \\
(\mathrm{n}=66)\end{array}$ \\
\hline $\begin{array}{l}\text { Age, mean } \\
(\mathrm{SD})\end{array}$ & $\begin{array}{c}43.3 \\
(11.3)\end{array}$ & $\begin{array}{c}42.4 \\
(11.1)\end{array}$ & $\begin{array}{c}45.1 \\
(11.4)\end{array}$ & $\begin{array}{l}44.1 \\
(9.7)\end{array}$ & $\begin{array}{c}40.8 \\
(10.7)\end{array}$ & $\begin{array}{c}40.4 \\
(12.6)\end{array}$ \\
\hline \multicolumn{7}{|l|}{ Gender, n (\%) } \\
\hline Male & $75(45)$ & $76(50)$ & $43(44)$ & $39(46)$ & $32(46)$ & $37(56)$ \\
\hline Female & $93(55)$ & $75(50)$ & $55(56)$ & $46(54)$ & $38(54)$ & $29(44)$ \\
\hline \multicolumn{7}{|l|}{ Race, n (\%) } \\
\hline NHW & $119(71)$ & $99(66)$ & $54(55)$ & $40(47)$ & $65(93)$ & $59(89)$ \\
\hline NHB & $47(28)$ & $46(30)$ & $43(44)$ & $45(53)$ & $4(6)$ & $1(2)$ \\
\hline OTH & $2(1)$ & $5(4)$ & $1(1)$ & $0(0)$ & $1(1)$ & $5(9)$ \\
\hline Fagerstrom, & 5.52 & 5.68 & 5.57 & 5.91 & 5.44 & 5.39 \\
\hline mean (SD) & $(2.0)$ & $(2.2)$ & $(2.3)$ & $(2.2)$ & $(1.7)$ & $(2.2)$ \\
\hline CES-D, mean & 9.39 & 8.44 & 9.88 & 10.07 & 8.70 & 6.35 \\
\hline$(\mathrm{SD})$ & $(6.9)$ & (6.7) & $(7.3)$ & $(6.9)$ & $(6.1)$ & $(5.8)^{\mathrm{a}}$ \\
\hline CPD, mean & 22.7 & 21.9 & 23.7 & 23.0 & 21.3 & 20.5 \\
\hline$(\mathrm{SD})$ & $(10.2)$ & $(10.0)$ & (11.2) & $(11.6)$ & $(8.4)$ & $(7.3)$ \\
\hline $\mathrm{CO}$, mean & 22.12 & 21.80 & 23.36 & 23.51 & 22.70 & 22.22 \\
\hline (SD) & $(11.4)$ & $(11.4)$ & $(12.2)$ & $(11.6)$ & $(9.8)$ & $(10.9)$ \\
\hline
\end{tabular}

Note: UTHSC sample includes study completers as of May 31, 2009.

${ }^{a}$ Statistically significant at $\mathrm{p}=0.03$

Abbreviations: CO: carbon monoxide, CES-D: Centers for Epidemiologic Studies Depression Scale, CPD: cigarettes per day (number), NHB: non-Hispanic black, NHW: non-Hispanic white, OTH: other race, UTHSC: University of Tennessee Health Science Center. 
Table 4-2. STEP Study Outcomes

\begin{tabular}{|c|c|c|c|c|c|c|c|c|c|}
\hline \multirow[b]{3}{*}{ Outcomes } & \multicolumn{7}{|c|}{ Participants } & \multicolumn{2}{|c|}{ Quitters } \\
\hline & \multicolumn{3}{|c|}{ Overall } & \multicolumn{2}{|c|}{ Mayo } & \multicolumn{2}{|c|}{ UTHSC } & \multirow{2}{*}{$\frac{\mathrm{PPA}}{\mathrm{A}}$} & \multirow{2}{*}{$\frac{\mathrm{CA}}{\mathrm{A}}$} \\
\hline & A & $\mathrm{S}$ & $\mathrm{R}$ & $\mathrm{S}$ & $\mathrm{R}$ & $\mathrm{S}$ & $\mathrm{R}$ & & \\
\hline \multicolumn{10}{|l|}{$\begin{array}{l}\text { Visits } \\
\text { attended } \\
(\%)\end{array}$} \\
\hline 1 & $\begin{array}{r}47 \\
(15)\end{array}$ & $\begin{array}{r}16 \\
(11)\end{array}$ & $\begin{array}{r}31 \\
(18)\end{array}$ & $\begin{array}{r}16 \\
(24)\end{array}$ & $\begin{array}{r}30 \\
(43)\end{array}$ & $0(0)$ & $1(0)$ & - & - \\
\hline 2 & $\begin{array}{l}21 \\
(7)\end{array}$ & $\begin{array}{r}14 \\
(9)\end{array}$ & $7(4)$ & $\begin{array}{r}14 \\
(21)\end{array}$ & $5(7)$ & $0(0)$ & $2(2)$ & - & - \\
\hline 3 & $\begin{array}{l}16 \\
(5)\end{array}$ & $\begin{array}{r}6 \\
(4)\end{array}$ & $\begin{array}{r}10 \\
(6)\end{array}$ & $\begin{array}{r}4 \\
(6)\end{array}$ & $\begin{array}{r}9 \\
(13)\end{array}$ & $2(2)$ & $1(1)$ & - & - \\
\hline 4 & $\begin{array}{r}30 \\
(9)\end{array}$ & $\begin{array}{r}11 \\
(7)\end{array}$ & $\begin{array}{r}19 \\
(12)\end{array}$ & $\begin{array}{r}5 \\
(8)\end{array}$ & $\begin{array}{r}7 \\
\text { (10) }\end{array}$ & $\begin{array}{r}6 \\
(7)\end{array}$ & $\begin{array}{r}12 \\
(12)\end{array}$ & $\begin{array}{r}5 \\
(7)\end{array}$ & $\begin{array}{r}5 \\
(12)\end{array}$ \\
\hline 5 & $\begin{array}{l}205 \\
(64)\end{array}$ & $\begin{array}{l}104 \\
(69)\end{array}$ & $\begin{array}{l}101 \\
(60)\end{array}$ & $\begin{array}{r}27 \\
(41)\end{array}$ & $\begin{array}{r}19 \\
(27)\end{array}$ & $\begin{array}{r}77 \\
(91)\end{array}$ & $\begin{array}{r}82 \\
(84)\end{array}$ & $\begin{array}{r}62 \\
(93)\end{array}$ & $\begin{array}{r}36 \\
(88)\end{array}$ \\
\hline Total & 319 & 151 & 168 & 66 & 70 & 85 & 98 & 67 & 41 \\
\hline \multicolumn{10}{|l|}{$\begin{array}{l}\text { Therapy } \\
(\%)\end{array}$} \\
\hline 2 & $\begin{array}{l}205 \\
(64)\end{array}$ & $\begin{array}{l}106 \\
(70)\end{array}$ & $\begin{array}{r}99 \\
(59)\end{array}$ & $\begin{array}{r}34 \\
(52)\end{array}$ & $\begin{array}{r}29 \\
(41)\end{array}$ & $\begin{array}{r}72 \\
(73)\end{array}$ & $\begin{array}{r}70 \\
(82)\end{array}$ & - & - \\
\hline 3 & $\begin{array}{r}179 \\
(56)\end{array}$ & $\begin{array}{r}89 \\
(59)\end{array}$ & $\begin{array}{r}90 \\
(54)\end{array}$ & $\begin{array}{r}19 \\
(29)\end{array}$ & $\begin{array}{r}18 \\
(26)\end{array}$ & $\begin{array}{r}70 \\
(71)\end{array}$ & $\begin{array}{r}72 \\
(84)\end{array}$ & - & - \\
\hline \multicolumn{10}{|l|}{ Quits, (\%) } \\
\hline PPA & $\begin{array}{r}67 \\
(21)\end{array}$ & $\begin{array}{r}31 \\
(21)\end{array}$ & $\begin{array}{r}38 \\
(23)\end{array}$ & $\begin{array}{r}15 \\
(23)\end{array}$ & $\begin{array}{r}16 \\
(23)\end{array}$ & $\begin{array}{r}16 \\
(19)\end{array}$ & $\begin{array}{r}22 \\
(22)\end{array}$ & - & - \\
\hline $\mathrm{CA}$ & $\begin{array}{r}41 \\
(13) \\
\end{array}$ & $\begin{array}{r}18 \\
(12) \\
\end{array}$ & $\begin{array}{r}24 \\
(14) \\
\end{array}$ & $\begin{array}{r}11 \\
(17) \\
\end{array}$ & $\begin{array}{r}11 \\
(16) \\
\end{array}$ & $7(8)$ & $\begin{array}{r}13 \\
(12) \\
\end{array}$ & - & - \\
\hline
\end{tabular}

Abbreviations: A: all, CA: continuous abstinence, PPA: point-prevalence abstinence, R: repeat care, S: stepped care, UTHSC: University of Tennessee Health Science Center. 
Table 4-3. Cost-Effectiveness Results, Overall and by Site

\begin{tabular}{|c|c|c|c|c|c|c|c|}
\hline \multirow[b]{2}{*}{ Variable } & \multirow[b]{2}{*}{ Arm } & \multicolumn{2}{|c|}{ All } & \multicolumn{2}{|c|}{ Mayo } & \multicolumn{2}{|c|}{ UTHSC } \\
\hline & & Mean & SE & Mean & SE & Mean & SE \\
\hline \multirow[t]{3}{*}{ Costs } & $\mathrm{S}$ & $\$ 875.09$ & $\$ 36.60$ & $\$ 617.09$ & $\$ 51.20$ & $\$ 1,075.40$ & $\$ 39.76$ \\
\hline & $\mathrm{R}$ & $\$ 422.26$ & $\$ 10.53$ & $\$ 332.55$ & $\$ 16.73$ & $\$ 486.34$ & $\$ 9.14$ \\
\hline & Diff & $\$ 452.83$ & & $\$ 284.54$ & & $\$ 589.06$ & \\
\hline \multirow[t]{3}{*}{ PPA } & $\mathrm{S}$ & 0.2053 & 0.033 & 0.2273 & 0.052 & 0.1882 & 0.043 \\
\hline & $\mathrm{R}$ & 0.2262 & 0.032 & 0.2286 & 0.051 & 0.2245 & 0.042 \\
\hline & Diff & -0.0209 & & -0.0013 & & -0.0363 & \\
\hline \multirow[t]{3}{*}{ CA } & $\mathrm{S}$ & 0.1192 & 0.027 & 0.1667 & 0.046 & 0.0824 & 0.030 \\
\hline & $\mathrm{R}$ & 0.1429 & 0.027 & 0.1571 & 0.044 & 0.1327 & 0.034 \\
\hline & Diff & -0.0237 & & 0.0096 & & -0.0503 & \\
\hline \multicolumn{8}{|l|}{ ICER } \\
\hline PPA & & -- & & -- & & -- & \\
\hline CA & & -- & & $\$ 29,640$ & & -- & \\
\hline
\end{tabular}

Note: Dotted lines denote scenarios in which stepped care was dominated by repeat care (being more costly and less effective). Negative ICERs are not calculated.

Abbreviations: CA: continuous abstinence, Diff: difference in estimates (cost, effect), ICER: incremental cost-effectiveness ratio, PPA: point-prevalence abstinence, R: repeat intervention, S: stepped care intervention, SE: standard error, UTHSC: University of Tennessee Health Science Center. 
Table 4-4. Cost-Effectiveness of STEP Study, Women

\begin{tabular}{|c|c|c|c|c|c|c|c|}
\hline \multirow[b]{2}{*}{ Variable } & \multirow[b]{2}{*}{ Arm } & \multicolumn{2}{|c|}{ All } & \multicolumn{2}{|c|}{ Mayo } & \multicolumn{2}{|c|}{ UTHSC } \\
\hline & & Mean & SE & Mean & SE & Mean & SE \\
\hline \multirow[t]{3}{*}{ Costs } & $\mathrm{S}$ & $\$ 837.75$ & $\$ 52.72$ & $\$ 505.80$ & $\$ 68.80$ & $\$ 1,047.00$ & $\$ 55.47$ \\
\hline & $\mathrm{R}$ & $\$ 438.73$ & $\$ 14.08$ & $\$ 356.92$ & $\$ 24.69$ & $\$ 495.26$ & $\$ 11.73$ \\
\hline & Diff & $\$ 399.02$ & & $\$ 148.88$ & & $\$ 551.74$ & \\
\hline \multirow[t]{3}{*}{ PPA } & $\mathrm{S}$ & 0.2 & 0.047 & 0.1724 & 0.071 & 0.2174 & 0.062 \\
\hline & $\mathrm{R}$ & 0.1935 & 0.041 & 0.2105 & 0.067 & 0.1818 & 0.053 \\
\hline & Diff & 0.0065 & & -0.0381 & & 0.0356 & \\
\hline \multirow[t]{3}{*}{ CA } & $\mathrm{S}$ & 0.1067 & 0.036 & 0.1379 & 0.065 & 0.087 & 0.042 \\
\hline & $\mathrm{R}$ & 0.1075 & 0.032 & 0.1053 & 0.051 & 0.1091 & 0.042 \\
\hline & Diff & -0.0008 & & 0.0326 & & -0.0221 & \\
\hline \multicolumn{8}{|l|}{ ICER } \\
\hline PPA & & $\$ 61,388$ & & -- & & $\$ 15,498$ & \\
\hline CA & & -- & & $\$ 4,567$ & & -- & \\
\hline
\end{tabular}

Note: Dotted lines denote scenarios in which stepped care was dominated by repeat care (being more costly and less effective). Negative ICERs are not calculated.

Abbreviations: CA: continuous abstinence, Diff: difference in estimates (cost, effect), ICER: incremental cost-effectiveness ratio, PPA: point-prevalence abstinence, R: repeat intervention, S: stepped care intervention, SE: standard error, UTHSC: University of Tennessee Health Science Center. 
Table 4-5. Cost-Effectiveness of STEP Study, Men

\begin{tabular}{|c|c|c|c|c|c|c|c|}
\hline \multirow[b]{2}{*}{ Variable } & \multirow[b]{2}{*}{ Arm } & \multicolumn{2}{|c|}{ All } & \multicolumn{2}{|c|}{ Mayo } & \multicolumn{2}{|c|}{ UTHSC } \\
\hline & & Mean & $\mathrm{SE}$ & Mean & $\mathrm{SE}$ & Mean & $\mathrm{SE}$ \\
\hline \multirow[t]{3}{*}{ Costs } & $\mathrm{S}$ & $\$ 911.94$ & $\$ 50.80$ & $\$ 704.32$ & $\$ 71.25$ & $\$ 1,108.90$ & $\$ 57.13$ \\
\hline & $\mathrm{R}$ & $\$ 401.84$ & $\$ 15.66$ & $\$ 303.62$ & $\$ 21.20$ & $\$ 474.94$ & $\$ 14.43$ \\
\hline & Diff & $\$ 510.10$ & & $\$ 400.70$ & & $\$ 633.96$ & \\
\hline \multirow[t]{3}{*}{ PPA } & $\mathrm{S}$ & 0.2105 & 0.047 & 0.2703 & 0.074 & 0.1538 & 0.059 \\
\hline & $\mathrm{R}$ & 0.2667 & 0.051 & 0.25 & 0.078 & 0.2791 & 0.069 \\
\hline & Diff & -0.0562 & & 0.0203 & & -0.1253 & \\
\hline \multirow[t]{3}{*}{ CA } & $\mathrm{S}$ & 0.1316 & 0.039 & 0.1892 & 0.065 & 0.0769 & 0.043 \\
\hline & $\mathrm{R}$ & 0.1867 & 0.045 & 0.2188 & 0.074 & 0.1628 & 0.057 \\
\hline & Diff & -0.0551 & & -0.0296 & & -0.0859 & \\
\hline \multicolumn{8}{|l|}{ ICER } \\
\hline PPA & & -- & & $\$ 19,739$ & & -- & \\
\hline $\mathrm{CA}$ & & -- & & -- & & -- & \\
\hline
\end{tabular}

Note: Dotted lines denote scenarios in which stepped care was dominated by repeat care (being more costly and less effective). Negative ICERs are not calculated.

Abbreviations: CA: continuous abstinence, Diff: difference in estimates (cost, effect), ICER: incremental cost-effectiveness ratio, PPA: point-prevalence abstinence, R: repeat intervention, S: rtepped care intervention, SE: standard error, UTHSC: University of Tennessee Health Science Center. 
men) were \$837.75 (\$911.94), \$505.80 (\$704.32), and \$1,047.00 (\$1,108.90) overall, at Mayo, and at UTHSC, in that order. Conversely, costs for repeat intervention were higher for women, at \$438.00 (\$401.84), \$356.92 (\$303.62), and \$495.26 (\$474.94) among the same groups. Stepped care was cost-effective for women achieving continuous abstinence in the Mayo sample. Incremental cost-effectiveness in this population was $\$ 4,567$ per quit. Stepped care yielded incremental cost-effectiveness ratios for pointprevalence abstinence among all women, UTHSC women, and Mayo men; these estimates were $\$ 61,388, \$ 15,498$, and $\$ 19,739$ per quit for the respective populations. Large cost and small effect differences yielded higher ICER estimates in these scenarios.

Racial/ethnic differences in costs and effectiveness were evident; these data are presented in Table 4-6 and Table 4-7 for non-Hispanic white and ethnic minority populations, respectively. Intervention costs, in either arm, were lower for non-Hispanic whites versus ethnic minorities. Mean costs for stepped care and repeat interventions for whites were $\$ 800.61$ and $\$ 400.86$, respectively; these costs among ethnic minorities were $\$ 1,016.90$ and $\$ 474.24$, correspondingly. Similar differences in costs existed in the UTHSC sample. Comparisons across race were not feasible in the Mayo sample, due to underrepresentation of ethnic minorities. Non-Hispanic whites reported much higher rates of cessation compared to ethnic minorities. Point-prevalence estimates were nearly twice as high in both arms of the study overall among whites, at $24 \%$ versus $13 \%$ (stepped) and $26 \%$ versus $14 \%$ (repeat). Continuous abstinence was also consistently higher among whites across study arms. Nearly $18 \%$ of whites using repeat intervention achieved abstinence compared to only $6 \%$ of ethnic minorities. In stepped intervention, continuous abstinence rates among whites and minorities were $15 \%$ and $6 \%$, respectively. Differences in effectiveness were even larger within the UTHSC sample. Pointprevalence abstinence was reported in $25 \%$ and $30 \%$ of white stepped and repeat intervention patients, compared to $13 \%$ and $14 \%$ of ethnic minorities. Only $4 \%$ and $5 \%$ of black stepped care and repeat intervention patients achieved continuous abstinence at study-end; whites achieved rates of $13 \%$ and $20 \%$ in corresponding study arms. Stepped care produced incremental cost-effectiveness ratios of $\$ 45,777$ and $\$ 28,952$ per quit in the Mayo sample for point-prevalence and continuous abstinence.

\section{Simulating Future Outcomes of Smoking Cessation}

Results of the long-term simulation are reported in Table 4-8. In general, encouraging smoking cessation through the STEP study was highly cost-effective. Mean lifetime costs post-intervention were $\$ 49,025$ per patient $(95 \% \mathrm{CI}$ : $\$ 6,320-\$ 126,310)$ and yielded 8.62 QALYs (95\% CI: 0.46-20.64 QALYs). Average cost-effectiveness was $\$ 6,530$ per QALY (95\% CI: \$2,767-\$19,441/QALY). Average age at model entry was 46 years; average age at death was 59 years. Figure 4-1 displays the distribution of costeffectiveness estimates for the simulation. Blue bars indicate probability of costeffectiveness below $\$ 2,000, \$ 4,000$, etc. For example, one cost-effectiveness estimate fell below \$2,000 per QALY; this is indicated in the 2000 bar. Fourteen estimates were $\$ 2,000-\$ 3,000$, at a probability of 0.044 ; these are displayed in the next bar. The red bars indicate where $10 \%, 50 \%$, and $90 \%$ of cost-effectiveness estimates fell. Overall, $90 \%$ of cost-effectiveness estimates were less than $\$ 9,000$ per QALY. 
Table 4-6. Cost-Effectiveness of STEP Study, Non-Hispanic Whites

\begin{tabular}{|c|c|c|c|c|c|c|c|}
\hline \multirow[b]{2}{*}{ Variable } & \multirow[b]{2}{*}{ Arm } & \multicolumn{2}{|c|}{ All } & \multicolumn{2}{|c|}{ Mayo } & \multicolumn{2}{|c|}{ UTHSC } \\
\hline & & Mean & SE & Mean & SE & Mean & SE \\
\hline \multirow[t]{3}{*}{ Costs } & $\begin{array}{l}\mathrm{S} \\
\end{array}$ & 800.61 & 45.134 & 636.1 & 54.665 & 1043.3 & 59.841 \\
\hline & $\mathrm{R}$ & 400.86 & 12.807 & 338.55 & 17.647 & 475.87 & 12.56 \\
\hline & Diff & 399.75 & & 297.55 & & 567.43 & \\
\hline \multirow[t]{3}{*}{ PPA } & $\mathrm{S}$ & 0.2424 & 0.0433 & 0.2373 & 0.0559 & 0.25 & 0.0693 \\
\hline & $\mathrm{R}$ & 0.2605 & 0.0404 & 0.2308 & 0.0527 & 0.2963 & 0.0627 \\
\hline & Diff & -0.0181 & & 0.0065 & & -0.0463 & \\
\hline \multirow[t]{3}{*}{ CA } & $\mathrm{S}$ & 0.1515 & 0.0362 & 0.1695 & 0.0493 & 0.125 & 0.053 \\
\hline & $\mathrm{R}$ & 0.1765 & 0.0351 & 0.1538 & 0.0451 & 0.2037 & 0.0553 \\
\hline & Diff & -0.025 & & 0.0157 & & -0.0787 & \\
\hline \multicolumn{8}{|l|}{ ICER } \\
\hline PPA & & -- & & $\$ 45,777$ & & -- & \\
\hline CA & & -- & & $\$ 18,952$ & & -- & \\
\hline
\end{tabular}

Note: Dotted lines denote scenarios in which stepped care was dominated by repeat care (being more costly and less effective). Negative ICERs are not calculated.

Abbreviations: CA: continuous abstinence, Diff: difference in estimates (cost, effect), ICER: incremental cost-effectiveness ratio, PPA: point-prevalence abstinence, R: repeat intervention, S: stepped care intervention, SE: standard error, UTHSC: University of Tennessee Health Science Center. 
Table 4-7. Cost-Effectiveness of STEP Study, Ethnic Minorities

\begin{tabular}{|c|c|c|c|c|c|}
\hline \multirow[b]{3}{*}{ Variable } & \multirow[b]{3}{*}{ Arm } & \multicolumn{4}{|c|}{ Ethnic Minorities } \\
\hline & & \multicolumn{2}{|c|}{ All } & \multicolumn{2}{|c|}{ UTHSC } \\
\hline & & Mean & SE & Mean & $\mathrm{SE}$ \\
\hline \multirow[t]{3}{*}{ Costs } & $\mathrm{S}$ & $\$ 1,016.90$ & $\$ 58.19$ & $\$ 1,104.00$ & $\$ 53.29$ \\
\hline & $\mathrm{R}$ & $\$ 474.24$ & $\$ 16.27$ & $\$ 499.20$ & $\$ 13.20$ \\
\hline & Diff & $\$ 542.66$ & & $\$ 604.80$ & \\
\hline \multirow[t]{3}{*}{ PPA } & $\mathrm{S}$ & 0.1346 & 0.048 & 0.1333 & 0.051 \\
\hline & $\mathrm{R}$ & 0.1429 & 0.051 & 0.1364 & 0.052 \\
\hline & Diff & -0.0083 & & -0.0031 & \\
\hline \multirow[t]{3}{*}{ CA } & $\mathrm{S}$ & 0.0577 & 0.033 & 0.0444 & 0.031 \\
\hline & $\mathrm{R}$ & 0.0612 & 0.035 & 0.0455 & 0.032 \\
\hline & Diff & -0.0035 & & -0.0011 & \\
\hline \multicolumn{6}{|l|}{ ICER } \\
\hline PPA & & -- & & -- & \\
\hline $\mathrm{CA}$ & & -- & & -- & \\
\hline
\end{tabular}

Note: Dotted lines denote scenarios in which stepped care was dominated by repeat care (being more costly and less effective). Negative ICERs are not calculated.

Abbreviations: CA: continuous abstinence, Diff: difference in estimates (cost, effect), ICER: incremental cost-effectiveness ratio, PPA: point-prevalence abstinence, R: repeat intervention, S: stepped care intervention, SE: standard error, UTHSC: University of Tennessee Health Science Center. 
Table 4-8. Cost-Effectiveness of Future Outcomes Simulation, Summary Statistics

\begin{tabular}{lrrrrr}
\hline Statistic & \multicolumn{1}{c}{ Cost } & \multicolumn{1}{c}{ Effect } & Cost/Eff & Start age & Death age \\
\hline Mean & $\$ 49,025$ & $8.62 \mathrm{Q}$ & $\$ 6,530$ & 46.4 & 58.5 \\
Std Dev & $\$ 33,491$ & $5.75 \mathrm{Q}$ & $\$ 3,535$ & 11.1 & 10.6 \\
Minimum & $\$ 2,637$ & $0.44 \mathrm{Q}$ & $\$ 1,401$ & 22 & 27 \\
$2.50 \%$ & $\$ 6,320$ & $0.46 \mathrm{Q}$ & $\$ 2,767$ & 26 & 37 \\
$10 \%$ & $\$ 10,118$ & $1.36 \mathrm{Q}$ & $\$ 3,639$ & 31 & 45 \\
Median & $\$ 42,740$ & $8.07 \mathrm{Q}$ & $\$ 5,976$ & 47 & 58 \\
$90 \%$ & $\$ 99,156$ & $16.58 \mathrm{Q}$ & $\$ 8,686$ & 61 & 73 \\
$97.50 \%$ & $\$ 126,310$ & $20.64 \mathrm{Q}$ & $\$ 19,441$ & 68 & 78 \\
Maximum & $\$ 140,447$ & $23.66 \mathrm{Q}$ & $\$ 29,236$ & 82 & 83 \\
Sum (n*mean) & $\$ 15,638,951$ & $2,750.62 \mathrm{Q}$ & -- & -- & -- \\
\hline
\end{tabular}

Note: Estimates at $2.5 \%$ and $97.5 \%$ denote the lower and upper bounds of the $95 \%$ confidence interval.

Abbreviations: Cost/Eff: cost-effectiveness (average), Q; QALY, Std Dev: standard deviation.

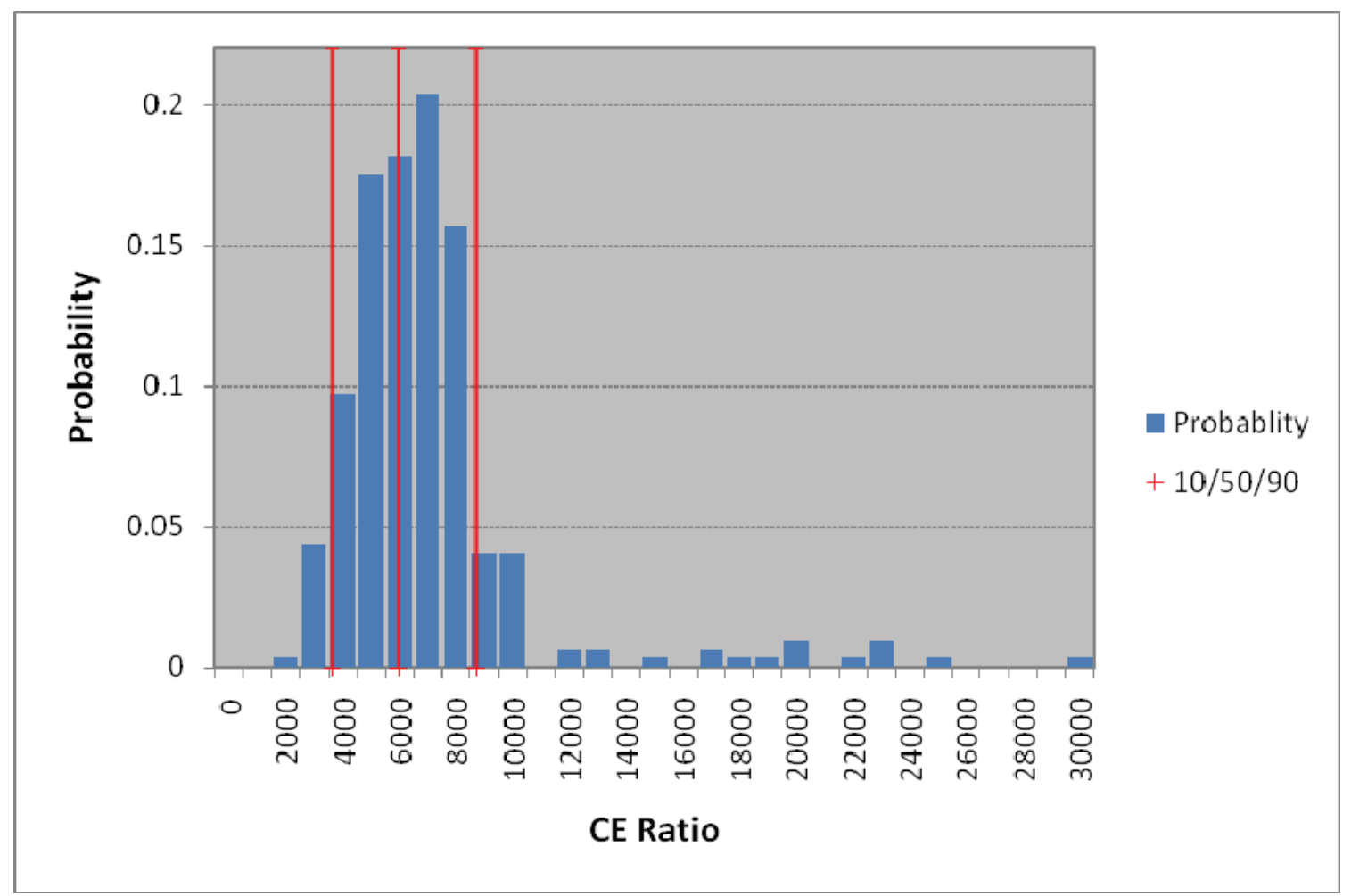

Figure 4-1. Distribution of Cost-Effectiveness Ratios 
Table 4-9 outlines outcomes of the original versus amended analyses. Differences across analyses reflect benefit of cessation following the STEP intervention. In the original simulation, 41 of 319 participants were abstinent at entry; of these, over half (24) remained abstinent until death. Nearly $22 \%$ of participants were quitters at death. Costs in the smoking simulation were $\$ 48,956$ per person; this estimate was $\$ 69$ lower than the original simulation. Fewer QALYs were gained in the smoking simulation when compared to the original (8.6 versus 8.62). Participants in the original simulation did not live any longer than when in the smoking simulation. Age at death for each population was 58.5 years. The smoking simulation yielded two more cases of cerebrovascular disease, one more case each of emphysema and lung cancer, and two fewer cases of ischemic heart disease than the original group. In all, this was a net decrease of two cases of smoking-related disease. Incremental cost-effectiveness of successful STEP study cessation was $\$ 3,450$ per QALY gained.

Results of sensitivity analysis are reported in Table 4-10. These estimates account for changes in natural quit, disease incidence, mortality, cost and utility parameters. When considered individually, the largest drivers of incremental cost-effectiveness were cerebrovascular disease incidence (248\% increase), lung cancer and emphysema incidence (155\% increase for each) when set at their lower bounds and emphysema incidence at its upper bound (164\% increase). Individual parameters yielding more favorable ICERs (compared to baseline) were ischemic heart disease mortality at its lower bound (17\% decrease) and cerebrovascular disease incidence and natural quit rates when set at their upper bounds (12\% and $7 \%$ decreases, respectively). When multiple factors were considered (costs, utilities, incidence, and mortality for all smoking-related diseases), changes in incremental cost-effectiveness ranged from cost-saving to $248 \%$ beyond baseline. When all parameters were set at lower bounds, simulation yielded smaller estimates. Participants in the original simulation yielded $\$ 32,842$ in mean costs versus $\$ 32,578$ in the smoking simulation. Original and smoking simulations yielded 8.17 and 8.15 QALYs, respectively. Incremental cost-effectiveness was $\$ 13,200$ per QALY gained. At the upper bound of sensitivity analysis, costs increased to $\$ 64,150$ and $\$ 64,264$ in original and smoking simulations. QALYs gained were higher, due to an increased percentage of quitting over the lifetime (8.79 and 8.77 QALYs). In this case the original simulation was cost-saving; successful quitters produced smaller mean costs. Average age at death remained unchanged in sensitivity analysis. Disease cases averted did change, however, ranging from an additional case of ischemic heart disease at lower bounds to two cases of disease averted at upper bounds (one case each of cerebrovascular disease and emphysema). Table 4-11 shows the impact of discounting on costeffectiveness estimates. Discount rates were adjusted in baseline analyses to five percent and zero percent (undiscounted). Costs ranged from $\$ 41,920-\$ 65,479$ in the original simulation and $\$ 41,863-\$ 65,388$ in the smoking simulations. Incremental costeffectiveness of successful quitting versus unsuccessful quitting ranged from $\$ 2,850$ $\$ 4,550$ per QALY. 
Table 4-9. Comparisons of Original and All Smokers Simulations

\begin{tabular}{lrr}
\hline Statistic & Original & All smokers \\
\hline Cost & $\$ 49,025$ & $\$ 48,956$ \\
Effect & 8.62 & 8.6 \\
ACER & $\$ 6,530$ & $\$ 6,643$ \\
Cost difference & $\$ 69$ & -- \\
Effect difference & 0.02 & -- \\
ICER & $\$ 3,450$ & -- \\
Quits at entry & 41 & 0 \\
Quit \%, smokers & $21.6 \%$ & $16.9 \%$ \\
SR disease, n & & \\
IHD & 32 & 30 \\
CBD & 11 & 13 \\
LC & 3 & 4 \\
EMP & 16 & 17 \\
Age at death & 58.5 & 58.5 \\
\hline
\end{tabular}

Note: Baseline simulations discounted at 3\%. All costs are presented in year 2009 U.S. dollars. Original simulation includes successful STEP study quitters. The 'All smokers' simulation assumes that all participants entered the model as smokers.

Abbreviations: ACER: average cost-effectiveness ratio, CBD: cerebrovascular disease, EMP: emphysema, ICER: incremental cost-effectiveness ratio, IHD: ischemic heart disease, LC: lung cancer, n: number, SR: smoking-related. 
Table 4-10. Sensitivity Analysis of Future Outcomes Simulations

\begin{tabular}{|c|c|c|c|c|c|c|c|c|c|}
\hline Param & $\mathrm{L} / \mathrm{H}$ & Statistic & O Sim & AS Sim & IC & IE & ICER & $\triangle$ ICER & $\% \Delta$ \\
\hline \multirow[t]{2}{*}{ Base } & -- & Cost & $\$ 49,025$ & $\$ 48,956$ & $\$ 69$ & 0.02 & $\$ 3,450$ & -- & - \\
\hline & & QALY & 8.62 & 8.6 & & & & & \\
\hline \multirow{5}{*}{$\begin{array}{l}\text { NQ } \\
\text { Rate }\end{array}$} & $\mathrm{L}$ & Cost & $\$ 48,934$ & $\$ 48,863$ & $\$ 71$ & 0.02 & $\$ 3,550$ & $\$ 100$ & $3 \%$ \\
\hline & & QALY & 8.61 & 8.59 & & & & & \\
\hline & $\mathrm{H}$ & Cost & $\$ 49,166$ & $\$ 49,100$ & $\$ 66$ & 0.02 & $\$ 3,300$ & $(\$ 150)$ & $(4 \%)$ \\
\hline & & QALY & 8.64 & 8.62 & & & & & \\
\hline & & QALY & 8.79 & 8.78 & & & & & \\
\hline \multirow{4}{*}{$\begin{array}{l}\text { IHD } \\
\text { inc }\end{array}$} & $\mathrm{L}$ & Cost & $\$ 48,682$ & $\$ 48,583$ & $\$ 99$ & 0.02 & $\$ 4,950$ & $\$ 1,500$ & $43 \%$ \\
\hline & & QALY & 8.63 & 8.61 & & & & & \\
\hline & $\mathrm{H}$ & Cost & $\$ 49,179$ & $\$ 49,096$ & $\$ 83$ & 0.02 & $\$ 4,150$ & $\$ 700$ & $20 \%$ \\
\hline & & QALY & 8.62 & 8.6 & & & & & \\
\hline \multirow{4}{*}{$\begin{array}{l}\text { CBD } \\
\text { inc }\end{array}$} & $\mathrm{L}$ & Cost & $\$ 48,845$ & $\$ 48,725$ & $\$ 120$ & 0.01 & $\$ 12,000$ & $\$ 8,550$ & $248 \%$ \\
\hline & & QALY & 8.62 & 8.61 & & & & & \\
\hline & $\mathrm{H}$ & Cost & $\$ 49,114$ & $\$ 49,053$ & $\$ 61$ & 0.02 & $\$ 3,050$ & $(\$ 400)$ & $(12 \%)$ \\
\hline & & QALY & 8.62 & 8.6 & & & & & \\
\hline \multirow{4}{*}{$\begin{array}{l}\text { LC } \\
\text { inc }\end{array}$} & L & Cost & $\$ 48,976$ & $\$ 48,888$ & $\$ 88$ & 0.01 & $\$ 8,800$ & $\$ 5,350$ & $155 \%$ \\
\hline & & QALY & 8.62 & 8.61 & & & & & \\
\hline & $\mathrm{H}$ & Cost & $\$ 49,075$ & $\$ 49,006$ & $\$ 69$ & 0.02 & $\$ 3,450$ & $\$ 0$ & $0 \%$ \\
\hline & & QALY & 8.62 & 8.6 & & & & & \\
\hline \multirow{4}{*}{$\begin{array}{l}\text { EMP } \\
\text { inc }\end{array}$} & L & Cost & $\$ 48,987$ & $\$ 48,899$ & $\$ 88$ & 0.01 & $\$ 8,800$ & $\$ 5,350$ & $155 \%$ \\
\hline & & QALY & 8.62 & 8.61 & & & & & \\
\hline & $\mathrm{H}$ & Cost & $\$ 48,975$ & $\$ 48,884$ & $\$ 91$ & 0.01 & $\$ 9,100$ & $\$ 5,650$ & $164 \%$ \\
\hline & & QALY & 8.62 & 8.61 & & & & & \\
\hline \multirow{4}{*}{$\begin{array}{l}\text { IHD } \\
\text { mort }\end{array}$} & $\mathrm{L}$ & Cost & $\$ 48,855$ & $\$ 48,798$ & $\$ 57$ & 0.02 & $\$ 2,850$ & $(\$ 600)$ & $(17 \%)$ \\
\hline & & QALY & 8.62 & 8.6 & & & & & \\
\hline & $\mathrm{H}$ & Cost & $\$ 49,195$ & $\$ 49,115$ & $\$ 80$ & 0.01 & $\$ 8,000$ & $\$ 4,550$ & $132 \%$ \\
\hline & & QALY & 8.62 & 8.61 & & & & & \\
\hline \multirow{4}{*}{$\begin{array}{l}\text { CBD } \\
\text { mort }\end{array}$} & $\mathrm{L}$ & Cost & $\$ 48,963$ & $\$ 48,881$ & $\$ 82$ & 0.02 & $\$ 4,100$ & $\$ 650$ & $19 \%$ \\
\hline & & QALY & 8.62 & 8.6 & & & & & \\
\hline & $\mathrm{H}$ & Cost & $\$ 49,087$ & $\$ 49,031$ & $\$ 56$ & 0.01 & $\$ 5,600$ & $\$ 2,150$ & $62 \%$ \\
\hline & & QALY & 8.62 & 8.61 & & & & & \\
\hline \multirow{4}{*}{$\begin{array}{l}\text { LC } \\
\text { mort }\end{array}$} & L & Cost & $\$ 48,976$ & $\$ 48,888$ & $\$ 88$ & 0.02 & $\$ 4,400$ & $\$ 950$ & $28 \%$ \\
\hline & & QALY & 8.62 & 8.6 & & & & & \\
\hline & $\mathrm{H}$ & Cost & $\$ 49,073$ & $\$ 49,024$ & $\$ 49$ & 0.01 & $\$ 4,900$ & $\$ 1,450$ & $42 \%$ \\
\hline & & QALY & 8.62 & 8.61 & & & & & \\
\hline \multirow{2}{*}{$\begin{array}{l}\text { EMP } \\
\text { mort }\end{array}$} & L & Cost & $\$ 49,006$ & $\$ 48,936$ & $\$ 70$ & 0.02 & $\$ 3,500$ & $\$ 50$ & $1 \%$ \\
\hline & & QALY & 8.62 & 8.6 & & & & & \\
\hline
\end{tabular}


Table 4-10. (continued)

\begin{tabular}{|c|c|c|c|c|c|c|c|c|c|}
\hline Param & $\mathrm{L} / \mathrm{H}$ & Statistic & O Sim & AS Sim & IC & IE & ICER & $\triangle$ ICER & $\% \Delta$ \\
\hline \multirow{6}{*}{ Costs } & \multirow{2}{*}{$\mathrm{H}$} & Cost & $\$ 49,044$ & $\$ 48,976$ & \multirow[t]{2}{*}{$\$ 68$} & \multirow{2}{*}{0.01} & \multirow{2}{*}{$\$ 6,800$} & \multirow{2}{*}{$\$ 3,350$} & \multirow{2}{*}{$97 \%$} \\
\hline & & QALY & 8.62 & 8.61 & & & & & \\
\hline & \multirow[t]{2}{*}{$\mathrm{L}$} & Cost & $\$ 34,766$ & $\$ 34,492$ & \multirow[t]{2}{*}{$\$ 274$} & \multirow[t]{2}{*}{0.02} & \multirow[t]{2}{*}{$\$ 13,700$} & \multirow[t]{2}{*}{$\$ 10,250$} & \multirow[t]{2}{*}{$297 \%$} \\
\hline & & QALY & 8.62 & 8.6 & & & & & \\
\hline & \multirow[t]{2}{*}{$\mathrm{H}$} & Cost & $\$ 63,283$ & $\$ 63,420$ & \multirow[t]{2}{*}{$(\$ 137)$} & \multirow[t]{2}{*}{0.02} & \multirow[t]{2}{*}{ CS } & \multirow[t]{2}{*}{-- } & -- \\
\hline & & QALY & 8.62 & 8.6 & & & & & \\
\hline \multirow[t]{4}{*}{ Util } & \multirow[t]{2}{*}{$\mathrm{L}$} & Cost & $\$ 49,025$ & $\$ 48,956$ & \multirow[t]{2}{*}{$\$ 69$} & \multirow[t]{2}{*}{0.02} & \multirow[t]{2}{*}{$\$ 3,450$} & \multirow[t]{2}{*}{$\$ 0$} & \multirow[t]{2}{*}{$0 \%$} \\
\hline & & QALY & 8.45 & 8.43 & & & & & \\
\hline & \multirow[t]{2}{*}{$\mathrm{H}$} & Cost & $\$ 49,025$ & $\$ 48,956$ & \multirow[t]{2}{*}{$\$ 69$} & \multirow[t]{2}{*}{0.01} & \multirow[t]{2}{*}{$\$ 6,900$} & \multirow[t]{2}{*}{$\$ 3,450$} & \multirow[t]{2}{*}{$100 \%$} \\
\hline & & QALY & 8.79 & 8.78 & & & & & \\
\hline \multirow{4}{*}{$\begin{array}{l}\text { Inc } \\
\text { (all) }\end{array}$} & \multirow[t]{2}{*}{$\mathrm{L}$} & Cost & $\$ 48,537$ & $\$ 48,422$ & $\$ 115$ & 0.02 & $\$ 5,750$ & $\$ 2,300$ & $67 \%$ \\
\hline & & QALY & 8.63 & 8.61 & & & & & \\
\hline & $\mathrm{H}$ & Cost & $\$ 49,349$ & $\$ 49,283$ & $\$ 66$ & 0.02 & $\$ 3,300$ & $(\$ 150)$ & $(4 \%)$ \\
\hline & & QALY & 8.62 & 8.6 & & & & & \\
\hline Mort & $\mathrm{L}$ & Cost & $\$ 48,726$ & $\$ 48,635$ & $\$ 91$ & 0.02 & $\$ 4,550$ & $\$ 1,100$ & $32 \%$ \\
\hline (all) & & QALY & 8.62 & 8.6 & & & & & \\
\hline & $\mathrm{H}$ & Cost & $\$ 49,324$ & $\$ 49,278$ & $\$ 46$ & 0.02 & $\$ 2,300$ & $(\$ 1,150)$ & $(33 \%)$ \\
\hline & & QALY & 8.63 & 8.61 & & & & & \\
\hline All & $\mathrm{L}$ & Cost & $\$ 32,842$ & $\$ 32,578$ & $\$ 264$ & 0.02 & $\$ 13,200$ & $\$ 9,750$ & $283 \%$ \\
\hline & & QALY & 8.17 & 8.15 & & & & & \\
\hline & $\mathrm{H}$ & Cost & $\$ 64,150$ & $\$ 64,264$ & $(\$ 114)$ & 0.02 & CS & -- & -- \\
\hline & & QALY & 8.79 & 8.77 & & & & & \\
\hline
\end{tabular}

Note: Baseline simulations discounted at 3\%. All costs are presented in year 2009 U.S. dollars. Original simulation (O Sim) includes successful STEP study quitters. The 'All Smokers' simulation (AS Sim) assumes that all participants entered the model as smokers. Low and high parameters denote values for $95 \%$ confidence intervals.

Abbreviations: $\Delta$ : change in, \%: percent, AS Sim: all smokers simulation, CBD: cerebrovascular disease, CS: cost-saving, EMP: emphysema, H: high, IC: incremental cost, IE: incremental effect, ICER: incremental cost-effectiveness ratio, IHD: ischemic heart disease, L: low, LC: lung cancer, L/H: low/high, O Sim: original simulation, Param: parameter, QALY: quality-adjusted life year, SR: smoking-related. 
Table 4-11. Sensitivity Analysis, Discount Rate

\begin{tabular}{lrrrrrrrr}
\hline & \multicolumn{2}{c}{ Baseline } & & \multicolumn{2}{c}{ Discount: 5\% } & & \multicolumn{2}{c}{ Undiscounted } \\
\cline { 2 - 3 } \cline { 8 - 9 } Statistic & Original & Smokers & & Original & Smokers & & Original & Smokers \\
\hline Cost & $\$ 49,025$ & $\$ 48,956$ & & $\$ 41,920$ & $\$ 41,863$ & & $\$ 65,479$ & $\$ 65,388$ \\
Effect & 8.62 & 8.60 & & 7.48 & 7.46 & & 11.19 & 11.17 \\
ACE & $\$ 6,530$ & $\$ 6,643$ & & $\$ 6,473$ & $\$ 6,586$ & & $\$ 6,624$ & $\$ 6,738$ \\
Cost Diff & $\$ 69$ & -- & & $\$ 57$ & -- & & $\$ 91$ & - \\
Eff Diff & 0.02 & -- & & 0.02 & -- & & 0.02 & -- \\
ICER & $\$ 3,450$ & -- & & $\$ 2,850$ & -- & & $\$ 4,550$ & - \\
\hline
\end{tabular}

Note: Baseline simulations discounted at 3\%. All costs are presented in year 2009 U.S. dollars. Original simulation includes successful STEP study quitters. The 'All smokers' simulation assumes that all participants entered the model as smokers.

Abbreviations: ACE: average cost-effectiveness, Diff: difference, Eff: effect, ICER: incremental cost-effectiveness ratio. 


\section{Comparing STEP Cost-Effectiveness Analyses to the Literature}

The league tables previously reported in Chapter 2 were updated to include results of the current analyses. These results are reported in Table 4-12. STEP analysis is reported at the end of all studies reporting costs per quit. This reflects stepped care as a dominated strategy compared to repeat intervention. The long-term result is shown among studies reporting cost per QALY. This result falls near the middle of all estimates. Considering that STEP study participants received intervention as many as three times, the incremental cost-effectiveness estimate for long-term intervention was expected to be higher. However, at $\$ 3,450$ per QALY, the Future Outcomes Simulation is highly costeffective. 
Table 4-12. Adjusted League Table, Cost-Effectiveness of Smoking Cessation Interventions

\begin{tabular}{|c|c|c|}
\hline Author & Intervention & Cost $(\$, 2009)$ \\
\hline \multicolumn{3}{|c|}{ Cost/Quit } \\
\hline Hall et al. & MM + PI vs. MM alone & $\$ 545$ \\
\hline Feenstra et al. & MC vs. current practice & $\$ 768$ \\
\hline Hall et al. & MM + Nortrip vs. MM alone & $\$ 917$ \\
\hline Hall et al. & MM + Bupr vs. MM alone & $\$ 1,868$ \\
\hline Woolacott et al. & Counsel + Bupr vs. counsel & $\$ 2,723$ \\
\hline Feenstra et al. & TC vs. current practice & $\$ 2,798$ \\
\hline Feenstra et al. & MC + NRT vs. current practice & $\$ 2,986$ \\
\hline Woolacott et al. & Counsel + NRT + Bupr vs. counsel & $\$ 3,795$ \\
\hline Feenstra et al. & IC + Bupr vs. current practice & $\$ 4,112$ \\
\hline Woolacott et al. & Counsel + NRT vs. counsel & $\$ 4,264$ \\
\hline Feenstra et al. & IC + NRT vs. current practice & $\$ 5,067$ \\
\hline Barnett et al. & Stepped care vs. Brief intervention & $\$ 7,189$ \\
\hline STEP Study & Stepped care vs. repeat intervention & Dominated \\
\hline \multicolumn{3}{|c|}{ Cost/Quality-Adjusted Life-Year } \\
\hline Bolin et al. & Bupr vs. Patch (Males) & cost-saving \\
\hline Bolin et al. & Bupr vs. Gum (Males) & cost-saving \\
\hline Feenstra et al. & MC vs. current practice & cost-saving \\
\hline Woolacott et al. & Counsel + Bupr vs. counsel & $\$ 1,008$ \\
\hline Woolacott et al. & Counsel + NRT + Bupr vs. counsel & $\$ 1,406$ \\
\hline Woolacott et al. & Counsel + NRT vs. counsel & $\$ 1,579$ \\
\hline Feenstra et al. & TC vs. current practice & $\$ 1,877-\$ 2,559$ \\
\hline Feenstra et al. & MC + NRT vs. current practice & $\$ 2,389-\$ 2,900$ \\
\hline Bolin et al. & Bupr vs. Patch (Females) & $\$ 2,539$ \\
\hline STEP Study & Successful quitters vs. non-quitters & $\$ 3,450$ \\
\hline Bolin et al. & Bupr vs. Gum (Females) & $\$ 4,054$ \\
\hline Feenstra et al. & $\mathrm{IC}+$ Bupr vs. current practice & $\$ 5,801-\$ 6,142$ \\
\hline Feenstra et al. & IC + NRT vs. current practice & $\$ 8,360-\$ 8,872$ \\
\hline
\end{tabular}

Note: STEP Study intervention denoted in italics.

Abbreviations: Bupr: bupropion; IC: intensive counseling; MC: minimal counseling; MM: medical management; Nortrip: nortriptyline; NRT: nicotine replacement therapy; PI: psychological intervention; TC: telephone counseling. 


\section{CHAPTER 5: CONCLUSIONS}

\section{Discussion}

This study sought to evaluate the use of stepped care in smoking cessation interventions to increase cessation among smokers ready to quit. When compared to a repeated therapy intervention, stepped care did not prove cost-effective. Stepped care produced a greater percentage of continuous quitters only among women in the Mayo Clinic sample; this was the only scenario in which the ICER fell within estimates reported in the literature review in Chapter 2. Cessation rates favored stepped care in UT women, Mayo men, and the overall Mayo sample, but none of the differences observed were statistically significant. Thus, ICERs produced in these subgroups fell beyond the threshold of $\$ 10,000$ per quit. However, when comparing alternatives that are considered equally efficacious, the general rule is to choose the strategy with the lower cost. In the case of STEP, repeat care dominated stepped care, as it was less costly and equally effective. As such, it would not be wise to recommend stepped care over repeated intervention.

While stepped care was not proven cost effective, both study arms produced significant rates of continuous abstinence at two years. These rates, for both continuous and point-prevalence abstinence, are in line with results reported in short-term studies reviewed. Many of the short-term studies evaluated outcomes at one year or 18 months; STEP results are comparable at 24 months. This study fills a large gap in the literature regarding rates of long-term abstinence after cessation intervention. The benefits seen with repeat care affirm newer findings by Fu and Han. ${ }^{105,106} \mathrm{Fu}$ and colleagues evaluated a sample of Veterans Affairs (VA) patients who had relapsed at six months post-tobacco cessation treatment, demonstrating that nearly two-thirds were interesting in recycling. The researchers also inquired about the type of treatment the smokers were interested in using; the majority were interested in combination pharmacotherapy and behavioral counsel. ${ }^{102}$ Han and colleagues examined a subset of patients who returned to a tobacco dependence clinic to receive repeat treatment(s) following initial relapse. Subsequent quit attempts by repeaters were similar to abstinence rates achieved in a larger sample receiving intervention once. ${ }^{106}$

Several differences were noted among participants across study sites, race, and gender. First, participation rates were quite different across sites, with nearly three-fold greater attendance at all visits among UTHSC versus Mayo participants. Unfortunately, increased participation did not impact quitting. CES-D scores were higher among UTHSC versus Mayo Clinic, and specifically in the stepped care arm. This could have likely influenced lower levels of quitting at the UTHSC site. Differences in efficacy observed across race and gender also require further discussion. Non-Hispanic whites achieved higher rates of cessation versus ethnic minorities, as did men (versus women). A variety of factors may have contributed to these differences, but that discussion extends beyond the scope of this analysis. The low rates achieved by ethnic minorities are concerning, suggesting that neither repeated nor stepped care was beneficial for achieving cessation. In fact, the continuous abstinence rate observed in ethnic minorities was 
similar to one reported by Hughes which was based on self-quitting. That such a significant portion of minorities participated in the study is moderately encouraging; however, the results are still disappointing. Data affirm that success rates among ethnic minorities are generally lower, despite making as many or more quit attempts compared to white smokers. ${ }^{107-109}$ Qualitative studies, specifically those addressing barriers to treatment delivery, use, or success, might play a significant role in informing future research in this population. ${ }^{33,109}$

The results of the future outcomes simulation were very positive. Study intervention produced a cost-effectiveness estimate that was extremely cost-effective when compared to other studies in the literature. Average age at death in the original simulation was no higher than in the smoking simulation; smoking cessation did not impact age at death, but did impact cause. Ultimately, participants in whom smokingrelated disease was averted died from other causes. In sensitivity analysis, costeffectiveness remained favorable, but benefits of cessation related to disease incidence were lost, especially when disease incidence decreased or more smokers quit on their own. Successful smoking cessation impacted incidence of emphysema, lung cancer, and cerebrovascular disease, but not ischemic heart disease. This is likely due to the fact that smoking is only attributable to one-fifth of ischemic heart disease incidence. ${ }^{10}$ Overall, the impact of decreased smoking-related disease incidence yielded an attractive estimate of incremental cost-effectiveness. Results of the future outcomes simulations demonstrate the importance and economic feasibility of investing in smoking cessation, even in small populations.

\section{Strengths}

This study has a number of strengths. First, the underlying study is comprised of a diverse mix of smokers, especially those of ethnic minority or low income populations. As mentioned previously, these are two smoking groups that have been challenged with disparate access to therapy and ultimately difficulties with successful cessation. The literature evaluating smoking cessation interventions among these two key groups is still sparse. This study confirms that continued research is warranted to address tobacco dependence among ethnic minorities. Also, using the assumption of smoking for patients missing the final visit likely provides a conservative estimate of efficacy and costeffectiveness. This strategy is generally employed in smoking cessation studies for persons lost to follow-up.

In terms of the simulation of future outcomes, the data sources utilized were relatively new, using the most recent year(s) available. Moreover, these data are nationally representative, providing reliable estimates of disease incidence, mortality risk, healthcare costs and utilities across age, race, and gender. In addition, the model constructed for simulation of future health outcomes was derived from various models which have been widely used in the literature. ${ }^{94,95}$ It accounts for a wider variety of tobacco-related diseases than earlier single-disease models. However, it is not as complex as a newer cessation model, which encompasses 14 tobacco-related diseases. ${ }^{85}$ Given the uncertainty about the disease pathways that smokers follow after cessation, only more 
common smoking-related diseases were captured. Because of this, long-term costeffectiveness analysis likely underestimates the economic benefits of quitting. Further, the model did not account for productivity gains associated with smoking cessation or gains associated with reallocation of resources used to purchase tobacco products. Other economic impacts of smoking cessation on society are also ignored. For example, smoking cessation reduces involuntary exposure to tobacco smoke, potentially averting cases of illness caused by secondhand smoke.

\section{Limitations}

Results of the cost-effectiveness analysis of stepped care versus repeat care must be interpreted with caution. It must be noted that UTHSC patients in the analysis sample reported higher CES-D scores and baseline carbon monoxide readings than the remaining group. The extent to which these variables might influence other outcomes is unknown. Moreover, the study was not powered to detect significant differences in costeffectiveness. Especially among joint clinical/economic studies, underlying studies may be adequately powered for clinical outcomes, but inadequately powered for economic outcomes. ${ }^{110}$ To achieve joint power, much larger sample sizes are required; this introduces potential ethical and practical issues. ${ }^{111}$ Several methods have been put forward to power studies for economic outcomes, but these techniques have not yet been widely employed in cost-effectiveness analyses. ${ }^{112-117}$ The current study utilized confidence interval estimation to characterize uncertainty around cost-effectiveness estimates; this technique is a generally accepted alternative to hypothesis testing or power calculations. $^{118-121}$

Next, the extent to which the demographic profile of STEP participants resembles the current smoking population in the United States will impact the generalizability of results to a larger group. A key limitation here is related to the absence of certain special populations of smokers in the study, including those who were pregnant, had psychiatric comorbidities or other medical conditions deemed ineligible for inclusion. Smoking cessation interventions containing pharmacotherapy have not yet been deemed appropriate for pregnant smokers; as such, no statement regarding cost-effectiveness of this particular stepped care intervention can be made for them. In addition, results cannot be extended to other key smoking populations not represented in the STEP study. Another limiting factor in this analysis is related to the study setting. Study participants, though diverse, may not be representative of the larger smoking population, as their interest in participating in STEP may differentiate them from other smokers. Receipt of free medication and compensation for time may have impacted participation throughout the study. As such, the outcomes observed in STEP may not be reflected in natural settings. Finally, the reliability of the results obtained in the simulation wholly depends on the accuracy of assumptions made in structure of and data used in the model.

In the long-term model evaluating future outcomes of smoking cessation, utilities were derived using a mapping algorithm from Sullivan. Other algorithms have been used similarly to map between SF-12 and EQ-5D scores, including one by Brazier. ${ }^{122}$ Use of mapping techniques may not accurately reflect utilities among this or a community-based 
population. Another issue to consider in use of HRQL scores is the ensuing debate regarding racial/ethnic differences in valuation and its impact on cost-effectiveness research. Wang, Saalfrank, and Gaskin have demonstrated through literature review and other analysis that racial and ethnic differences do exist. ${ }^{123-125}$ Further, they emphasize a need for research to explore factors influencing these differences and to use caution when applying health-related quality of life across diverse populations in cost-utility analysis. For this reason, utilities used in the model were not adjusted for race/ethnicity to avoid biases in the cost-effectiveness measures.

\section{Promoting Smoking Cessation in Primary Care}

Greater efforts are needed for integrating smoking cessation treatment into primary care practice. The primary care setting is considered the most appropriate for addressing tobacco dependence; opportunities exist for repeated intervention by physicians, nurses, pharmacists, and dentists, among others. However, provision of support for smoking cessation has not been a priority for general clinicians, as evidenced in a recent report. An analysis conducted by Maciosek and colleagues revealed significant underutilization of preventive services for smoking cessation. ${ }^{126}$ Using 2005 HEDIS data, the researchers found that $48 \%$ of smokers received advice to quit from physicians, while only $28 \%$ of smokers reported receiving medical assistance to quit. They surmised that if the percentage offered assistance were increased to $90 \%$, an additional 42,000 lives might be saved. Similar inconsistencies in intervention among providers have been documented in the Guidelines and other literature.

The design of the STEP study provides a feasible model for smoking cessation intervention in the primary care setting. Research indicates that smokers make more visits per year to a physician than non-smokers. ${ }^{11}$ These primary care visits could serve as treatment visits, in which physicians or nurses could assess smoking status, gauge readiness and commitment to quit, provide counseling and/or pharmacotherapy, and schedule follow-up. Telephone follow-up could be conducted by a nurse or staff person to provide support until the next visit. At subsequent visits, quit status could be assessed and repeated intervention employed if necessary until a quit is achieved. Provision of continuous intervention is key; it has been shown to increase cessation nearly four-fold when compared to one-time intervention. ${ }^{127}$ Follow-up through and beyond 12 months post-cessation is equally critical for ensuring long-term success.

\section{Economic Evaluation for Healthcare Financing}

In many countries, the formal use of economic evaluation is mandated to guide healthcare financing (including coverage of healthcare medications and treatments). Since 1992, Australia, Canada, Portugal, Finland, and the Netherlands have formalized and issued guidelines on the systematic use of economic evaluation in healthcare policy and decision making. More recently, the United Kingdom established an independent organization, National Institute for Health and Clinical Excellence (NICE), to provide clinical and economic guidance in public health, health technologies, and clinical 
practice. In other European countries, informal guidelines have been established to achieve these aims. In the United States, informal guidelines or recommendations have been published, but their use is not enforced. As such, Gold and colleagues emphasize a need for standardization, due to the increased use of economic data in guiding allocation of healthcare resources.

While growth of economic evaluation in healthcare decision-making is acknowledged, it has yet to be wholly embraced as a systematic tool for justifying healthcare financing. Given the extent to which cost-effectiveness drives approval of new medicines in the United Kingdom, researchers there assert that even where the best possible economic evaluations are available, they are only one element in a complex process of decision-making that is also shaped by what is politically feasible. In the United States, Williams and colleagues highlight two key barriers to the use of economic analyses in healthcare - accessibility and acceptability of research evidence. ${ }^{128}$ Difficulties in interpretation of data (due to lack of statistical expertise) and presentation of results hamper the accessibility of economic evaluation for decision-making. In addition, acceptance of economic evaluation hinges on decision-makers' perception of its relevance in addressing emerging health needs. A focus group study evaluating usefulness of economic evaluations found that decision makers valued information on cost-effectiveness, but suggested methodological improvements to increase the reliability of economic studies. ${ }^{129}$ A small body of literature has surfaced in the last decade, which promotes incorporating the scientific rigors of clinical studies into economic evaluations. Several researchers have proposed the adoption of hypothesis testing and put forth various methods for constructing confidence intervals and performing sample size and power calculations. ${ }^{113,115-117}$ In Europe, the generalized cost-effectiveness analysis has been developed to address shortcomings of previous economic evaluations.

Gold and colleagues assert that improvements in the standardization of costeffectiveness analysis methods will allow progress toward more systematic use of CEA in policy- and decision-making, especially for the United States. In the meantime, the health system will continue to use other implicit or explicit means to allocate limited resources. Whether through formal means of cost-effectiveness analysis or otherwise, healthcare payers in the U.S. are using clinical and economic evidence in their considerations of coverage of tobacco cessation pharmacotherapies and related programs. Phillips-Tangum and colleagues have studied trends in health plan coverage of smoking cessation therapies; their recent analysis found that coverage for any tobacco dependence treatment increased from 25 percent of health plans in 1997 to 88 percent of health plans in 2003, the most recent year data were available. ${ }^{130}$ The authors attributed this increase in coverage to the growing body of literature indicating that reducing treatment costs is associated with greater use of tobacco cessation programs and services, which can increase rates of cessation.

Medicaid is one payer that has given particular attention to the economic benefits of smoking cessation treatment coverage. Whereas smokers comprise one-fifth of the general population, one-third of Medicaid enrollees are current smokers. Medicaid coverage of smoking cessation therapies and counseling increased substantially from 2002-2006. ${ }^{131}$ At the end of 2002, 36 Medicaid programs covered some tobacco- 
dependence counseling or medication for all Medicaid recipients, four states offered coverage only for pregnant women, two states offered coverage for all pharmacotherapy and counseling treatments recommended by the 2000 PHS guideline, and seven states covered all recommended medications and at least one form of counseling. By 2006, 39 state Medicaid programs (including the District of Columbia) covered some form of tobacco-dependence treatment (i.e., medication or counseling) for all Medicaid recipients and one state program provided coverage for all recommended treatments. Two states that previously provided no coverage for tobacco-dependence treatment began coverage in 2006. In addition, 32 states added coverage for varenicline (Chantix ${ }^{\mathrm{TM}}$ [Pfizer, Mission, Kansas]), one state expanded its coverage to include the nicotine lozenge, and one state expanded coverage to include individual counseling. ${ }^{131}$

Despite inherent limitations of economic evaluation as a complete tool for healthcare decision-making, the overwhelming affirmation of the cost-effectiveness of smoking cessation therapies indicates that any future economic evaluations will continue to influence (formally or informally) greater coverage of pharmacotherapies and adoption of novel interventions and programs to promote cessation efforts. A new report by the Pacific Center on Health and Tobacco has proposed integrating telephone quitlines into healthcare systems. ${ }^{132}$ The need for referrals among quitlines and referral sources among healthcare systems creates a unique opportunity for partnership. The report documented initiatives taken by several states to develop enhanced smoking cessation service networks. Smoking cessation is also a key focus in the healthcare platform of the current presidential administration; economic stimulus bills presented to Congress have included over $\$ 75$ million for funding smoking cessation campaigns and purchasing equipment for smoking research.

\section{Future Directions}

Newer tobacco control initiatives targeting current smokers are increasingly focused on technology-based methods for increasing cessation. Given the popularity of the iPhone ${ }^{\mathrm{TM}}$ [Apple, Inc.], the National Tobacco Cessation Collaborative (NTCC) and George Washington University School of Public Health and Health Services have developed an application, "My Quitline", to help smokers quit. The free application, once downloaded, will place users in direct contact with National Cancer Institute's quitline counselors via phone or text. Mobile-phone based programs in the U.S. have targeted young adults, particularly college students, with some success. ${ }^{133,134}$ Bock and her colleagues, in 2008, updated a previous review of the quality of web-assisted tobacco interventions (WATIs). ${ }^{135}$ Their search yielded over 80 websites claiming to offer U.S. smokers assistance with quitting smoking, but only one-fourth of these met Guidelines criteria. The excluded websites sold smoking-cessation programs rather than providing support for smokers wanting to quit. Their findings, however, did suggest improvement in quality of websites in providing advice to quit, offering practical counseling, and enhancing motivation to quit. The researchers proposed further research on maximizing interactive capabilities (personalizing treatment, providing a virtual support system, facilitating follow-up) of smoking cessation websites to improve outcomes. ${ }^{135}$ While technology-based methods are promising, their success depends on their ability to affect 
the remaining smoking population. Telephone quitlines have improved in this regard, with a new study showing increased reach among ethnic minorities as well as older, less educated, heavier smokers. ${ }^{57}$

\section{Conclusions}

Stepped care cannot be dismissed yet as a viable method for improving smoking cessation rates. In the most recent update of the Guidelines, both the inconsistency of results and overall paucity of literature kept panel members from recommending stepped care or tailored methods for smoking cessation. Since the update, two other studies have evaluated the use of stepped therapy in a smoking cessation intervention and reported positive results. Christenhusz et al evaluated use of stepped care intervention in smokers with moderate to severe COPD. ${ }^{136}$ Usual care participants received a brief counseling intervention with an opportunity to receive pharmacotherapy at cost; stepped care participants received individual and group counseling and bupropion. If stepped care patients lapsed within three months, additional counseling was provided. Usual care participants received no further intervention. Ultimately, higher rates of continuous abstinence at one year for stepped care versus usual care (19\% versus $9 \%)$ were reported. Further, logistic regression results found no baseline characteristics (i.e. attitude toward quitting, baseline cotinine value) to significantly predict cessation in the stepped care arm, indicating that less-motivated smokers could benefit from intensive stepped care therapy. Barnett et al applied a stepped care intervention to smokers in a mental health setting. ${ }^{77}$ Usual care participants received brief counsel and a list of available smoking cessation services. Stepped care patients received up to three assessments of readiness to quit, with contemplators or requestors receiving 10 weeks of NRT therapy and counseling. Upon relapse, additional counseling was provided. At 18-month follow-up, $24.6 \%$ of stepped care patients versus $19.1 \%$ of usual care patients achieved pointprevalent cessation. Incremental cost-effectiveness of stepped care was $\$ 6,204$ per quit. A large-scale study of stepped care $(n=3,024)$ has been conducted in Spain; the results have not yet been reported. ${ }^{137}$

Future studies of stepped care in smoking cessation will need to provide solid evidence of its effectiveness before any formal recommendation can be made. Particular emphasis should be placed on development of standardized study protocols. Published studies evaluating stepped care have lacked agreement on decision criteria for implementing subsequent steps for stepped care interventions. Four studies used relapse as the determinant for intensifying therapy, ${ }^{74,77,136,138}$ while the remainder used looser criteria for initiating subsequent steps. ${ }^{75,139}$ Additionally, one study attributed poor results to inconsistency of staff follow-up. ${ }^{136}$ Research investigating optimal timing and content of interventions is also warranted; Smith and Reid mentioned these as contributors to poor study outcomes. ${ }^{74,75}$ If stepped care in smoking cessation is to become viable, researchers will need to explore and implement factors that have influenced its success in treatment of other various chronic diseases, especially substance abuse disorders. 


\section{LIST OF REFERENCES}

(1) Centers for Disease Control and Prevention. Cigarette smoking among adults-United States, 2006. MMWR Morb Mortal Wkly Rep. 2007 November 9; 56(44):1157-61.

(2) World Health Organization. WHO Report on the Global Tobacco Epidemic, 2008. Geneva: World Health Organization; 2008.

(3) U.S. Department of Health and Human Services. Reducing tobacco use : a report of the Surgeon General. Rockville, MD: U.S. Department of Health and Human Services, Public Health Service, Office of the Surgeon General; 2000: p.7.

(4) United States Public Health Service. Reducing the health consequences of smoking: 25 years of progress: a report of the Surgeon General, 1989. Office of the Surgeon General, United States. Office on Smoking and Health.1989 Jan 1.

(5) Chaloupka FJ, Warner KE. The Economics of Smoking. National Bureau of Economic Research Working Paper Series 1999; No. 7047.

(6) de Walque D. Education, information, and smoking decisions: evidence from smoking histories, 1940-2000. Washington, D.C.: World Bank, Development Research Group, Public Services Team; 2004.

(7) Sander W. Schooling and quitting smoking. Review of Economics \& Statistics. 1995 February; 77(1):191.

(8) Meara ER, Richards S, Cutler DM. The gap gets bigger: changes in mortality and life expectancy, by education, 1981-2000. Health Aff (Millwood). 2008 March; 27(2):350-60.

(9) Centers for Disease Control and Prevention. Cessation. Fact Sheet. 2008. http://www.cdc.gov/tobacco/data_statistics/fact_sheets/cessation/cessation2.htm. Accessed July 13, 2008.

(10) Centers for Disease Control and Prevention. Smoking-attributable mortality, years of potential life lost, and productivity losses--United States, 2000-2004. MMWR Morb Mortal Wkly Rep. 2008 November 14; 57(45):1226-8.

(11) U.S. Department of Health and Human Services. The health consequences of smoking: a Report of the Surgeon General. Rockville, MD: Department of Health and Human Services, Public Health Service, Centers for Disease Control, National Center for Chronic Disease Prevention and Health Promotion, Office on Smoking and Health; 2004.

(12) Sloan FA, Ostermann J, Picone G, Conover C, Taylor RH. The price of smoking. Cambridge, Mass.: MIT Press; 2004. 
(13) Viscusi WK, Hersch J. The mortality cost to smokers. J Health Econ. 2008 July; 27(4):943-58.

(14) McBride CM, Lozano P, Curry SJ, Rosner D, Grothaus LC. Use of health services by children of smokers and nonsmokers in a health maintenance organization. Am J Public Health. 1998 June; 88(6):897-902.

(15) Centers for Disease Control and Prevention. Health Effects of Cigarette Smoking. Fact Sheet. 2008.

http://www.cdc.gov/tobacco/data_statistics/fact_sheets/health_effects/health_effe cts.htm. Accessed July 13, 2009.

(16) Etzel RA. How environmental exposures influence the development and exacerbation of asthma. Pediatrics. 2003 July; 112(1 Pt 2):233-9.

(17) American Academy of Pediatrics: Tobacco's toll: implications for the pediatrician. Pediatrics. 2001 April; 107(4):794-8.

(18) Gilliland FD, Li YF, Peters JM. Effects of maternal smoking during pregnancy and environmental tobacco smoke on asthma and wheezing in children. Am J Respir Crit Care Med. 2001 February; 163(2):429-36.

(19) DiFranza JR, Aligne CA, Weitzman M. Prenatal and postnatal environmental tobacco smoke exposure and children's health. Pediatrics. 2004 April; 113(4 Suppl):1007-15.

(20) Strachan DP, Cook DG. Health effects of passive smoking. 6. Parental smoking and childhood asthma: longitudinal and case-control studies. Thorax. 1998 March; 53(3):204-12.

(21) Tariq SM, Hakim EA, Matthews SM, Arshad SH. Influence of smoking on asthmatic symptoms and allergen sensitisation in early childhood. Postgrad Med J. 2000 November; 76(901):694-9.

(22) Lannero E, Wickman M, Pershagen G, Nordvall L. Maternal smoking during pregnancy increases the risk of recurrent wheezing during the first years of life (BAMSE). Respir Res. 2006 January 5; 7:3.

(23) Frieden TR, Blakeman DE. The dirty dozen: 12 myths that undermine tobacco control. Am J Public Health. 2005 September; 95(9):1500-5. 
(24) United States Environmental Protection Agency. Respiratory Health Effects of Passive Smoking (Also Known as Exposure to Secondhand Smoke or Environmental Tobacco Smoke ETS). National Center for Environmental Assessment. 2008. http://cfpub2.epa.gov/ncea/cfm/recordisplay.cfm?deid=2835. Accessed July 13, 2008.

(25) Centers for Disease Control and Prevention (CDC). Decline in smoking prevalence--New York City, 2002-2006. MMWR Morb Mortal Wkly Rep. 2007 June 22; 56(24):604-8.

(26) Javitz HS, Zbikowski SM, Swan GE et al. Financial burden of tobacco use: An employer's perspective. Clin Occup Environ Med. 2006 February; 5(1):9-29, vii.

(27) Ong MK, Glantz SA. Free nicotine replacement therapy programs vs implementing smoke-free workplaces: A cost-effectiveness comparison. Am J Public Health. 2005 June; 95(6):969-75.

(28) Tonnesen H, Moller AM. Smoke-free workplaces. Ugeskr Laeger. 2004 October $11 ; 166(42): 11$.

(29) Enstrom JE, Kabat GC. Environmental tobacco smoke and tobacco related mortality in a prospective study of Californians, 1960-98. BMJ. 2003 May 17; 326(7398):1057.

(30) Blizzard R. Second-Hand Smoke: Harmful or Hyperbole? 2004 September 14. http://www.gallup.com/poll/13006/SecondHand-Smoke-Harmful-Hyperbole.aspx. Accessed July 13, 2008.

(31) Miller LS, Zhang X, Rice DP et al. State estimates of total medical expenditures attributable to cigarette smoking, 1993. Public Health Rep. 1998 September; 113(5):447-58.

(32) Emmons KM. Smoking cessation and tobacco control: an overview. Chest. 1999 December; 116(6 Suppl):490S-2S.

(33) Fiore MC, Jaén CR, Baker TB et al. Treating tobacco use and dependence: 2008 update. Clinical Practice Guideline ed. Rockville, MD: Department of Health and Human Services. Public Health Service; 2008.

(34) Eisenberg D, Quinn BC. Estimating the effect of smoking cessation on weight gain: an instrumental variable approach. Health Serv Res. 2006 December; 41(6):2255-66.

(35) Pomerleau CS, Zucker AN, Stewart AJ. Characterizing concerns about postcessation weight gain: results from a national survey of women smokers. Nicotine Tob Res. 2001 February; 3(1):51-60. 
(36) Doll R, Hill AB. The mortality of doctors in relation to their smoking habits; a preliminary report. Br Med J. 1954 June 26; 1(4877):1451-5.

(37) Schneider NG, Terrace S, Koury MA et al. Comparison of three nicotine treatments: initial reactions and preferences with guided use.

Psychopharmacology (Berl). 2005 November; 182(4):545-50.

(38) Schmelzle J, Rosser WW, Birtwhistle R. Update on pharmacologic and nonpharmacologic therapies for smoking cessation. Can Fam Physician. 2008 July; 54(7):994-9.

(39) Zyban package insert. Research Triangle Park, NC: GlaxoSmithKline; 2004.

(40) Chantix package insert. New York, NY: Pfizer Labs; 2008.

(41) Klesges RC, Johnson KC, Somes G. Varenicline for smoking cessation: definite promise, but no panacea. JAMA. 2006 July 5; 296(1):94-5.

(42) Fagerstrom K. What is new with tobacco dependence. Respiration. 2002; 69(1):56.

(43) Etter JF, Stapleton JA. Nicotine replacement therapy for long-term smoking cessation: a meta-analysis. Tob Control. 2006 August; 15(4):280-5.

(44) Myung SK, Yoo KY, Oh SW et al. Meta-analysis of studies investigating oneyear effectiveness of transdermal nicotine patches for smoking cessation. Am J Health Syst Pharm. 2007 December 1; 64(23):2471-6.

(45) Wu P, Wilson K, Dimoulas P et al. Effectiveness of smoking cessation therapies: a systematic review and meta-analysis. BMC Public Health. 2006 December 11; $6: 300$.

(46) Eisenberg MJ, Filion KB, Yavin D et al. Pharmacotherapies for smoking cessation: a meta-analysis of randomized controlled trials. CMAJ. 2008 July 15; $179(2): 135-44$.

(47) Javitz HS, Swan GE, Zbikowski SM et al. Cost-Effectiveness of different combinations of Bupropion SR dose and behavioral treatment for smoking cessation: a societal perspective. Am J Manag Care. 2004 Mar;10(3):217-26.

(48) Prochazka AV. Review: Bupropion and nortriptyline each increase smoking cessation rates. ACP J Club. 2005 May-June; 142(3):67.

(49) Woolacott NF, Jones L, Forbes CA et al. The clinical effectiveness and costeffectiveness of bupropion and nicotine replacement therapy for smoking cessation: a systematic review and economic evaluation. Health Technol Assess. 2002; 6(16):1-245. 
(50) Tengs TO, Adams ME, Pliskin JS et al. Five-hundred life-saving interventions and their cost-effectiveness. Risk Anal. 1995 June; 15(3):369-90.

(51) Keller PA, Bailey LA, Koss KJ et al. Organization, financing, promotion, and cost of U.S. quitlines, 2004. Am J Prev Med. 2007 Jan; 32(1):32-7.

(52) Anderson CM, Zhu SH. Tobacco quitlines: looking back and looking ahead. Tob Control. 2007 December; 16 Suppl 1:i81-i86.

(53) U.S. Preventive Services Task Force. Counseling and interventions to prevent tobacco use and tobacco-caused disease in adults and pregnant women: U.S. Preventive Services Task Force reaffirmation recommendation statement. Ann Intern Med. 2009 April 21; 150(8):551-5.

(54) Cokkinides VE, Halpern MT, Barbeau EM et al. Racial and ethnic disparities in smoking-cessation interventions: analysis of the 2005 National Health Interview Survey. Am J Prev Med. 2008 May; 34(5):404-12.

(55) Cokkinides VE, Ward E, Jemal A et al. Under-use of smoking-cessation treatments: results from the National Health Interview Survey, 2000. Am J Prev Med. 2005 January; 28(1):119-22.

(56) Warner DO, Klesges RC, Dale LC et al. Telephone quitlines to help surgical patients quit smoking patient and provider attitudes. Am J Prev Med. 2008 December; 35(6 Suppl):S486-S493.

(57) Sood A, Andoh J, Verhulst S et al. "Real-World" effectiveness of reactive telephone counseling for smoking cessation: a randomized controlled trial. Chest. 2009 February 18. [Epub ahead of print]

(58) Hughes JR, Cummings KM, Hyland A. Ability of smokers to reduce their smoking and its association with future smoking cessation. Addiction. 1999 January; 94(1):109-14.

(59) Ranney L, Melvin C, Lux L et al. Systematic review: smoking cessation intervention strategies for adults and adults in special populations. Ann Intern Med. 2006 December 5; 145(11):845-56.

(60) Von Korff M., Moore JC. Stepped care for back pain: activating approaches for primary care. Ann Intern Med. 2001 May 1; 134(9 Pt 2):911-7.

(61) The sixth report of the Joint National Committee on prevention, detection, evaluation, and treatment of high blood pressure. Arch Intern Med. 1997 November 24; 157(21):2413-46.

(62) Guidelines for the diagnosis and management of asthma. National Heart, Lung, and Blood Institute. National Asthma Education Program. Expert Panel Report. J Allergy Clin Immunol. 1991 September; 88(3 Pt 2):425-534. 
(63) Guidelines for the management of rheumatoid arthritis. American College of Rheumatology Ad Hoc Committee on Clinical Guidelines. Arthritis Rheum. 1996 May; 39(5):713-22.

(64) American Diabetes Association: clinical practice recommendations 1999. Diabetes Care. 1999 January; 22 Suppl 1:S1-114.

(65) Gjerdingen D, Katon W, Rich DE. Stepped care treatment of postpartum depression: a primary care-based management model. Womens Health Issues. 2008 January; 18(1):44-52.

(66) Sculpher M, Millson D, Meddis D et al. Cost-effectiveness analysis of stratified versus stepped care strategies for acute treatment of migraine: The Disability in Strategies for Care (DISC) Study. Pharmacoeconomics. 2002; 20(2):91-100.

(67) Carels RA, Darby L, Cacciapaglia HM et al. Applying a stepped-care approach to the treatment of obesity. J Psychosom Res. 2005 December; 59(6):375-83.

(68) Masheb RM, Grilo CM. Rapid response predicts treatment outcomes in binge eating disorder: implications for stepped care. J Consult Clin Psychol. 2007 August; 75(4):639-44.

(69) Rich SR, Coleman IC, Cook R et al. Stepped-care approach to treating MS: a managed care treatment algorithm. J Manag Care Pharm. 2004 June; 10(3 Suppl B):S26-S32.

(70) Coulton S, Watson J, Bland M et al. The effectiveness and cost-effectiveness of opportunistic screening and stepped care interventions for older hazardous alcohol users in primary care (AESOPS) - a randomised control trial protocol. BMC Health Serv Res. 2008; 8:129.

(71) Sobell MB, Sobell LC. Stepped care as a heuristic approach to the treatment of alcohol problems. J Consult Clin Psychol. 2000 August; 68(4):573-9.

(72) Bischof G, Grothues JM, Reinhardt S et al. Evaluation of a telephone-based stepped care intervention for alcohol-related disorders: a randomized controlled trial. Drug Alcohol Depend. 2008 March 1; 93(3):244-51.

(73) Kakko J, Gronbladh L, Svanborg KD et al. A stepped care strategy using buprenorphine and methadone versus conventional methadone maintenance in heroin dependence: a randomized controlled trial. Am J Psychiatry. 2007 May; 164(5):797-803.

(74) Reid R, Pipe A, Higginson L et al. Stepped care approach to smoking cessation in patients hospitalized for coronary artery disease. J Cardiopulm Rehabil. 2003 May-June; 23(3):176-82. 
(75) Smith SS, Jorenby DE, Fiore MC et al. Strike while the iron is hot: can steppedcare treatments resurrect relapsing smokers? J Consult Clin Psychol. 2001 June; 69(3):429-39.

(76) Bower P, Gilbody S. Stepped care in psychological therapies: access, effectiveness and efficiency. Narrative literature review. Br J Psychiatry. 2005 January; 186:11-17.

(77) Barnett PG, Wong W, Hall S. The cost-effectiveness of a smoking cessation program for out-patients in treatment for depression. Addiction 2008 May; 103(5):834-40.

(78) Klesges, RC. Step Care Manual of Procedures. 2006: p.11 (unpublished).

(79) O'Sullivan AK, Thompson D, Drummond MF. Collection of health-economic data alongside clinical trials: is there a future for piggyback evaluations? Value Health. 2005 January; 8(1):67-79.

(80) Gold MR, Siegel JE, Russell LB et al. Cost-effectiveness in health and medicine. Oxford, England: Oxford University Press; 1996.

(81) Hall SM, Lightwood JM, Humfleet GL et al. Cost-effectiveness of bupropion, nortriptyline, and psychological intervention in smoking cessation. J Behav Health Serv Res. 2005 October-December; 32(4):381-92.

(82) Bolin K, Lindgren B, Willers S. The cost utility of bupropion in smoking cessation health programs: Simulation model results for Sweden. Chest. 2006 March; 129(3):651-60.

(83) Cornuz J, Pinget C, Gilbert A et al. Cost-effectiveness analysis of the first-line therapies for nicotine dependence. Eur J Clin Pharmacol. 2003 July;59(3):201-6.

(84) Cornuz J, Gilbert A, Pinget C et al. Cost-effectiveness of pharmacotherapies for nicotine dependence in primary care settings: a multinational comparison. Tob Control. 2006 June; 15(3):152-9.

(85) Feenstra TL, Hamberg-Van Reenen HH, Hoogenveen RT et al. Cost-effectiveness of face-to-face smoking cessation interventions: A dynamic modeling study. Value Health. 2005 May-June; 8(3):178-90

(86) Gilbert AR, Pinget C, Bovet P et al. The cost effectiveness of pharmacological smoking cessation therapies in developing countries: a case study in the Seychelles. Tob Control. 2004 June; 13(2):190-5.

(87) Wasley MA, McNagny SE, Phillips VL et al. The cost-effectiveness of the nicotine transdermal patch for smoking cessation. Prev Med. 1997 March-April; 26(2):264-70. 
(88) Woolacott NF, Jones L, Forbes CA et al. The clinical effectiveness and costeffectiveness of bupropion and nicotine replacement therapy for smoking cessation: A systematic review and economic evaluation. Health Technol Assess. 2002; 6(16):1-245.

(89) Velicer WF, Prochaska JO. A comparison of four self-report smoking cessation outcome measures. Addict Behav. 2004 Jan; 29(1):51-60. Review.

(90) Godfrey C, Parrott S, Coleman T, Pound E. The cost-effectiveness of the English smoking treatment services: Evidence from practice. Addiction. 2005 April; 100 Suppl 2:70-83.

(91) Niaura R, Abrams DB. Smoking cessation: progress, priorities, and prospectus. J Consult Clin Psychol. 2002 June; 70(3):494-509.

(92) Bureau of Labor Statistics. Occupational Employment Statistics: May 2006. 2006. http://www.bls.gov/oes/2006/may/oes_stru.htm\#31-0000. Accessed August $18,2009$.

(93) Hughes JR, Keely JP, Niaura RS et al. Measures of abstinence in clinical trials: issues and recommendations. Nicotine Tob Res. 2003 February; 5(1):13-25.

(94) Hoogenveen RT, van Baal PH, Boshuizen HC et al. Dynamic effects of smoking cessation on disease incidence, mortality and quality of life: The role of time since cessation. Cost Eff Resour Alloc. 2008 January 11; 6:1.

(95) Hurley SF, Matthews JP. The Quit Benefits Model: a Markov model for assessing the health benefits and health care cost savings of quitting smoking. Cost Eff Resour Alloc. 2007 January 23; 5:2.

(96) Centers for Disease Control and Prevention, National Center for Health Statistics. CDC WONDER Online Database. http://wonder.cdc.gov/. Accessed August 19, 2009.

(97) Anderson RN. A method for constructing complete annual U.S. life tables. Vital Health Stat 2. 2000; (129):1-28.

(98) Centers for Disease Control and Prevention. National Center for Health Statistics (NCHS). National Health and Nutrition Examination Survey Data. Hyattsville, MD: U.S. Department of Health and Human Services, Centers for Disease Control and Prevention, 2001-2006. http://www.cdc.gov/nchs/nhanes/nhanes_questionnaires.htm. Accessed August 19, 2009.

(99) Centers for Disease Control and Prevention, National Center for Health Statistics. Compressed Mortality File 1999-2006. CDC WONDER Online Database, compiled from Compressed Mortality File 1999-2006 Series 20 No. 2L, 2009. http://wonder.cdc.gov/cmf-icd10.html. Accessed August 19, 2009. 
(100) Stapleton JA, Sutherland G, Russell MA. How much does relapse after one year erode effectiveness of smoking cessation treatments? Long-term follow up of randomised trial of nicotine nasal spray. BMJ. 1998 March 14; 316(7134):830-1.

(101) Wetter DW, Cofta-Gunn L, Fouladi RT et al. Late relapse/sustained abstinence among former smokers: a longitudinal study. Prev Med. 2004 December; 39(6):1156-63.

(102) Hughes JR, Keely J, Naud S. Shape of the relapse curve and long-term abstinence among untreated smokers. Addiction. 2004 January; 99(1):29-38.

(103) Center for Financing, Access, and Cost Trends, Agency for Healthcare Research and Quality. Medical Expenditure Panel Survey, 2006.

(104) Sullivan PW, Ghushchyan V. Mapping the EQ-5D index from the SF-12: US general population preferences in a nationally representative sample. Med Decis Making. 2006 July-August; 26(4):401-9.

(105) Fu SS, Partin MR, Snyder A et al. Promoting repeat tobacco dependence treatment: are relapsed smokers interested? Am J Manag Care. 2006 April; 12(4):235-43.

(106) Han ES, Foulds J, Steinberg MB et al. Characteristics and smoking cessation outcomes of patients returning for repeat tobacco dependence treatment. Int J Clin Pract. 2006 September; 60(9):1068-74.

(107) Fagan P, Moolchan ET, Lawrence D et al. Identifying health disparities across the tobacco continuum. Addiction. 2007 October; 102 Suppl 2:5-29.

(108) Fu SS, Kodl MM, Joseph AM et al. Racial/Ethnic disparities in the use of nicotine replacement therapy and quit ratios in lifetime smokers ages 25 to 44 years. Cancer Epidemiol Biomarkers Prev. 2008 July;1 7(7):1640-7.

(109) Webb MS, Francis J, Hines BC, Quarles FB. Health disparities and culturally specific treatment: perspectives and expectancies of African American smokers. J Clin Psychol. 2007 June; 63(6):567-83.

(110) Ramsey SD, McIntosh M, Sullivan SD. Design issues for conducting costeffectiveness analysis alongside clinical trials. Annu Rev Public Health. 2001; 22:129-41.

(111) Briggs A. Economic evaluation and clinical trials: size matters. BMJ. 2000 December 2; 321(7273):1362-3.

(112) Briggs AH, O'Brien BJ, Blackhouse G. Thinking outside the box: recent advances in the analysis and presentation of uncertainty in cost-effectiveness studies. Annu Rev Public Health. 2002; 23:377-401. 
(113) Briggs AH, Gray AM. Power and sample size calculations for stochastic costeffectiveness analysis. Med Decis Making. 1998 April; 18(2 Suppl):S81-S92.

(114) Gafni A, Walter SD, Birch S, Sendi P. An opportunity cost approach to sample size calculation in cost-effectiveness analysis. Health Econ. 2008 January; 17(1):99-107.

(115) Gardiner JC, Huebner M, Jetton J, Bradley CJ. Power and sample assessments for tests of hypotheses on cost-effectiveness ratios. Health Econ. 2000 April; 9(3):227-34.

(116) Walter SD, Gafni A, Birch S. Estimation, power and sample size calculations for stochastic cost and effectiveness analysis. Pharmacoeconomics. 2007; 25(6):45566.

(117) Willan AR, O'Brien BJ. Sample size and power issues in estimating incremental cost-effectiveness ratios from clinical trials data. Health Econ. 1999 May; 8(3):203-11.

(118) Campbell MK, Torgerson DJ. Bootstrapping: estimating confidence intervals for cost-effectiveness ratios. QJM. 1999 March; 92(3):177-82.

(119) Chaudhary MA, Stearns SC. Estimating confidence intervals for costeffectiveness ratios: an example from a randomized trial. Stat Med. 1996 July 15; 15(13):1447-58.

(120) Severens JL, De Boo TM, Konst EM. Uncertainty of incremental costeffectiveness ratios. A comparison of Fieller and bootstrap confidence intervals. Int J Technol Assess Health Care. 1999 Summer; 15(3):608-14.

(121) Willan AR, O'Brien BJ. Confidence intervals for cost-effectiveness ratios: an application of Fieller's theorem. Health Econ. 1996 July; 5(4):297-305.

(122) Brazier JE, Yang Y, Tsuchiya A, Rowen DL. A review of studies mapping (or cross walking) non-preference based measures of health to generic preferencebased measures. Eur J Health Econ. 2009 July 8. [Epub ahead of print]

(123) Saalfrank MF, Wang J, Brown LM. Racial and ethnic differences in preferences for health states and the implications for cost-utility analysis. Expert Rev Pharmacoecon Outcomes Res. 2009 August; 9(4):365-73.

(124) Wang J, Saalfrank MF, Hong SH et al. Patterns of reporting health-related quality of life across racial and ethnic groups. Expert Rev Pharmacoecon Outcomes Res. 2007; 7(2):177-86.

(125) Gaskin DJ, Frick KD. Race and ethnic disparities in valuing health. Med Decis Making. 2008 January; 28(1):12-20. 
(126) Maciosek MV, Coffield AB, Edwards NM et al. Priorities among effective clinical preventive services: results of a systematic review and analysis. Am J Prev Med. 2006 July; 31(1):52-61.

(127) Solberg LI, Maciosek MV, Edwards NM, Khanchandani HS, Goodman MJ. Repeated tobacco-use screening and intervention in clinical practice: health impact and cost effectiveness. Am J Prev Med. 2006 July; 31(1):62-71.

(128) Williams I, McIver S, Moore D, Bryan S. The use of economic evaluations in NHS decision-making: a review and empirical investigation. Health Technol Assess. 2008 April; 12(7):iii, ix-iii,175.

(129) Hoffmann C, Stoykova BA, Nixon J et al. Do health-care decision makers find economic evaluations useful? The findings of focus group research in UK health authorities. Value Health. 2002 March; 5(2):71-8.

(130) Phillips-Tangum C, Rehm B, Carreon R et al. Addressing tobacco in managed care: results of the 2003 survey. Prev Chronic Dis. 2006 July; 3(3):A87.

(131) State Medicaid coverage for tobacco-dependence treatments--United States, 2006. MMWR Morb Mortal Wkly Rep. 2008 February 8; 57(5):117-22.

(132) Pacific Center on Health and Tobacco. Linking a Network: Integrate Quitlines with Health Care Systems. 2003.

(133) Riley W, Obermayer J, Jean-Mary J. Internet and mobile phone text messaging intervention for college smokers. J Am Coll Health. 2008 September; 57(2):2458.

(134) Obermayer JL, Riley WT, Asif O et al. College smoking cessation using cell phone text messaging. J Am Coll Health. 2004 September; 53(2):71-8.

(135) Bock BC, Graham AL, Whiteley JA et al. A review of web-assisted tobacco interventions (WATIs). J Med Internet Res. 2008; 10(5):e39.

(136) Christenhusz L, Pieterse M, Seydel E et al. Prospective determinants of smoking cessation in COPD patients within a high intensity or a brief counseling intervention. Patient Educ Couns. 2007 May; 66(2):162-6.

(137) Cabezas C, Martin C, Granollers S et al. Effectiveness of a stepped primary care smoking cessation intervention (ISTAPS): design of a cluster randomised trial. BMC Public Health. 2009 February 4; 9(1):48.

(138) Russell MA, Stapleton JA, Feyerabend C et al. Targeting heavy smokers in general practice: randomised controlled trial of transdermal nicotine patches. BMJ. 1993 May 15; 306(6888):1308-12. 
(139) Reeve K, Calabro K, McNeill J. Tobacco cessation intervention in a nurse practitioner managed clinic. J Am Acad Nurse Pract. 2000 May; 12(5):163-9. 


\section{VITA}

Brandi Everett Franklin was born to David and Sammie Everett on October 5, 1979. She was reared and educated in Lake City, Florida, graduating with highest honors from Columbia High School in June 1998. Brandi pursued business degrees at Sybil C. Mobley School of Business and Industry, Florida A\&M University. During her matriculation, she was a FAMU Presidential Scholar, Golden Key Honour Society member, and actively participated in school and community organizations. In addition, she completed three internships with National Aeronautic and Space AdministrationKennedy Space Center (NASA-KSC), Johnson \& Johnson, and Pfizer, Inc. In December 2003, Brandi graduated with dual Bachelor and Master of Business Administration degrees.

Brandi began a career in the pharmaceutical industry, with a focus on cardiovascular disease. After two years, she decided to return to school to pursue a doctoral degree at University of Tennessee Health Science Center. She entered the PhD program in Health Science Administration in August 2005. During her tenure, she conducted research in the areas of diabetes disease burden, cost-effectiveness analysis and decision modeling, and novel approaches to smoking cessation. Brandi successfully co-wrote a National Institutes of Health (NIH) Supplement grant to conduct dissertation research connected to CA106667: Long-term Smoking Cessation Using Prescription Step Care (STEP). This research, a cost-effectiveness analysis and future simulation of outcomes of STEP, was presented in October 2009. 